\title{
Long-term ozone changes and associated climate impacts in CMIP5 simulations
}

\author{
V. Eyring, ${ }^{1}$ J. M. Arblaster, ${ }^{2,3}$ I. Cionni, ${ }^{4}$ J. Sedláček, ${ }^{5}$ J. Perlwitz, ${ }^{6,7}$ P. J. Young,,${ }^{6,7,8}$ \\ S. Bekki, ${ }^{9}$ D. Bergmann, ${ }^{10}$ P. Cameron-Smith, ${ }^{10}$ W. J. Collins, ${ }^{11,12}$ G. Faluvegi, ${ }^{13}$ \\ K.-D. Gottschaldt, ${ }^{1}$ L. W. Horowitz, ${ }^{14}$ D. E. Kinnison, ${ }^{3}$ J.-F. Lamarque, ${ }^{3}$ D. R. Marsh, ${ }^{3}$ \\ D. Saint-Martin, ${ }^{15}$ D. T. Shindell, ${ }^{13}$ K. Sudo, ${ }^{16}$ S. Szopa, ${ }^{9}$ and S. Watanabe ${ }^{17}$
}

Received 31 July 2012; revised 7 March 2013; accepted 7 March 2013; published 30 May 2013.

[1] Ozone changes and associated climate impacts in the Coupled Model Intercomparison Project Phase 5 (CMIP5) simulations are analyzed over the historical (1960-2005) and future (2006-2100) period under four Representative Concentration Pathways (RCP). In contrast to CMIP3, where half of the models prescribed constant stratospheric ozone, CMIP5 models all consider past ozone depletion and future ozone recovery. Multimodel mean climatologies and long-term changes in total and tropospheric column ozone calculated from CMIP5 models with either interactive or prescribed ozone are in reasonable agreement with observations. However, some large deviations from observations exist for individual models with interactive chemistry, and these models are excluded in the projections. Stratospheric ozone projections forced with a single halogen, but four greenhouse gas (GHG) scenarios show largest differences in the northern midlatitudes and in the Arctic in spring ( 20 and 40 Dobson units (DU) by 2100, respectively). By 2050, these differences are much smaller and negligible over Antarctica in austral spring. Differences in future tropospheric column ozone are mainly caused by differences in methane concentrations and stratospheric input, leading to $\sim 10 \mathrm{DU}$ increases compared to 2000 in RCP 8.5. Large variations in stratospheric ozone particularly in CMIP5 models with interactive chemistry drive correspondingly large variations in lower stratospheric temperature trends. The results also illustrate that future Southern Hemisphere summertime circulation changes are controlled by both the ozone recovery rate and the rate of GHG increases, emphasizing the importance of simulating and taking into account ozone forcings when examining future climate projections.

Citation: Eyring, V., et al. (2013), Long-term ozone changes and associated climate impacts in CMIP5 simulations, J. Geophys. Res. Atmos., 118, 5029-5060, doi:10.1002/jgrd.50316.

\section{Introduction}

[2] To improve understanding of climate and to provide estimates of future climate change, the Working Group on Coupled Modelling (WGCM) of the World Climate Research Programme (WCRP) has defined coordinated climate model experiments, forming phase 5 of the Coupled Model Intercomparison Project (CMIP5) [Taylor et al.,

\footnotetext{
${ }^{1}$ Deutsches Zentrum für Luft- und Raumfahrt (DLR), Institut für Physik der Atmosphäre, Oberpfaffenhofen, Germany.

${ }^{2}$ Centre for Australian Weather and Climate Research, Bureau of Meteorology, Melbourne, Victoria, Australia.

${ }^{3}$ National Center for Atmospheric Research (NCAR), Boulder, Colorado, USA.

${ }^{4}$ Agenzia nazionale per le nuove tecnologie, l'energia e lo sviluppo economico sostenibile (ENEA), Bologna, Italy.

${ }^{5}$ Institute for Atmospheric and Climate Science, ETH Zurich, Switzerland.

${ }^{6}$ NOAA Earth System Research Laboratory, Boulder, Colorado, USA.

Corresponding author: V. Eyring, Deutsches Zentrum für Luft- und Raumfahrt (DLR), Institut für Physik der Atmosphäre, Oberpfaffenhofen, Germany. (Veronika.Eyring@dlr.de)

C2013. American Geophysical Union. All Rights Reserved.

2169-897X/13/10.1002/jgrd.50316
}

2012]. Since the previous round (CMIP3), the participating models have been further developed, new models have joined, and new emission scenarios, so-called Representative Concentration Pathways (RCPs), have been established [Meinshausen et al., 2011; Moss et al., 2010]. The focus of this study is to examine the stratospheric and tropospheric ozone evolution in the CMIP5 historical (1960-2005) and

\footnotetext{
${ }^{7}$ Cooperative Institute for Research in Environmental Sciences, University of Colorado, Boulder, Colorado, USA.

${ }^{8}$ Now at Lancaster Environment Centre, Lancaster University, Lancaster, UK.

${ }^{9}$ Institut Pierre Simon Laplace (IPSL), Paris, France.

${ }^{10}$ Lawrence Livermore National Laboratory, Livermore, California, USA

${ }^{11}$ Met Office Hadley Centre, Exeter, UK.

${ }^{12}$ Now at Department of Meteorology, University of Reading, Reading, $\mathrm{UK}$.

${ }^{13}$ NASA Goddard Institute for Space Studies, New York, USA.

${ }^{14}$ NOAA Geophysical Fluid Dynamics Laboratory, Princeton, New Jersey,

${ }^{15}$ Centre National de Recherches Météorologiques (CNRM-GAME), Toulouse, France.

${ }^{16}$ Graduate School of Environmental Studies, Nagoya University, Nagoya, Japan.

${ }^{17}$ Japan Agency for Marine-Earth Science and Technology, Yokohama, Japan.
} 
future (2006-2100) simulations under varying greenhouse gas (GHG) and halogen concentrations and to highlight some related climate impacts.

[3] Stratospheric ozone depletion has been found to play a prominent role in recent Southern Hemisphere $(\mathrm{SH})$ climate change, with impacts on the tropospheric circulation and surface climate in austral summer [Kang et al., 2011; Son et al., 2010; Thompson et al., 2011]. For future projections, the interplay between stratospheric ozone recovery from a decrease of ozone-depleting substances (ODSs) [WMO, 2011] and increasing GHGs could in addition have important long-term implications for $\mathrm{CO}_{2}$ uptake in the Southern Ocean [Le Quere et al., 2007; Lenton et al., 2009] and changes to Antarctic ice sheets [Turner et al., 2009a]. Recent studies have also suggested that changes in stratospheric ozone could have potential impacts on $\mathrm{SH}$ sea ice [Bitz and Polvani, 2012; Sigmond and Fyfe, 2010; Smith et al., 2012; Turner et al., 2009b]. To date, stratospheric ozone projections have been produced with ChemistryClimate Models (CCM) [WMO, 2007; 2011], where sea surface temperatures (SSTs) and sea-ice concentrations (SICs) are mostly prescribed from observations or climate simulations. Similar to CMIP, coordinated community-wide simulations for stratospheric ozone have been organized by the Chemistry-Climate Model Validation (CCMVal) Activity of WCRP's Stratospheric Processes and their Role in Climate (SPARC) project [Austin et al., 2010; Eyring et al., 2010b; Eyring et al., 2006; Eyring et al., 2007; SPARC-CCMVal, 2010]. In these stratospheric-resolving CCMs, chemistry is interactively coupled to the dynamics and radiation, allowing for chemistry-climate feedbacks. Increasingly, the chemistry and dynamics of the stratosphere and troposphere are now being modeled as a single entity. The $2010 \mathrm{WMO} / \mathrm{UNEP}$ Scientific Assessment of Ozone Depletion [WMO, 2011] featured several stratospheric models that included tropospheric chemistry, and one model with a coupled ocean. It was one of the main recommendations of the SPARCCCMVal [2010] report that stratosphere-resolving CCMs should continue to evolve towards more comprehensive, self-consistent stratosphere-troposphere CCMs, including a coupled ocean.

[4] In CMIP3, which supported the Intergovernmental Panel on Climate Change (IPCC) Fourth Assessment Report (AR4) [IPCC, 2007] with climate simulations, all of the $\sim 20$ models examined for example by Son et al. [2010] used prescribed ozone. However, ozone in the CMIP3 simulations is not documented in detail, since it was not archived from the model simulations, and only some rough information exists. Around half of the CMIP3 models prescribed a timevarying stratospheric ozone time series, for example scaled by the evolution of equivalent effective stratospheric chlorine (EESC). The other half prescribed a constant ozone climatology, thus not accounting for climate effects induced by stratospheric ozone depletion in the past and projected recovery in the future. This led to biases in the tropospheric general circulation of the $\mathrm{SH}$ compared to observations [Cordero and Forster, 2006]. The missing Antarctic ozone depletion in late austral spring resulted in weaker poleward displacement of the tropospheric midlatitude jet and smaller expansion of the SH Hadley cell in summer [Son et al., 2009; Son et al., 2010] than in models with prescribed timevarying ozone. For the future projections, the CMIP3 models without ozone recovery did not simulate a reversal of the zonal mean wind trends that was projected over the first half of the 21 st century by both CCMs with interactive stratospheric chemistry [Perlwitz et al., 2008; Son et al., 2008; Son et al., 2010; SPARC-CCMVal, 2010; WMO, 2011] and CMIP3 models that prescribed ozone recovery [Son et al., 2010]. In addition, the incomplete representation of stratospheric ozone leads to biases in temperature trends in the upper troposphere/lower stratosphere (UTLS) region [Forster et al., 2007; Lanzante, 2007; Polvani and Solomon, 2012; Santer et al., 2012; Solomon et al., 2012; Young et al., 2013a].

[5] Similarly, chemistry-climate coupling and the consideration of time-varying ozone are also important in the troposphere, where ozone is of concern as a pollutant and GHG. Tropospheric ozone concentrations depend on the magnitude and spatial distribution of the emissions of its precursors, nitrogen oxides $\left(\mathrm{NO}_{\mathrm{x}}\right)$, carbon monoxide $(\mathrm{CO})$, and volatile organic compounds (VOCs), as well as on climate. Several studies have investigated the impact of emissions and climate changes on future ozone for a range of scenarios. In a warming climate, tropospheric ozone loss can increase due to higher absolute humidity [Johnson et al., 1999; Zeng et al., 2008]. On the other hand, climate change may increase tropospheric ozone, for example, through an increased influx of stratospheric ozone [Collins et al., 2003; Hegglin and Shepherd, 2009; Sudo et al., 2003] or through increases in lightning $\mathrm{NO}_{\mathrm{x}}$ emissions [Price and Rind, 1994; Schumann and Huntrieser, 2007], although static [Stevenson et al., 2006] or decreasing [Jacobson and Streets, 2009] emissions have also been projected. Climate-dependent emissions of biogenic VOCs [Arneth et al., 2010; Guenther, 2007; Guenther et al., 2006] are another potential climate feedback, although whether they will increase or decrease in the future is unclear [Arneth et al., 2010; Hauglustaine et al., 2005; Lathiere et al., 2005; Sanderson et al., 2003; Young et al., 2009]. While a positive relationship between anthropogenic emissions and tropospheric ozone has been shown [Stevenson et al., 2006; Young et al., 2013b], the net impact of climate and emission changes is uncertain and is likely to vary significantly by region, altitude, and season [Isaksen et al., 2009; Jacob and Winner, 2009; Stevenson et al., 2006].

[6] As a response to the inconsistencies in ozone representation in the CMIP3 models, the CMIP5 protocol recommended a time-varying ozone database for models without interactive chemistry. This continuous tropospheric and stratospheric vertically resolved ozone time series from 1850 to 2099 was developed as a joint effort of the International Global Atmospheric Chemistry (IGAC) and SPARC projects, hereafter referred to as the IGAC/SPARC ozone database [Cionni et al., 2011]. The historical stratospheric zonal mean data set is based on the Randel and Wu [2007] observational database from 1979 to 2009 and extrapolated backward to 1850 with the help of a regression representing EESC and the 11 year solar cycle variability. The data set continues beyond 2009 using the multimodel mean projections from $13 \mathrm{CCMs}$ that performed a simulation under the SRES (Special Report on Emission Scenarios) A1B GHG scenario [IPCC, 2000] and the A1 adjusted halogen scenario $[W M O, 2007]$ in the second round of CCMVal (CCMVal-2). The stratospheric zonal mean ozone 
time series is merged with a three-dimensional (3-D) tropospheric data set extracted from simulations of the past by two CCMs (CAM3.5 [Lamarque et al., 2012] and Goddard Institute for Space Studies (GISS)-PUCCINI [Shindell et al., 2006]) and of the future by one CCM (CAM3.5). The future tropospheric ozone time series continues the historical CAM3.5 simulation until 2099 following the four different RCPs. The majority, but not all, of the CMIP5 models without interactive chemistry prescribed ozone according to this or a modified version of the IGAC/SPARC ozone database (see Table 1 and details in the Appendix in section A2.1). However, a subset of nine of the CMIP5 models also includes interactive chemistry, spanning the surface through the stratosphere and above.

[7] This study thus represents the first opportunity to undertake a multimodel assessment of ozone and associated climate impacts in fully coupled transient chemistry-climate simulations and in the new set of CMIP5 models. We first evaluate the historical CMIP5 ozone simulations with observations, then assess the ozone projections, and finally highlight prominent features of associated climate impacts. In addition, we present a detailed documentation of ozone in the CMIP5 simulations both for the multimodel mean (or different classes of multimodel means, see below) as well as for individual models. We therefore provide a description of the chemistry schemes or the prescribed ozone database for each CMIP5 model in the Appendix and include individual models in the evaluation of ozone. The analysis presented here follows on from a previous study [Eyring et al., 2010a], which examined differences in future stratospheric ozone for six different GHG scenarios but only with a very limited set of models. In particular, there was only one model included that simulated ozone under the RCP scenarios. Tropospheric ozone is also briefly discussed to show that it contributes substantially to the differences in total column ozone among the four RCPs in the 21 st century, complementing Young et al. [2013b] who presented the evolution of tropospheric ozone with the historical and RCP scenarios in a set of (mostly) atmosphereonly models that participated in the Atmospheric Chemistry Climate Model Intercomparison Project (ACCMIP).

[8] The paper is organized as follows. Section 2 describes the CMIP5 models and simulations, with a focus on how ozone chemistry was treated (details are presented in the Appendix). In section 3, ozone in the historical simulations is evaluated against observations, and projections of ozone in the 21 st century are provided for the four RCP scenarios, using only the group of CMIP models with interactive or semi-offline chemistry (see section 2 for details). In section 4, climate impacts associated with stratospheric ozone changes are discussed for the past and future. The focus of the analysis is on different groups of multimodel mean analysis (see section 2), with the performance of individual CMIP5 models being discussed as part of the model evaluation. We close with a summary in section 5 .

\section{Models and Simulations}

[9] In this study, the CMIP5 historical (1850-2005) and future simulations under the RCPs (2006-2100) [Taylor et al., 2012] are analyzed for a total of 46 different model versions from 22 different modeling centers; see Table 1.
The model simulations are driven by concentrations of GHGs and also include changes in aerosols, ozone, land cover, and natural forcings. In order not to bias the multimodel mean towards the available number of ensembles from each model version, only one ensemble member is considered. It should be noted that the effective number of independent models in CMIP5 is smaller [Annan and Hargreaves, 2011; Jun et al., 2008; Knutti et al., 2013; Masson and Knutti, 2011; Pennell and Reichler, 2011].

[10] Since future ozone projections can only be derived from models with interactive chemistry, the models are grouped into two different categories: the first group includes CMIP5 models with interactive or semi-offline chemistry (CHEM, see section 2.1), and the second group includes models with prescribed ozone (NOCHEM, see section 2.2). The multimodel means are shown for these two groups as well as for the multimodel mean calculated from all CMIP5 simulations considered. Individual models are shown in selected figures in the main part of the paper and in addition in the Appendix.

[11] The main difference between the two groups is for stratospheric ozone, where the CHEM models were run under the emission specifications for each of the RCP scenarios, but the NOCHEM simulations prescribed ozone from simulations that were driven only with a single GHG scenario. The prescribed data set was either based on the original or a slightly modified version of the IGAC/SPARC ozone database or an alternate data set following just a single GHG scenario. Therefore, future stratospheric ozone concentrations are identical in all four RCPs in the NOCHEM group (see section 2.2). The ODSs are prescribed according to the A1 scenario of WMO [2003] in all RCPs [Meinshausen et al., 2011]. This scenario does not include the earlier phase out of hydrochlorofluorocarbons that was agreed to by the Parties to the Montreal Protocol in 2007. It is therefore slightly different from the adjusted halogen scenario of $W M O$ [2007] that was used in the CCMVal-2 simulations [SPARC-CCMVal, 2010; WMO, 2011] on which the IGAC/SPARC ozone data set is based. Ozone in the troposphere however follows ozone precursor emissions under the four RCPs in all CMIP5 simulations (CHEM and NOCHEM, see further details below and in the Appendix)

\subsection{CMIP5 Models With Interactive or Semi-Offline Chemistry}

[12] Eighteen of the 46 CMIP5 model versions analyzed here are CMIP5 models with interactive or semi-offline chemistry. Stratospheric and tropospheric ozone chemistry is interactively coupled in 9 of these 18 model versions. In the other nine, ozone was calculated semi-offline. We denote models as semi-offline if the prescribed ozone data set has been, unlike the models with prescribed ozone (see section 2.2), calculated with the underlying CMIP5 chemistry-climate model using prescribed SSTs and SICs following historical emissions from Lamarque et al. [2010] and future emissions under the RCP scenarios as described by Lamarque et al. [2011]. They differ from the class of prescribed ozone CMIP5 models (NOCHEM), because their stratospheric ozone evolution responds to changes in GHG concentrations in the four RCPs, although it is still calculated offline. They are here grouped together with the 


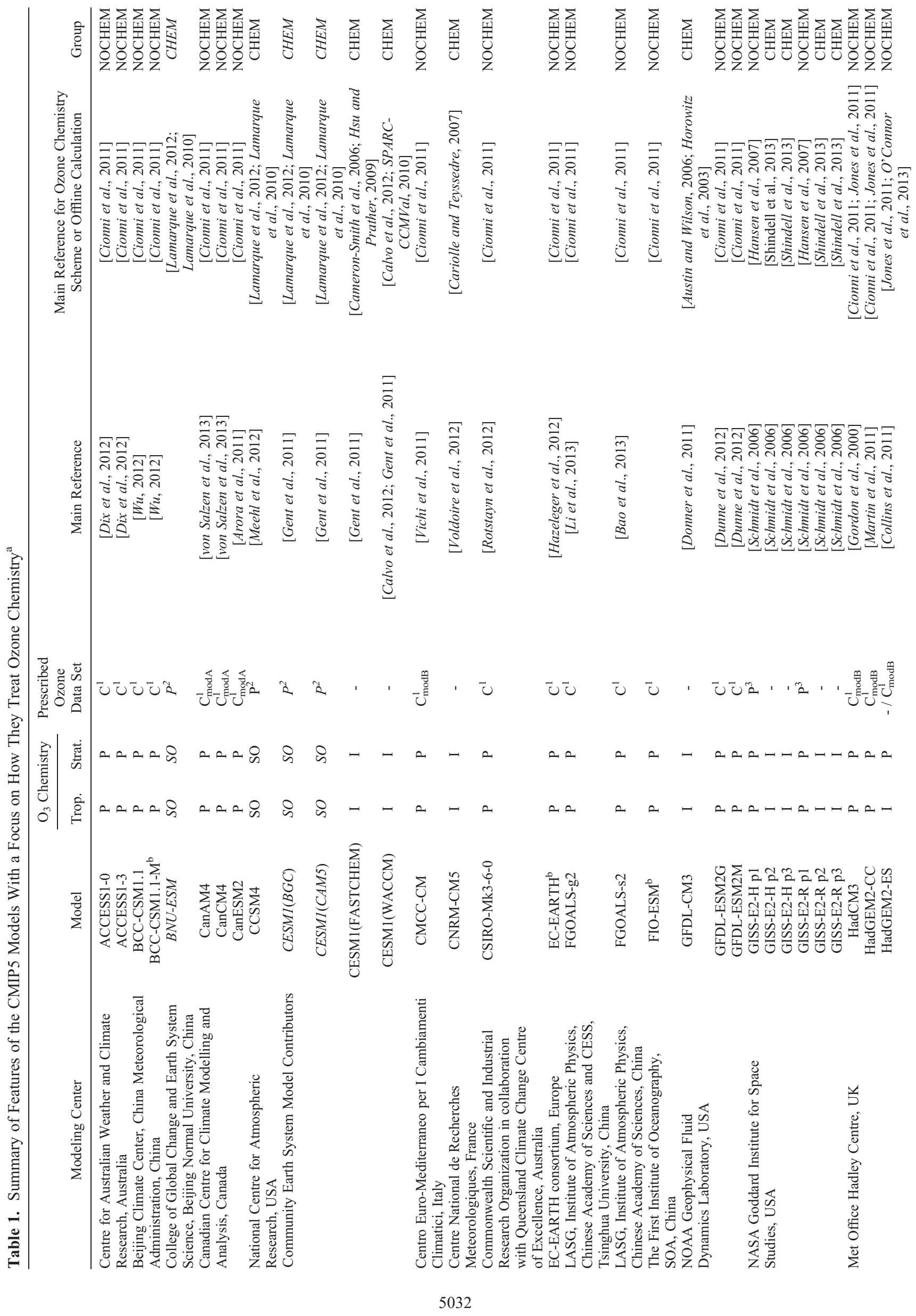




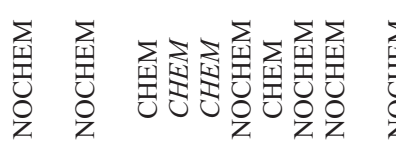

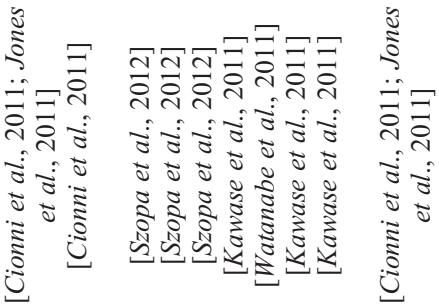

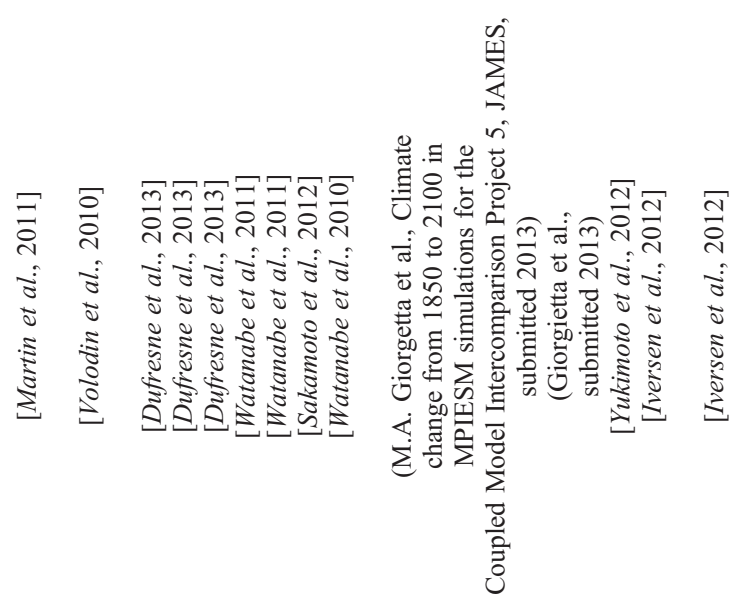

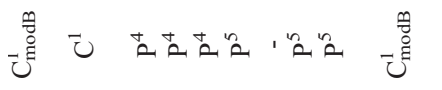

- Bobarana

$\alpha a 000-a a^{2}$

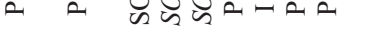

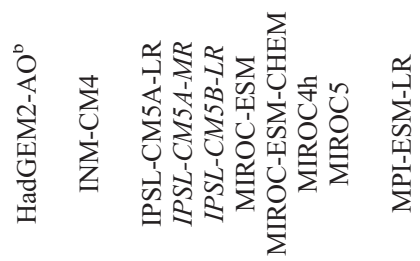

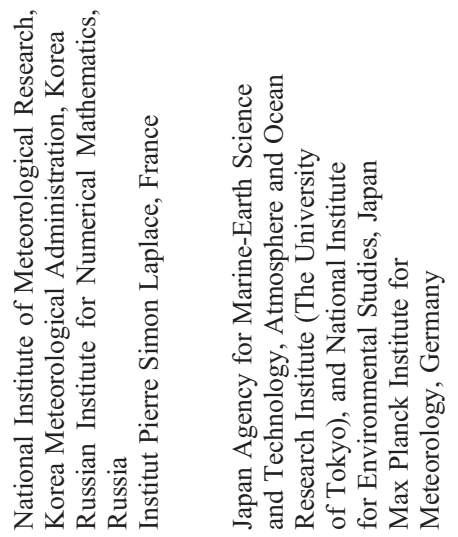

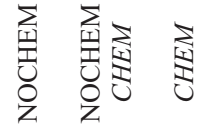

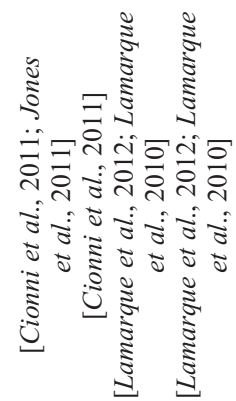

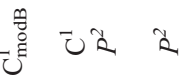

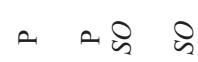

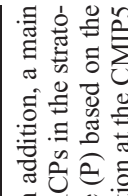

$\Xi$ 品

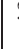

要

政

苦

莺 专

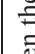

可

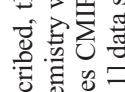

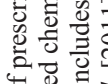

$\exists$ 过

远刻

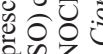

.

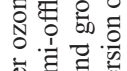

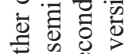

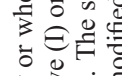

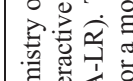

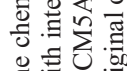

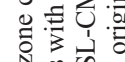

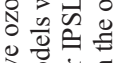

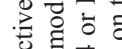

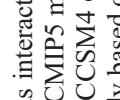

政

- aㅇ
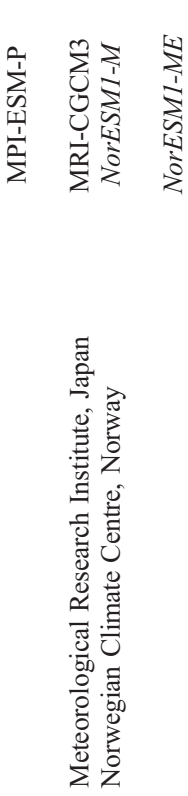

至言总

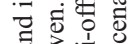

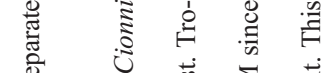

落 $\sum_{\text {I }}$

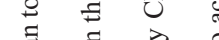

氠

竞 总

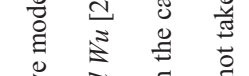

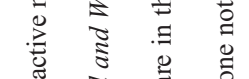

苋

.

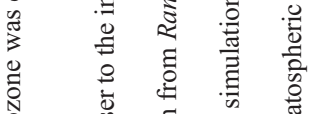

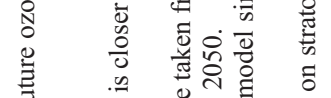

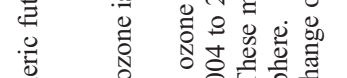

की

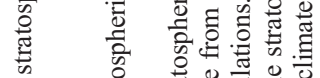

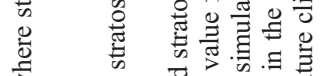

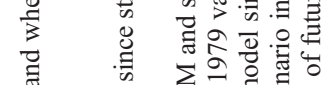

造 $\sum_{0}^{0}$

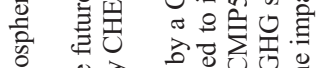

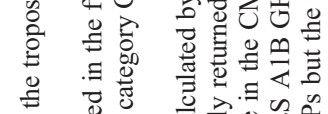

寻 密

(⿹)

要

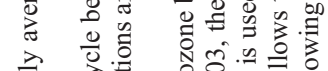

可

N

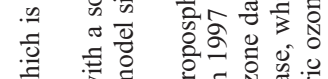

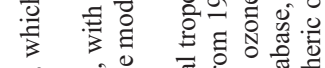

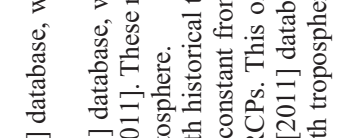

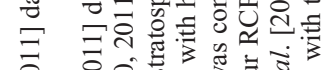

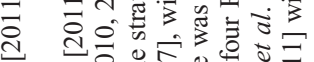

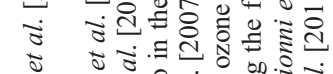

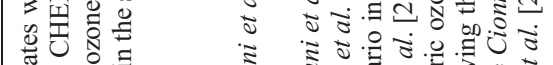

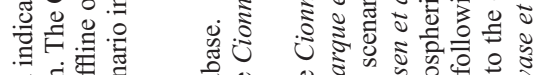

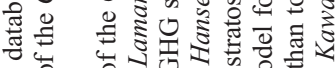

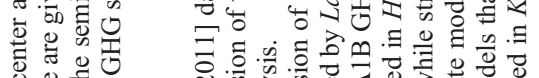

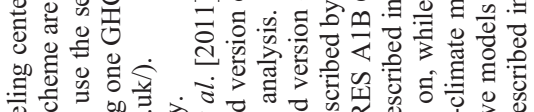

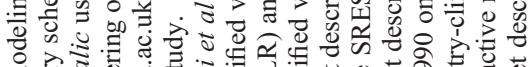

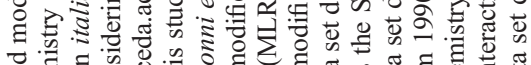

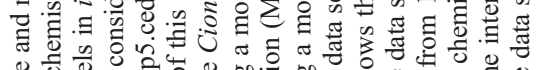

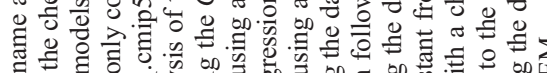

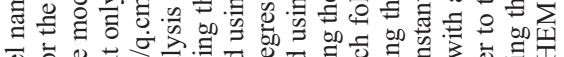

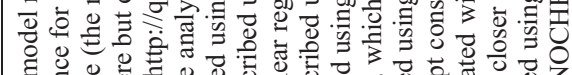

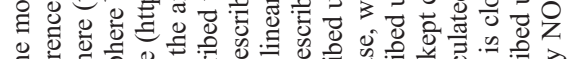

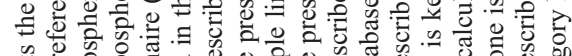

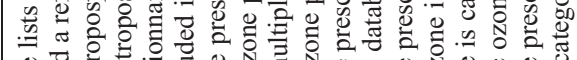

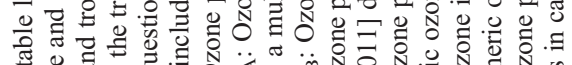

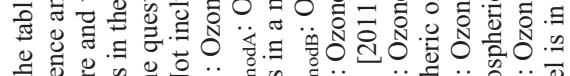

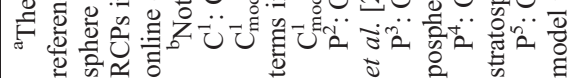


Total Column Ozone

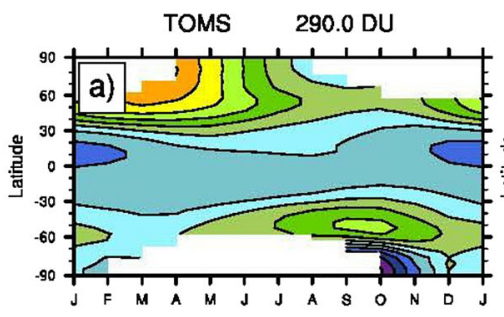

CMIP5Chem 288.2 DU

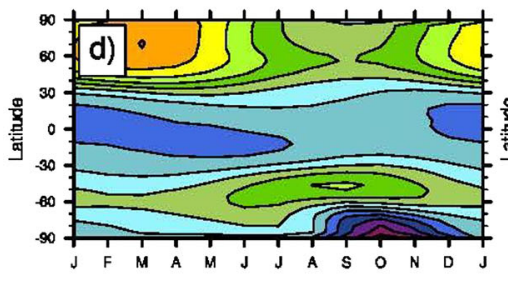

NIWA $286.3 \mathrm{DU}$
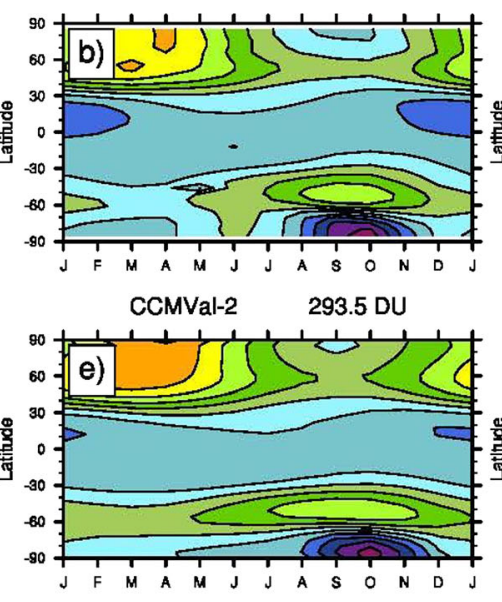

CCMVal-2 $293.5 \mathrm{DU}$

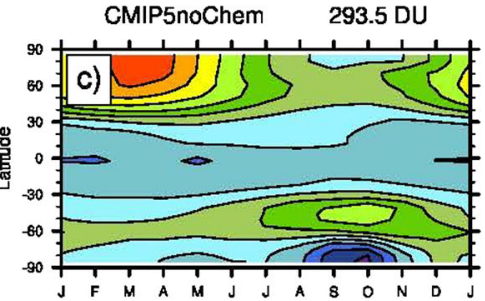

IGAC/SPARC

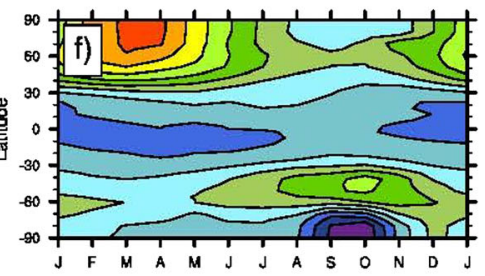

150175200225250275300325350375400425450475

Figure 1. Total column ozone climatologies (1986 to 2005) for (a) TOMS, (b) the NIWA combined total column ozone database, (c) the multimodel mean of CMIP5 models with prescribed ozone (NOCHEM), (d) the multimodel mean of CMIP5 models with interactive or semi-offline chemistry (CHEM), (e) the CCMVal-2 multimodel mean, and (f) the IGAC/SPARC ozone database. The values in the titles are calculated by interpolating the models to the same grid as the TOMS observations and by subtracting the grid cells without observations, then calculating the area-weighted average. Individual CMIP5 models are shown in Figure A1 of the Appendix.

interactive chemistry models, because the focus of the study is not on examining the difference between interactive and prescribed ozone but the sensitivity of stratospheric ozone evolution to GHG scenarios. The chemistry schemes of the interactive and semi-offline models are described in the Appendix (section A1.1 and Table 1).

\subsection{CMIP5 Model Versions With Prescribed Ozone}

[13] In 28 of the 46 CMIP5 model versions analyzed here, ozone concentrations were prescribed with an offline data set rather than calculated interactively or semi-interactively. The CMIP5 models with prescribed ozone that fall into this NOCHEM group are driven with the four RCPs in the troposphere. However, in contrast to the interactive and semioffline models discussed in section 2.1, in the stratosphere the offline ozone concentrations are calculated only for one GHG scenario (mostly the SRES A1B). The majority of the models used the original or slightly modified IGAC/ SPARC ozone database of Cionni et al. [2011], although five models prescribed a different data set-the IGAC/ SPARC ozone data set is a zonal mean field in the stratosphere but three-dimensional in the troposphere (see Appendix section A1.2 and Table 1).

\section{Long-Term Evolution of Ozone in the CMIP5 Models}

[14] We start the analysis by comparing the simulated ozone over the past decades to observations (section 3.1) and then discuss projections during the 21 st century in section 3.2 .

\subsection{Evaluation of Ozone in the CMIP5 Historical Simulations}

\subsubsection{Evaluation of Stratospheric Ozone}

[15] Figure 1 compares the climatological mean total column ozone from 1986 to 2005 from the CHEM and NOCHEM multimodel mean against the National Institute of Water and Atmospheric Research (NIWA) assimilated data set [Bodeker et al., 2005] and observations from the Total Ozone Mapping Spectrometer (TOMS) [Stolarski and Frith, 2006]. We divide the models into these two classes since the ozone projections shown in section 3.2 are done only with the CHEM models. The NIWA database includes measurements from four TOMS instruments, Global Ozone Monitoring Experiment (GOME), four solar backscatter ultraviolet [SBUV(/2)] instruments, and Ozone Monitoring Instrument (OMI). In addition, this figure includes a comparison to the CCMVal-2 multimodel mean [Eyring et al., 2010b] and the IGAC/SPARC ozone database [Cionni et al., 2011]. The individual CMIP5 models are shown in Figure A1 of the Appendix. Total column ozone has been calculated from the 3-D CMIP5 ozone mixing ratio fields (tro3) and the surface pressure (ps).

[16] Both the multimodel means of CHEM and NOCHEM represent the observed key features in the annual cycle well, with highest total column ozone values in northern spring, a small seasonal cycle and low ozone values in the tropics, a relative maximum in late winter/early spring in the southern midlatitudes, and the ozone hole over Antarctica in spring. In the NOCHEM group, not all models used the IGAC/SPARC database to prescribe ozone (see Appendix section A1.2), which explains the differences between these two panels. 
The amplitude and phase of the annual cycle in individual latitude bands is also well represented, but there are some quantitative differences, in particular over Antarctica in spring. Deviations from the NIWA observations over polar regions in spring are larger in the NOCHEM multimodel mean and the IGAC/SPARC ozone database than in the CHEM and CCMVal-2 multimodel means. The magnitude of the ozone hole is slightly underestimated in the prescribed ozone data set, as was reported by Cionni et al. [2011]. The IGAC/ SPARC database is based on observations and a regression fit that includes decadal trends, solar cycle, and quasi-biennial oscillation terms to generate continuous fields from Randel and $W u$ [2007], and over Antarctica relies on ozonesonde measurements from the Syowa station located at $69^{\circ} \mathrm{S}$. This station is at the vortex edge and thus has smaller October mean ozone depletion than the station at the South Pole [Hassler et al., 2011; Solomon et al., 2005]. In the CHEM and CCMVal-2 multimodel mean, the ozone hole over Antarctica in spring is well represented, with only small biases from the NIWA assimilated database. Larger deviations exist for the individual models with interactive chemistry or semi-offline ozone, also for other regions (see Figure A1 in the Appendix).

[17] Figure 2 compares the time series of total column ozone from 1960 to 2005 to five different observational data sets. The observations include ground-based measurements (updated from Fioletov et al. [2002]), NASA TOMS/OMI/SBUV(/2) merged satellite data [Stolarski and Frith, 2006], the NIWA combined total column ozone database [Bodeker et al., 2005], solar backscatter ultraviolet (SBUV, SBUV/2) retrievals (updated from Miller et al. [2002]), and GOME/ Scanning Imaging Absorption Spectrometer for Atmospheric CHartographY (SCIAMACHY)/GOME-2 [Loyola and Coldewey-Egbers, 2012; Loyola et al., 2009]. The linear trend over the period with highest ozone depletion (1980-2000) was calculated for models and observations and is given in Table 2 (note that GOME/SCIA/GOME-2 is not included in the trend calculation because it only started in 1995). The comparison is shown for the annual mean in the tropics and southern and northern midlatitudes, for March in the Arctic, and October in the Antarctic. To get insight into the vertical distribution, we additionally show comparisons of climatological mean vertical profiles at different latitudes (October $80^{\circ} \mathrm{S}$, March $0^{\circ}$, March $80^{\circ} \mathrm{N}$ ) and latitudinal profiles at $50 \mathrm{hPa}$ in March and October in Figure 3, similar to Figure A1 of Eyring et al. [2006]. The climatology covers the same period used to calculate the linear trends (i.e., 1980-2000).

[18] In general, the CHEM and NOCHEM multimodel means agree well with observations, both in terms of absolute values and trends (see Figure 2 and Table 2). In agreement with observations, smallest trends are simulated over the tropics and largest over Antarctica in spring.

[19] 1. In the tropics (Figure 2b), the trend and absolute values of the CHEM multimodel mean agree well with the observations, whereas the NOCHEM multimodel mean and the IGAC/SPARC ozone database slightly underestimate observed absolute values. All three simulate a small 1980-2000 linear trend, comparable to observations (see Table 2 for trends and associated uncertainties). The three data sets broadly follow the observed small modulation of total column ozone introduced by the 11 year solar cycle.
In the two models with semi-offline ozone (CCSM4, IPSL-CM5-LR), this modulation by the solar cycle is missing, since the time series are prescribed from decadal means (see section 2.1.2). Significant differences exist among the individual models, with three of the CHEM models (CNRM-CM5, MIROC-ESM, and GFDL-CM3) and one NOCHEM model (MIROC4h) deviating more than around 20 Dobson units (DU) from the observations. As noted above, total column ozone has been calculated from the tro3 fields and could slightly differ from the model's native total column ozone. In the MIROC-ESM, for example, total column ozone is around $5 \mathrm{DU}$ lower if calculated from the native grid, which could be due to the steep vertical gradient of ozone mixing ratio in the tropical lower stratosphere that is not captured by the coarse sampling of the tro3 fields. The overestimation in the MIROC4h model results from deviations in the prescribed State University of New York at Albany (SUNYA) data set [Wang et al., 1995] which was scaled by the observed stratospheric ozone trend from Randel and $W u$ [2007] for the past. The biases in the CNRM-CM5 could be related to the coarse vertical resolution, the low top of the model, and/or the simplified chemistry scheme (see Appendix). The CNRM-CM5 model has similar large biases in ozone in other regions and altitudes. We therefore exclude it from the multimodel mean for ozone projections and do not further explain deviations. All models except CNRM-CM5 simulate a small negative trend $(-0.1$ to $-0.36 \mathrm{DU} / \mathrm{yr}$, see Table 2) comparable to that in the observations $(-0.1 \pm 0.11$ to $-0.19 \pm 0.12 \mathrm{DU} /$ yr). The biases in the individual models can be attributed to different altitude regions in Figure 3. In the tropical lower stratosphere between 100 and $30 \mathrm{hPa}, 9$ out of 11 models agree well with Halogen Occultation Experiment (HALOE) observations and lie within the interannual standard deviation $(1 \sigma)$ of the HALOE mean (Figures $3 \mathrm{~b}, 3 \mathrm{~d}$, and $3 \mathrm{e}$ ). The GFDL-CM3 model's high bias (10 DU) seen in Figure 2 results from an overestimation of the ozone maximum at around $10 \mathrm{hPa}$. At altitudes above $7 \mathrm{hPa}$, where the photochemical lifetime of ozone is between 5 and 10 days and the primary odd-oxygen catalytic loss cycle is via $\mathrm{NO}_{\mathrm{x}}$ (e.g., Lary [1997]), the three high-top models (CESM1(WACCM), GFDL-CM3, and MIROCESM-CHEM) agree well with HALOE.

[20] 2. In the southern midlatitudes (Figure 2d), the biases in total column ozone for the individual models discussed above remain the same, with the same three models (CNRM-CM5, GFDL-CM3, MIROC-ESM-CHEM) being biased compared to observations. The excess ozone at southern midlatitudes in GFDL-CM3 is likely a result of the excessive strength of the Brewer-Dobson circulation from the tropics (where ozone is already too high) to midlatitudes. The CHEM multimodel mean starts at too high total column ozone values in 1960, similar to the CCMVal-2 multimodel mean. Overall, in using the Randel and Wu [2007] observations for this period, the NOCHEM multimodel mean and the IGAC/SPARC ozone database are in agreement with the observations shown here and agree better with the observations than the CCMVal-2 and CHEM multimodel means.

[21] 3. In the northern midlatitudes (Figure 2c), the MIROC-ESM-CHEM is still biased high, but the CNRMCM5 and the GFDL-CM3 are closer to observations. In this region, CCSM4 simulates a positive trend $(0.07 \pm 0.01 \mathrm{DU} /$ 

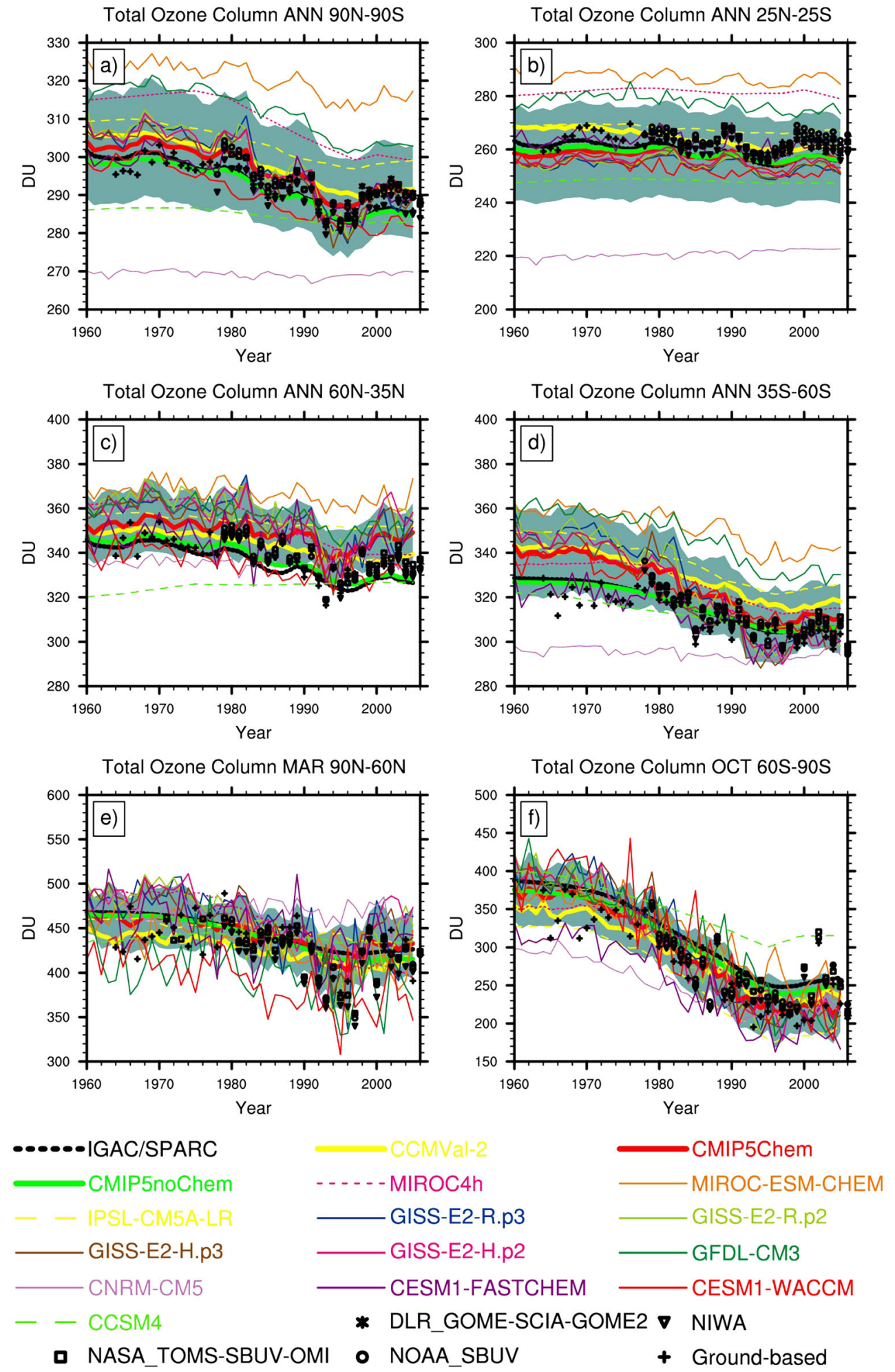

Figure 2. Time series of area-weighted total column ozone from 1960 to 2005 for the annual mean (a) global mean $\left(90^{\circ} \mathrm{S}-90^{\circ} \mathrm{N}\right)$, (b) in the tropics $\left(25^{\circ} \mathrm{S}-25^{\circ} \mathrm{N}\right)$, (c) in the northern midlatitudes $\left(35^{\circ} \mathrm{N}-60^{\circ} \mathrm{N}\right)$, (d) in the southern midlatitudes $\left(35^{\circ}-60^{\circ} \mathrm{S}\right)$, and for the March and October mean in the (e) Arctic $\left(60^{\circ} \mathrm{N}-90^{\circ} \mathrm{N}\right)$, and (f) Antarctic $\left(60^{\circ} \mathrm{S}-90^{\circ} \mathrm{S}\right)$, respectively. The figure shows the multimodel mean and individual CMIP5 models with interactive or semi-offline chemistry (CHEM, red solid and colored lines) and standard deviation (blue shaded area) compared to the IGAC/SPARC ozone database (black dotted line). In addition, the multimodel mean of the CMIP5 models that prescribe ozone (NOCHEM, green solid line), the CCMVal-2 multimodel mean (yellow solid line), and observations from five different sources (see text) are shown. 
Table 2. Linear Trends and Errors in Total Column Ozone (DU/year) ${ }^{\mathrm{a}}$

\begin{tabular}{|c|c|c|c|c|c|c|}
\hline & $\begin{array}{c}90^{\circ} \mathrm{S}-90^{\circ} \mathrm{N} \\
\mathrm{AM}\end{array}$ & $\begin{array}{c}25^{\circ} \mathrm{N}-25^{\circ} \mathrm{S} \text { Annual } \\
\text { Mean }\end{array}$ & $\begin{array}{c}35^{\circ} \mathrm{N}-60^{\circ} \mathrm{N} \text { Annual } \\
\text { Mean }\end{array}$ & $\begin{array}{c}60^{\circ} \mathrm{S}-35^{\circ} \mathrm{S} \text { Annual } \\
\text { Mean }\end{array}$ & $\begin{array}{c}60^{\circ} \mathrm{N}-90^{\circ} \mathrm{N} \text { March } \\
\text { mean }\end{array}$ & $\begin{array}{c}90^{\circ} \mathrm{S}-60^{\circ} \mathrm{S} \mathrm{Oct} \\
\text { mean }\end{array}$ \\
\hline Ground-based & $-0.56 \pm 0.11$ & $-0.08 \pm 0.10$ & $-0.84 \pm \mathbf{0 . 2 5}$ & $-0.90 \pm 0.17$ & $-3.18 \pm 0.95$ & $-5.25 \pm 0.77$ \\
\hline NOAA-SBUV & $-0.74 \pm 0.12$ & $-0.16 \pm 0.13$ & $-1.12 \pm 0.21$ & $-1.21 \pm 0.18$ & $-3.30 \pm 0.96$ & $-3.99 \pm 0.80$ \\
\hline $\begin{array}{l}\text { NASA TOMS-SBUV- } \\
\text { OMI }\end{array}$ & $-0.67 \pm 0.13$ & $-0.19 \pm 0.12$ & $-0.89 \pm 0.23$ & $-1.06 \pm 0.17$ & $-2.95 \pm 0.91$ & $-3.70 \pm 0.82$ \\
\hline NIWA & $-0.61 \pm 0.12$ & $-0.10 \pm 0.11$ & $-0.88 \pm 0.23$ & $-0.87 \pm 0.16$ & $-3.18 \pm 0.92$ & $-3.80 \pm 0.78$ \\
\hline CCSM4 & $-0.17 \pm 0.02$ & $-0.08 \pm 0.00$ & $0.07 \pm 0.01$ & $-0.35 \pm 0.03$ & $-0.60 \pm 0.04$ & $-2.63 \pm 0.26$ \\
\hline CESM1(WACCM) & $-0.52 \pm 0.05$ & $-0.13 \pm 0.06$ & $-0.31 \pm 0.16$ & $-0.94 \pm 0.12$ & $-1.85 \pm 0.86$ & $-5.60 \pm 1.25$ \\
\hline CESM1(FASTCHEM) & $-0.56 \pm 0.16$ & $-0.36 \pm 0.14$ & $-0.34 \pm 0.34$ & $-0.78 \pm 0.25$ & $-0.74 \pm 1.17$ & $-4.12 \pm 0.78$ \\
\hline CNRM-CM5 & $-0.00 \pm 0.03$ & $0.12 \pm 0.03$ & $0.16 \pm 0.09$ & $-0.19 \pm 0.06$ & $-0.03 \pm 0.38$ & $-2.30 \pm 0.37$ \\
\hline GFDL-CM3 & $-0.79 \pm 0.07$ & $-0.31 \pm 0.07$ & $-0.52 \pm 0.15$ & $-1.46 \pm 0.14$ & $-1.78 \pm 0.94$ & $-7.33 \pm 0.98$ \\
\hline GISS-E2-H.p2 & $-1.05 \pm 0.17$ & $-0.33 \pm 0.10$ & $-1.21 \pm 0.27$ & $-1.86 \pm 0.22$ & $-3.28 \pm 1.04$ & $-5.34 \pm 0.72$ \\
\hline GISS-E2-H.p3 & $-1.06 \pm 0.19$ & $-0.36 \pm 0.09$ & $-1.06 \pm 0.34$ & $-2.04 \pm 0.30$ & $-2.96 \pm 0.99$ & $-5.54 \pm 0.86$ \\
\hline GISS-E2-R.p2 & $-1.11 \pm 0.19$ & $-0.33 \pm 0.08$ & $-1.28 \pm 0.32$ & $-2.07 \pm 0.30$ & $-2.84 \pm 1.08$ & $-6.08 \pm 0.91$ \\
\hline GISS-E2-R.p3 & $-1.18 \pm 0.19$ & $-0.32 \pm 0.08$ & $-1.33 \pm 0.34$ & $-2.28 \pm 0.27$ & $-3.27 \pm 1.32$ & $-7.07 \pm 0.91$ \\
\hline IPSL-CM5-ALR & $-0.43 \pm 0.03$ & $-0.10 \pm 0.01$ & $-0.18 \pm 0.02$ & $-0.96 \pm 0.06$ & $-1.08 \pm 0.07$ & $-5.56 \pm 0.32$ \\
\hline MIROC-ESM-CHEM & $-0.55 \pm 0.07$ & $-0.17 \pm 0.07$ & $-0.37 \pm 0.11$ & $-1.17 \pm 0.15$ & $-0.80 \pm 0.58$ & $-5.24 \pm 0.70$ \\
\hline MIROC4h & $-0.82 \pm 0.04$ & $-0.05 \pm 0.02$ & $-1.26 \pm 0.04$ & $-1.06 \pm 0.04$ & $-3.85 \pm 0.14$ & $-6.51 \pm 0.21$ \\
\hline NOCHEM & $-0.63 \pm 0.05$ & $-0.22 \pm 0.04$ & $-0.84 \pm 0.08$ & $-0.83 \pm 0.04$ & $-2.00 \pm 0.08$ & $-4.63 \pm 0.21$ \\
\hline CHEM & $-0.67 \pm 0.09$ & $-0.21 \pm 0.04$ & $-0.58 \pm 0.13$ & $-1.28 \pm 0.13$ & $-1.75 \pm 0.41$ & $-5.16 \pm 0.38$ \\
\hline CCMVal-2 & $-0.61 \pm 0.03$ & $-0.32 \pm 0.03$ & $-0.56 \pm 0.04$ & $-0.97 \pm 0.05$ & $-1.45 \pm 0.21$ & $-4.08 \pm 0.26$ \\
\hline IGAC/SPARC & $-0.64 \pm 0.06$ & $-0.33 \pm 0.05$ & $-0.79 \pm 0.09$ & $-0.83 \pm 0.04$ & $-1.57 \pm 0.08$ & $-4.53 \pm 0.22$ \\
\hline
\end{tabular}

${ }^{\mathrm{a}}$ Over the 1980-2000 period for observations, the individual CMIP5 models, the CHEM, NOCHEM, and CCMVal-2 multimodel means, and the IGAC/ SPARC database for the different regions shown in Figure 2.

yr) over the 1980 to 2000 period in contrast to the observations which show a negative trend $(-1.12 \pm 0.21$ to $-0.84 \pm 0.25$ $\mathrm{DU} / \mathrm{yr}$ ) and is also biased low in terms of absolute values by around $20 \mathrm{DU}$ at the beginning of the time series in the $1960 \mathrm{~s}$. This is partially related to the fact that the model top is located at $2.2 \mathrm{hPa}$. There is also the factor that the fields in CCSM4 are linearly interpolated in time from decadal averages from the NCAR-CAM3.5 results, smoothing out the results (see section 2.1.2.1).

[22] 4. Over Antarctica in October (Figure 2f), CCSM4 and CNRM-CM5 substantially underestimate ozone depletion $(-2.63 \pm 0.26$ and $-2.3 \pm 0.37 \mathrm{DU} / \mathrm{yr}$, respectively, compared to observed $-5.25 \pm 0.77$ to $-3.70 \pm 0.82 \mathrm{DU} /$ yr). This underestimation will lead to subsequent biases in zonal mean wind changes [Son et al., 2008] which are further discussed in section 4. CESM1(FASTCHEM) is biased slightly low, in particular at the beginning of the time series in the 1960s. This is presumably because it uses a simple temperature threshold and decay to represent ozone hole loss processes [Cariolle et al., 1990] so the ozone loss starts in the winter before the sun rises. All other models and the CHEM, NOCHEM, and CCMVal-2 multimodel means agree well with observations, both in terms of trends and absolute values, although the CMIP5 CHEM multimodel mean represents the ozone depletion period slightly better (see also Figure 1). Ozone recovery starts too early in the CCSM4 and IPSL in around 1995. These are the two models where interannual variability in ozone is missing, since the data sets stem from decadal means. This could lead to biases in temperature trends as is further discussed below.

[23] 5. In the Arctic in March (Figure 2e), again CCSM4 and CNRM-CM5 underestimate ozone depletion $(-0.60 \pm 0.04$ and $-0.03 \pm 0.38$, respectively, compared to observed $-3.30 \pm 0.96$ to $-2.95 \pm 0.91 \mathrm{DU} / \mathrm{yr}$ ). All other models also simulate smaller trends than observed, leading to an underestimation of the trend by the CHEM multimodel mean $(-1.75 \pm 0.41 \mathrm{DU} / \mathrm{yr})$ and the NOCHEM multimodel mean
$(-2.00 \pm 0.08 \mathrm{DU} / \mathrm{yr})$, and also a similar underestimation by the IGAC/SPARC ozone database $(-1.57 \pm 0.08 \mathrm{DU} /$ yr). The absolute values are mostly of the order of those observed, except for CESM1(WACCM) and GFDL-CM3, which are biased low.

[24] 6. The global annual mean (Figure 2a) combines the different regions discussed above. In terms of absolute values, the CHEM and CCMVal-2 multimodel means agree well with observations. The NOCHEM multimodel mean and the IGAC/SPARC ozone database are biased slightly low, by around 10 DU. The 1980-2000 trends of all four time series lie between $-0.61 \pm 0.03$ and $-0.67 \pm 0.09 \mathrm{DU} / \mathrm{yr}$, within the observed range $(-0.56 \pm 0.11$ to $-0.74 \pm 0.12$ DU/yr). The models also consistently simulate a negative trend $(-0.17 \pm 0.02$ to $-1.18 \pm 0.19 \mathrm{DU} / \mathrm{yr})$ except for CNRM-CM5 that has a zero trend $( \pm 0.03)$.

\subsubsection{Evaluation of Tropospheric Ozone}

[25] As mentioned, ozone in both the CHEM and NOCHEM group follows the RCP scenarios in the future. The tropospheric ozone portion of the IGAC/SPARC ozone database, which was used in the majority of the models to prescribe ozone (see Table 1), is based on calculations of the historical period from CAM3.5 [Lamarque et al., 2010] and the NASA GISS model for Physical Understanding of Composition-Climate Interactions and Impacts (GISSPUCCINI, Shindell et al. [2006]); see further description by Cionni et al. [2011]. The three-dimensional (latitude, longitude, altitude) future tropospheric ozone time series continues the historical CAM3.5 simulation (not GISSPUCCINI) until 2099, following the four different RCPs. To be consistent with the ACCMIP calculations of Young et al. [2013b], we used the WMO tropopause definition to identify the tropopause. Here, the boundary between the troposphere and the stratosphere is defined as the lowest level at which the lapse rate decreases to $2 \mathrm{~K} / \mathrm{km}$ or less, provided that the average lapse rate between this level and all higher levels within $2 \mathrm{~km}$ does not exceed $2 \mathrm{~K} / \mathrm{km}$. Figure 4 shows 

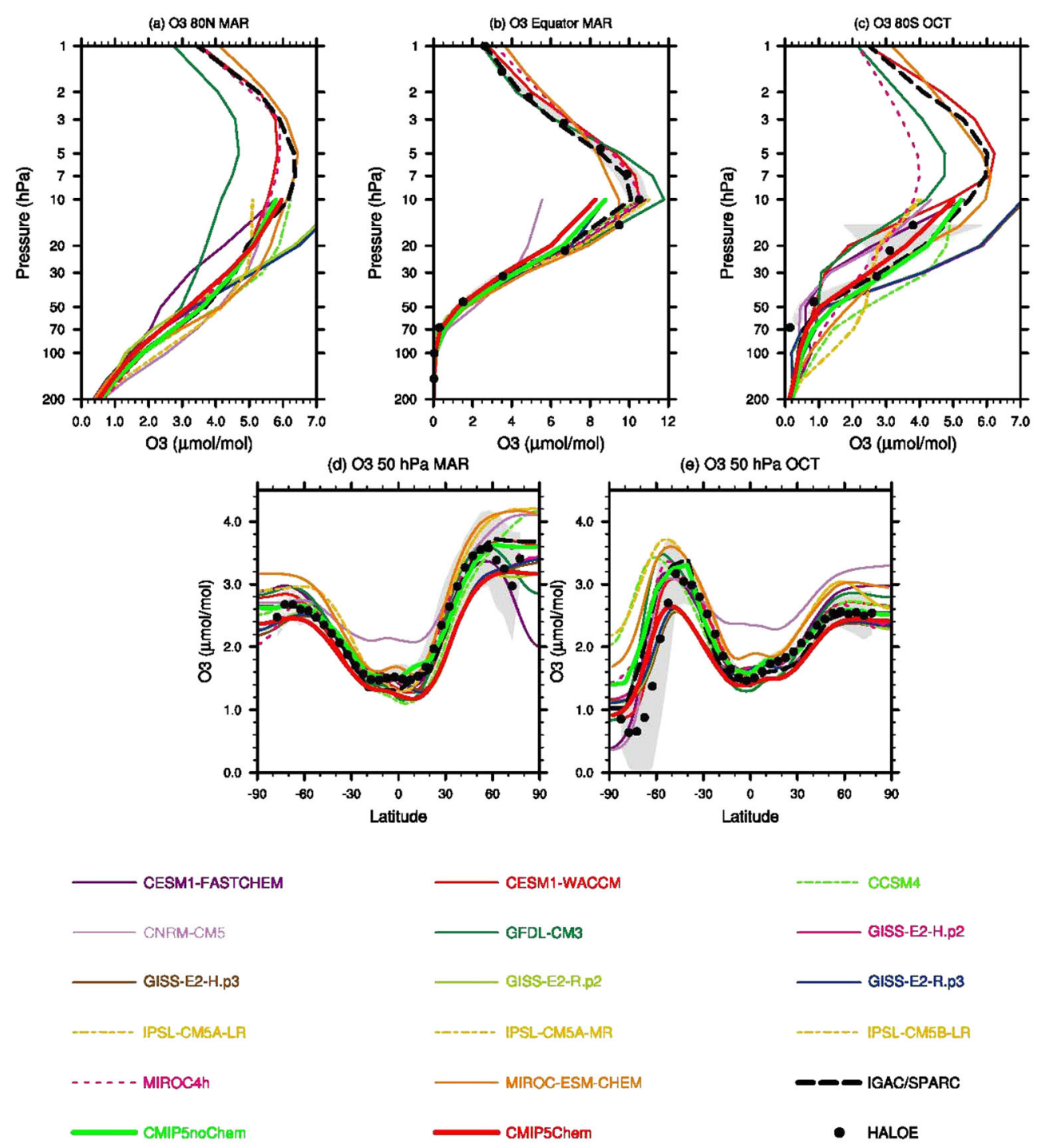

Figure 3. Climatological zonal mean (1980-2000) ozone mixing ratios from the individual CMIP5 models, the CHEM and NOCHEM multimodel means, and the IGAC/SPARC database compared to HALOE observations in $\mu \mathrm{mol} / \mathrm{mol}$. Vertical profiles at (a) $80^{\circ} \mathrm{N}$ in March, (b) $0^{\circ}$ in March, and (c) $80^{\circ} \mathrm{S}$ in October. Latitudinal profiles at $50 \mathrm{hPa}$ in (d) March and (e) October. The gray area shows $\mathrm{HALOE} \pm 1 \sigma$ about the climatological zonal mean.

a comparison of simulated tropospheric column ozone values averaged over the period 2000-2005 to values derived from OMI and Microwave Limb Sounder (MLS) instruments on board the Aura satellite averaged over 2000-2005 (Ziemke et al. [2011]; source: http://acdb-ext.gsfc.nasa.gov/Data services/cloud slice/new data.html). The individual models are shown in Figure A2 of the Appendix.

[26] Figure 4 shows that the geographical distribution of tropospheric column ozone is very similar in the CHEM and NOCHEM multimodel means. They agree in important aspects with the observations, for example, have lower values in the tropics and lower values in the $\mathrm{SH}$ compared to the Northern Hemisphere $(\mathrm{NH})$. Near-global $\left(60^{\circ} \mathrm{S}-60^{\circ} \mathrm{N}\right)$ mean absolute values nearly agree, but this is to some degree due to the compensation of a high model bias in NH midlatitudes and a low model bias in the tropics. The models overall show a stronger hemispheric gradient in tropospheric ozone than is seen in the observations. As with comparisons against stratospheric ozone data, substantial differences exist among the individual models and compared to observations (see Figure A2 in Appendix). Most notably, the IPSL models use zonal mean ozone in the troposphere and therefore miss the observed longitudinal structure, such as ozone maxima over regions with high ozone precursor emissions and the very low ozone over the tropical Pacific Ocean which has been previously detected (e.g., Singh et al. [1996]). The spatial distribution of ozone could be important for estimates of regional radiative forcing (RF) [Freckleton et al., 1998; Shindell and Faluvegi, 2009] and $\mathrm{OH}$ levels and hence lifetimes for many very short lived species (VSLSs). In addition, the differences in absolute ozone values among the CMIP5 models could lead to differences in global mean tropospheric ozone RF, discussed further by Young et al. [2013b].

[27] Figure 5 compares a 20 year (1986-2005) climatology of the CHEM models and the IGAC/SPARC ozone database against ozonesonde measurements, which broadly 

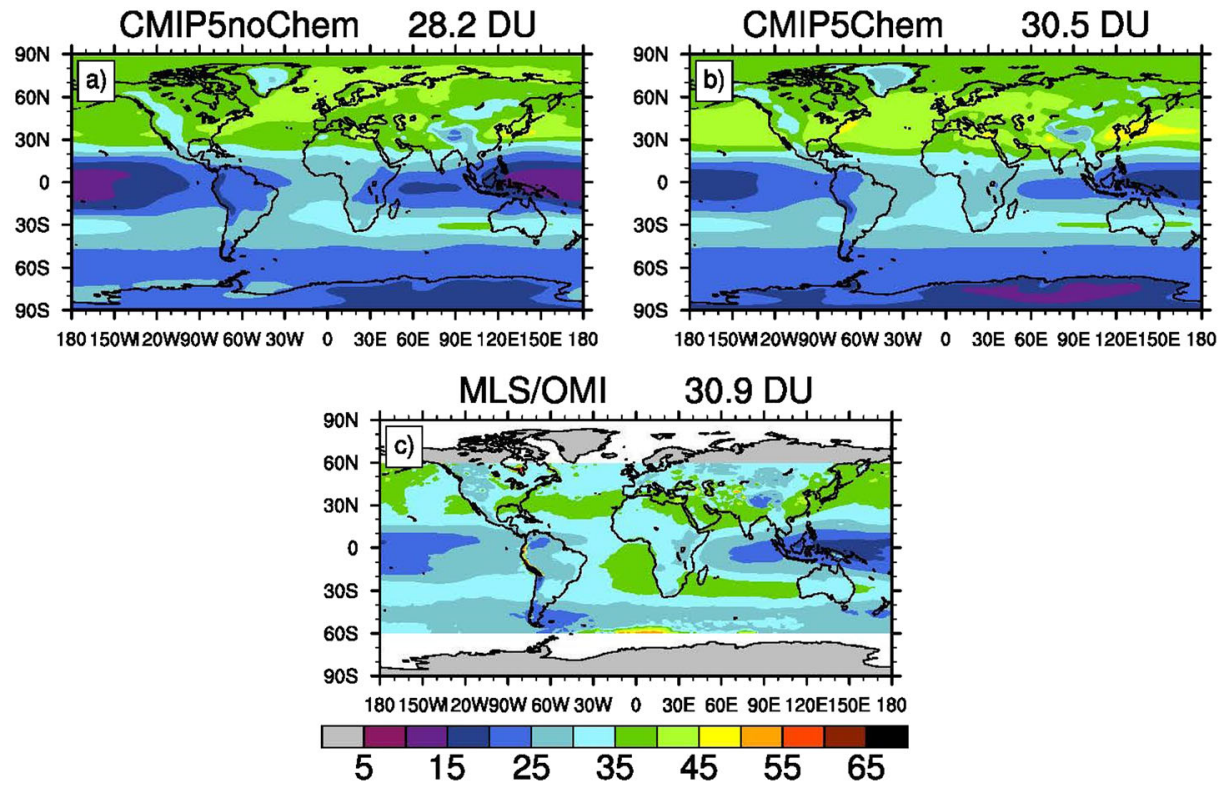

Figure 4. Climatological mean annual mean tropospheric column ozone averaged between 2000 and 2005 from the CMIP5 NOCHEM and the CHEM multimodel mean compared to the 2005-2009 MLS/ OMI observations [from Ziemke et al., 2011]. The numbers in the title show the near-global areaweighted mean $\left(60^{\circ} \mathrm{S}-60^{\circ} \mathrm{N}\right)$ as in the observations. Individual CMIP5 models are shown in Figure A2 of the Appendix.

cover the same time period and are described by Logan [1999]. The models were sampled at the ozonesonde sites, and the observational and model data were aggregated into four latitude bands; data from the lower $(750 \mathrm{hPa})$, mid $(500 \mathrm{hPa})$, and upper $(250 \mathrm{hPa})$ troposphere are shown. A similar summary figure was presented by Stevenson et al. [2006] and Young et al. [2013b]. The multimodel mean captures the seasonal cycle in observed ozone concentrations well, being significantly correlated $(\mathrm{r}>0.58 ; 5 \%$ level) with the ozonesondes in all locations except the $\mathrm{NH}$ tropical upper troposphere where the correlation is only 0.45 . Young et al. [2013b] showed that the multimodel mean from the 15 state-of-the-art chemistry models participating in ACCMIP also could not capture the seasonal cycle here, perhaps indicating problems with the modeling of the relevant processes for this region (e.g., convective transport, lightning $\mathrm{NO}_{\mathrm{x}}$, natural emissions, and stratosphere-troposphere connections), although we note that the interannual variation is comparatively large in this region. Compared to the climatological mean for the observations, there are negative biases for the multimodel mean in the SH and mostly positive biases in the $\mathrm{NH}$ (except the tropical upper troposphere again), which is also in agreement with Young et al. [2013b]. However, we note that the multimodel mean is within the interannual variability of the majority of the observations, except for winter and spring in the NH extratropics. The spread in performance of the individual CMIP5 models is generally larger than in similar multimodel comparisons [Stevenson et al., 2006; Young et al., 2013b], with CESM1(FASTCHEM) and CNRM-CM5 notably underestimating the observations through much of the tropics and the GISS models notably overestimating the observations in the $\mathrm{NH}$ extratropics. For CESM1(FASTCHEM), this is probably because lightning $\mathrm{NO}_{\mathrm{x}}$ was inadvertently missing in these simulations (see section 2.1.1.1) and differences in lightning $\mathrm{NO}_{\mathrm{x}}$ or isoprene emission could also be possible reasons for the deviations in the GISS model. Ozone concentrations from the IGAC/ SPARC ozone database are lower than the multimodel mean and fall outside the range of concentrations described by interannual variability in the SH tropical upper troposphere.

\subsection{Future Evolution of Ozone}

\subsubsection{Stratospheric Ozone Projections}

[28] The future evolution of stratospheric ozone is assessed in the concentration driven historical and RCP simulations of the models with interactive or semi-offline chemistry. However, we exclude the CNRM-CM5 model in this group, since the simplified chemistry scheme leads to poor performance of ozone compared to observations (see section 3.1). We also exclude the IPSL-CM5A model, since it uses a simplified scaling to determine ozone for the various RCPs (see section A1.2.2). In contrast to the historical simulations, future changes in tropospheric column ozone contribute a significant amount to changes in total column ozone under the RCPs (see section 3.2.2). Consequently, we show stratospheric column instead of total column ozone used in the previous section. In the evaluation section, total column ozone was chosen since long-term observations exist for this data product.

[29] The evolution of stratospheric ozone over the historical time period (1960 to 2005) and the sensitivity of ozone to future GHGs (2006-2100) for the four different RCPs are first analyzed for the six regions discussed above (Figure 6). We note again that all simulations follow the same ODS scenario in the future, namely the A1 scenario of $W M O$ [2003]. The CHEM models that are included in the different RCPs for future analysis are listed in the caption of Figure 6, and resulting historical and future changes among the RCPs for 


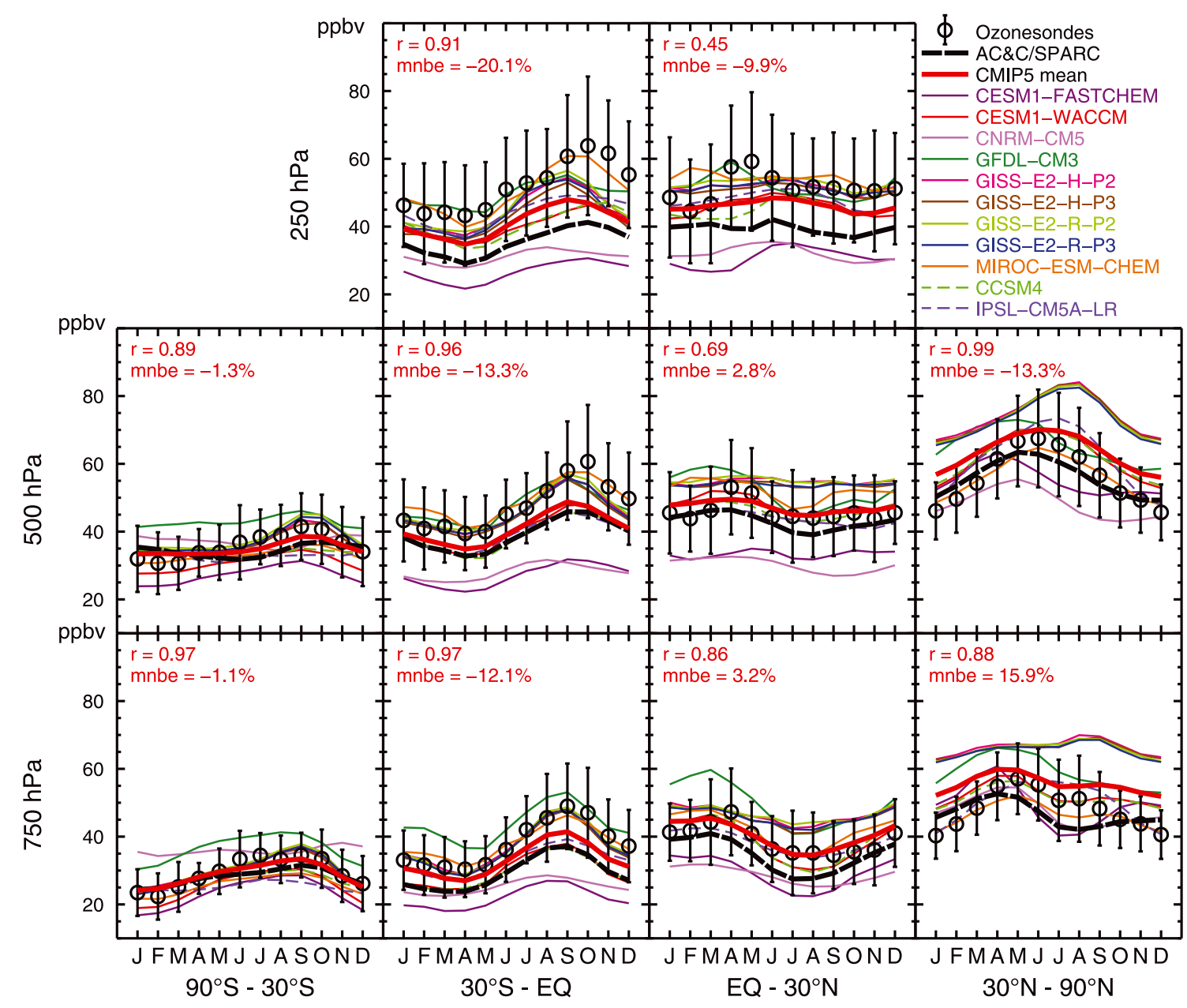

Figure 5. Comparison of the annual cycle of ozone, between observations (black circles) and the CMIP5 multimodel mean (solid red line) and CMIP5 multimodel median (dashed red line) averaged over the period 1986-2005. Model and observational data were grouped into four latitude bands $\left(90^{\circ} \mathrm{S}\right.$ to $30^{\circ} \mathrm{S}, 30^{\circ} \mathrm{S}$ to $0^{\circ}$, $0^{\circ}$ to $30^{\circ} \mathrm{N}$, and $30^{\circ} \mathrm{N}$ to $\left.90^{\circ} \mathrm{N}\right)$ and sampled at three altitudes $(700 \mathrm{hPa}, 500 \mathrm{hPa}$, and $250 \mathrm{hPa}$ ), with the models sampled at the ozonesonde locations before averaging together. The individual CHEM models are represented by the colored solid and dashed lines. Error bars on the observations indicate the average interannual standard deviation for each group of stations. The correlation (r) and mean normalized bias error (mnbe) for the CMIP5 multimodel mean versus the observations are also indicated in each panel. This figure is similar to Figure 4 of Young et al. [2013b], who discuss the ACCMIP instead of the CMIP5 CHEM models.

the corresponding multimodel global annual mean are summarized in Table 3.

[30] To calculate multimodel trends and their confidence and prediction uncertainties, we use the same time series additive model (TSAM) method [Scinocca et al., 2010] that was applied in previous CCMVal studies [Eyring et al., 2010b; SPARC-CCMVal, 2010]. We also use the same terminology, where the term "trend" refers to a smooth trajectory passing through the model time series. This represents the signal resulting from forced changes, leaving noise as a residual resulting from internal, unforced climate variability. Since we are interested in the question whether the long-term evolution differs between the RCPs, we show the point-wise $95 \%$ confidence interval. This interval has a $95 \%$ chance of overlapping the true trend, representing the local uncertainty in the trend at each year. The TSAM method was also previously applied in a study on the sensitivity of stratospheric ozone to GHG scenarios but applying a smaller set of models [Eyring et al., 2010a]. We reassess their conclusions with the help of the CMIP5 models with interactive and semi-offline chemistry in comparison to the IGAC/SPARC ozone database, which was used in the majority of the CMIP5 models with prescribed ozone. It should be noted that the model used to calculate semioffline ozone in CCSM4 (CAM3.5) was also included in Eyring et al. [2010a]. Similar to section 3.1, we additionally show vertical profiles (here: 2090s-2000s and 2090s-1960s) to probe the vertical distribution of future stratospheric ozone changes.

[31] There are no significant changes prior to 1960 (not shown). From 1960 onwards, stratospheric ozone decreases due to increase in ODSs until around 2000, except in the tropics where changes are generally small. This decrease is followed by a steady increase with a rate being dependent on the RCP and the region. Figure 7 shows the differences in vertically resolved ozone between the 2090s 
Stratospheric Ozone Column ANN 90N-90S

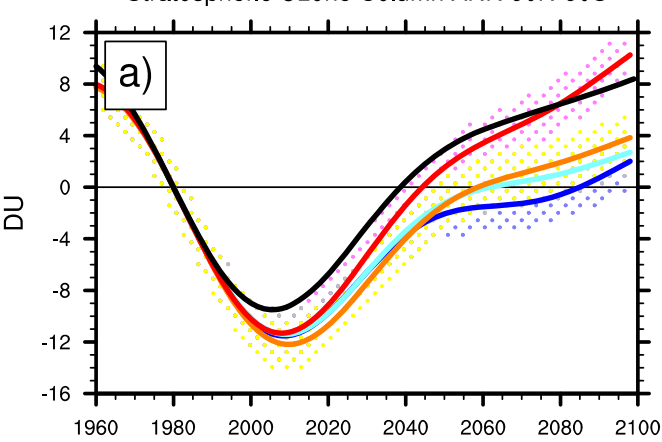

Stratospheric Ozone Column ANN 60N-35N

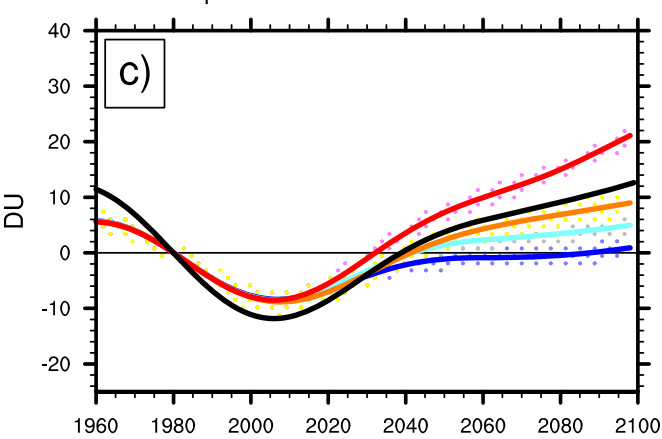

Stratospheric Ozone Column MAR 90N-60N

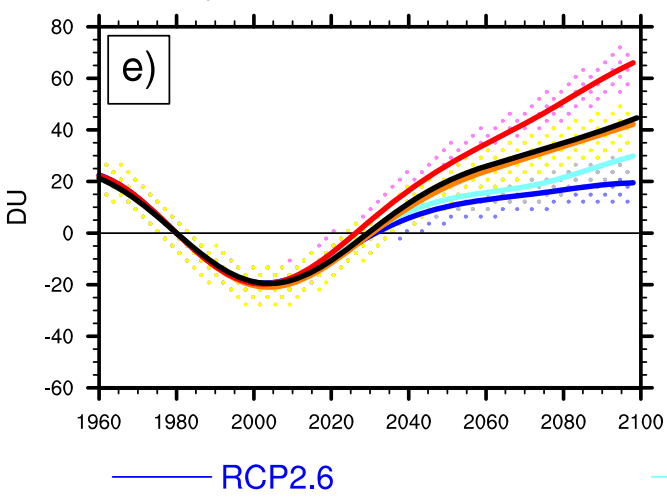

Stratospheric Ozone Column ANN 25N-25S

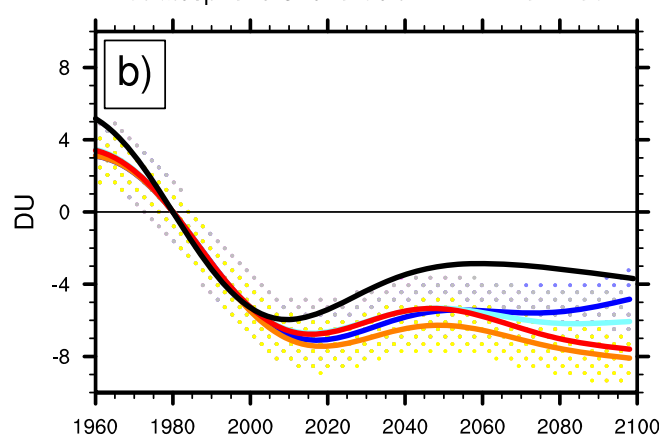

Stratospheric Ozone Column ANN 35S-60S

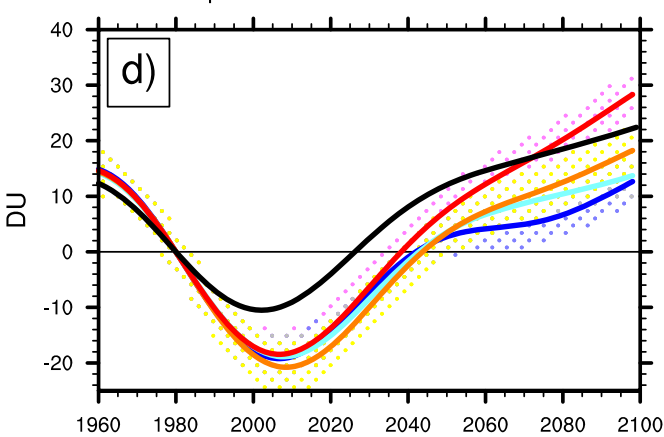

Stratospheric Ozone Column OCT 60S-90S

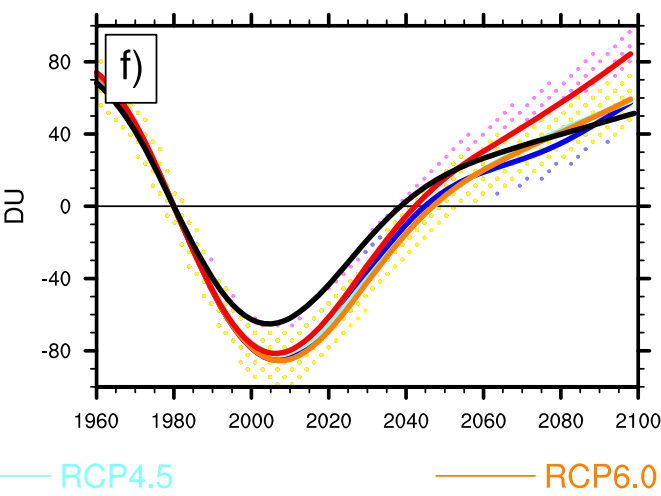

IGAC/SPARC

Figure 6. The 1980 baseline-adjusted stratospheric column ozone time series from 1960 to 2100 for the CMIP5 CHEM multimodel mean (colored lines) and the IGAC/SPARC ozone database (black line) for different regions. All time series by construction go through 0 in 1980. The RCP 2.6 (CCSM4, GFDL-CM3, GISS-E2-R.p2, GISS-E2-R.p3, MIROC-ESM-CHEM), RCP 4.5 (CCSM4, CESM1-WACCM, GFDLCM3, GISS-E2-R.p2, GISS-E2-R.p3, MIROC-ESM-CHEM), 6.0 (CCSM4, GFDL-CM3, GISS-E2-R.p2, GISS-E2-R.p3, MIROC-ESM-CHEM), and RCP 8.5 (CCSM4, CESM1-WACCM, GFDL-CM3, GISSE2-R.p2, GISS-E2-R.p3, MIROC-ESM-CHEM) are shown in blue, light blue, orange, and red, respectively, with the models included in the multimodel mean being shown in brackets. The corresponding color-coded stippled areas show the $95 \%$ confidence interval of the CHEM multimodel mean simulations.

and the pre-ozone depleted 1960s (left two columns) and between the 2090s and the 2000s (right two columns).

[32] 1. In all RCP simulations, a decrease in the tropical lower stratospheric ozone is simulated in the altitude range between around 100 and $30 \mathrm{hPa}$ compared to both the 2000s (Figure 7, left) and the 1960s (Figure 7, right). This decrease is smaller in the two lower (RCP 2.6 and 4.5) GHG scenarios compared to the higher ones (RCP 6.0 and 8.5). The decrease in the lower tropical stratosphere is a result of a projected strengthening of the Brewer-Dobson circulation [Butchart et al., 2010; Butchart et al., 2011; SPARC-CCMVal, 2010]. In contrast, in the upper stratosphere the sensitivity to GHG scenarios is opposite in sign, with smaller GHG-induced cooling leading to smaller changes in ozone from changes in ozone destruction rates. Compared to pre-ozone depletion (1960s), this increase quantifies "super-recovery," which is a $\mathrm{CO}_{2}$-induced cooling effect in the upper and middle stratosphere that slows down 
Table 3. Stratospheric Column Ozone (DU) ${ }^{\mathrm{a}}$

\begin{tabular}{ccccc}
\hline Year & RCP 2.6 & RCP 4.5 & RCP 6.0 & RCP 8.5 \\
\hline 1850 & $293 \pm 9$ & $293 \pm 9$ & $293 \pm 9$ & $293 \pm 9$ \\
1980 & $291 \pm 8$ & $291 \pm 8$ & $291 \pm 8$ & $291 \pm 8$ \\
2000 & $276 \pm 8$ & $276 \pm 8$ & $276 \pm 8$ & $276 \pm 8$ \\
2005 & $276 \pm 9$ & $276 \pm 9$ & $276 \pm 9$ & $276 \pm 9$ \\
2010 & $278 \pm 9$ & $275 \pm 11$ & $277 \pm 9$ & $274 \pm 12$ \\
2020 & $280 \pm 10$ & $276 \pm 12$ & $279 \pm 11$ & $278 \pm 11$ \\
2030 & $284 \pm 9$ & $280 \pm 10$ & $283 \pm 9$ & $281 \pm 10$ \\
2040 & $285 \pm 9$ & $283 \pm 11$ & $286 \pm 10$ & $285 \pm 10$ \\
2050 & $288 \pm 9$ & $286 \pm 12$ & $289 \pm 10$ & $288 \pm 11$ \\
2060 & $289 \pm 9$ & $288 \pm 11$ & $290 \pm 9$ & $291 \pm 11$ \\
2070 & $289 \pm 9$ & $287 \pm 9$ & $291 \pm 9$ & $292 \pm 8$ \\
2080 & $288 \pm 9$ & $287 \pm 10$ & $292 \pm 9$ & $291 \pm 11$ \\
2090 & $289 \pm 9$ & $288 \pm 10$ & $292 \pm 10$ & $294 \pm 10$ \\
2100 & $291 \pm 9$ & $289 \pm 11$ & $293 \pm 10$ & $296 \pm 11$ \\
\hline
\end{tabular}

${ }^{a}$ For the various RCPs as calculated from the multimodel mean of the CMIP5 models with interactive or semi-offline stratospheric chemistry (see caption of Figure 6). The multimodel mean is given along with uncertainties $( \pm 1 \mathrm{SD})$.

ozone destruction rates, leading to an increase in ozone. The resulting evolution of tropical stratospheric ozone column that can be seen in Figure 6 is a combination of decreases in lower stratospheric ozone and increases in upper stratospheric ozone that result in small changes in the total column over the 21 st century. The decrease that was projected by the CCMVal-2 models due to an enhanced Brewer-Dobson circulation under the SRES A1B scenario [SPARC-CCMVal, 2010] is again seen in the higher RCP 6.0 and 8.5 scenarios, in which $\mathrm{CO}_{2}$ concentrations continue to increase in the second half of the 21 st century (see for example Figure 1 of Cionni et al. [2011]). This decrease is not simulated in the RCP 4.5 and RCP 2.6 scenarios, where $\mathrm{CO}_{2}$ concentrations level or slightly decrease in the second half of the 21 st century, respectively. However, notably also in the RCP 2.6 and 4.5 scenarios, tropical ozone remains below 1960 levels at the end of the 21 st century. These findings agree well with current general understanding on processes in the upper and lower stratosphere [Butchart et al., 2010; Eyring et al., 2010a; SPARC-CCMVal, 2010].

[33] 2. In the midlatitudes, the ozone sensitivity to GHG scenarios in the upper stratosphere is the same as in the tropics. The upper stratospheric behavior is again related to stronger $\mathrm{CO}_{2}$-induced cooling in the higher GHG scenarios, in line with previous findings [SPARC-CCMVal, 2010; $W M O, 2011]$. In contrast to the tropics, in the lower stratosphere substantial increases compared to the 2000s (Figure 7, left) and the 1960s (Figure 7, right) are simulated. These increases are higher in the scenarios with higher GHG concentrations. The substantial increase of UTLS ozone as seen particularly in the higher RCP scenarios is important since ozone changes in this altitude region have the greatest impact on surface temperature on purely radiative grounds [Forster and Shine, 1997]. The increase could again be due to an increased Brewer-Dobson circulation in the higher $\mathrm{GHG}$ scenarios, resulting in an increased stratosphere-troposphere exchange and ozone flux. This increase is smaller in the southern than in the northern midlatitudes [Shepherd, 2008]. Overall, the positive ozone sensitivity to GHGs in the upper and lower stratosphere leads to an increase in stratospheric column ozone that is positively correlated with the GHG scenarios (Figure 6c).
[34] 3. Over the Arctic in March, the results are very similar to the northern midlatitudes, with a more pronounced sensitivity resulting in differences by 2100 that are larger than in the northern midlatitudes ( 40 DU among the RCPs). Despite this difference, the ozone return dates are mostly similar among the RCPs, since stratospheric ozone returns to pre-1980 values before the time when the scenarios deviate. Substantial super-recovery is simulated in the higher RCP scenarios. The IGAC/SPARC ozone database is overall very similar to RCP 6.0 .

[35] 4. Over Antarctica in September, the sensitivity of ozone to the GHG scenario is generally not very high, resulting in very similar evolution of stratospheric column ozone over the 21 st century in the four RCPs, with ozone starting to increase over the coming decades and returning back to pre-1960 values only by the end of the 21 st century, as has been found in previous studies [Austin et al., 2010; SPARC-CCMVal, 2010; WMO, 2011]. Similar to the midlatitudes and the Arctic, total column ozone values are highest in the RCP 8.5 at the end of the century. Differences among the RCPs until 2050 are very small, confirming that differences in GHGs are more important in the second half of the 21 st century when the impact of ODSs due to the projected decrease slowly disappears.

\subsubsection{Tropospheric Column Ozone Projections}

[36] Unlike the stratospheric halogen scenarios, the precursor emissions are not the same in the different RCPs (see, e.g., Figure 1 of Cionni et al. [2011]). While it is clear that by 2100 all RCPs have substantially smaller $\mathrm{NO}_{\mathrm{x}}, \mathrm{CO}$, and VOC emission totals compared to 2000, the largest emissions are in RCP 8.5. Furthermore, another major difference with RCP 8.5 is the change in the ozone precursor $\mathrm{CH}_{4}$, which nearly doubles between 2000 and 2100, while remaining at similar or decreased levels in the other three RCPs. Some of these factors are evident from comparing the panels in Figure 8, which presents decadal averages for the tropospheric ozone column in the CHEM mean for the 1940s and 2000s (historical), and 2040s and 2090s (RCPs). An extended list of decadal multimodel global mean values is given in Table 4, including standard deviations. This figure is similar to Figure 9 of Cionni et al. [2011] but uses the larger CHEM mean in contrast to a single model projection (CAM3.5), although the general evolution and key findings of that study remain. As noted previously [Cionni et al., 2011; Kawase et al., 2011; Lamarque et al., 2011; Young et al., 2013b], the large differences in tropospheric column ozone between RCP 8.5 and the other RCPs are likely due in part to the increased mixing ratios of the ozone precursor methane in RCP 8.5, which act to strongly increase tropospheric ozone globally, although the largest increases are around $30^{\circ} \mathrm{N}$ over Europe, Africa, and Far East Asia, which could relate to the redistribution of precursor emissions. In addition, the important role of an increase in the input of stratospheric ozone, driven both by the stratospheric ozone recovery [SPARC-CCMVal, 2010; $W M O, 2011]$ and the strengthening in the residual circulation with increased GHGs [Butchart et al., 2010; Butchart et al., 2011], has been noted [Kawase et al., 2011; Young et al., 2013b]. This process could be driving the approximately zonal increases in the tropospheric ozone column at midlatitudes, where much stratospheric ozone enters the troposphere [Olsen et al., 2004]. For RCP 2.6, tropospheric 

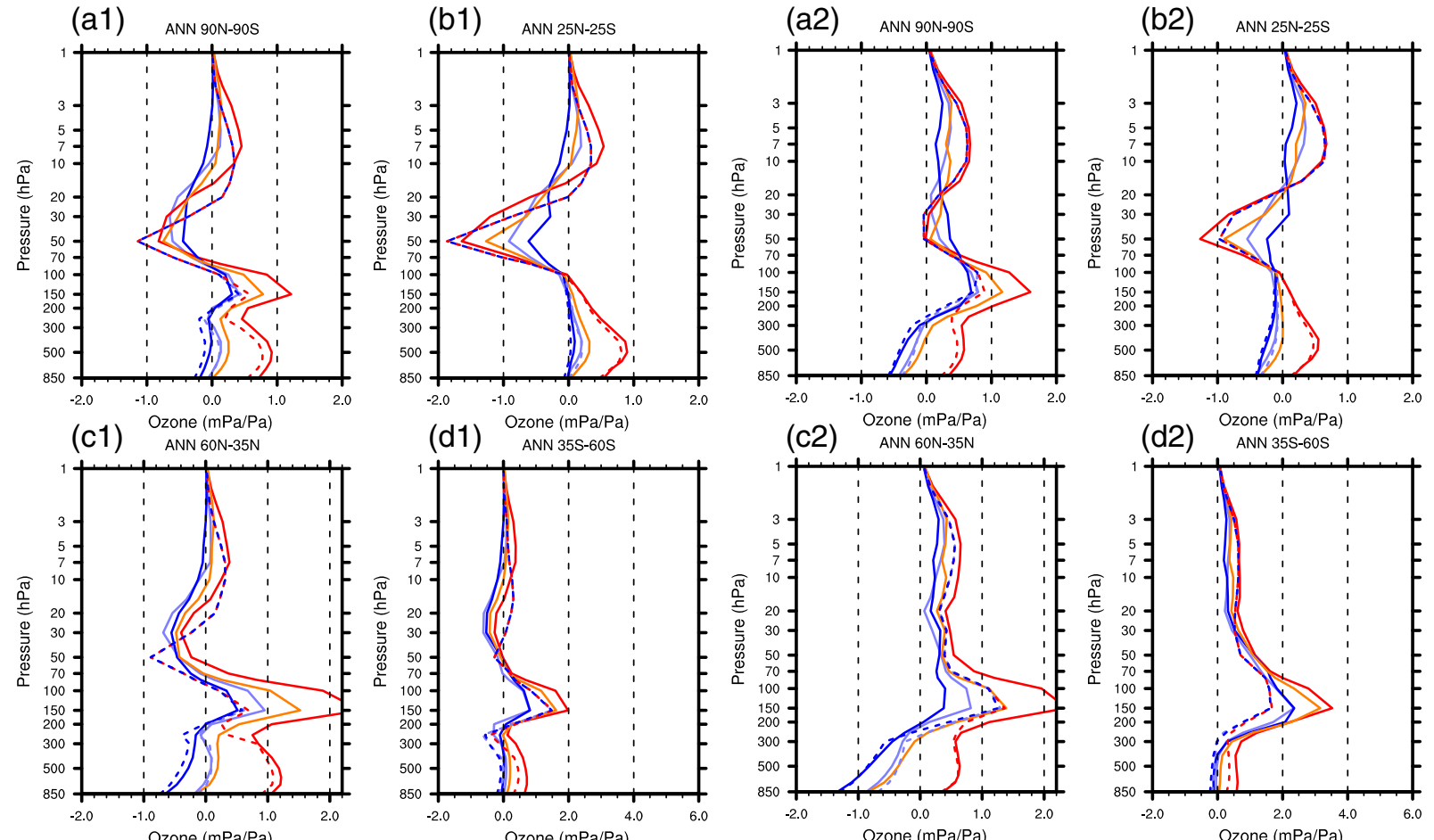

(d1) Ozone $(\mathrm{mPa} / \mathrm{Pa}$

(c2) Ozone (mPa/Pa)
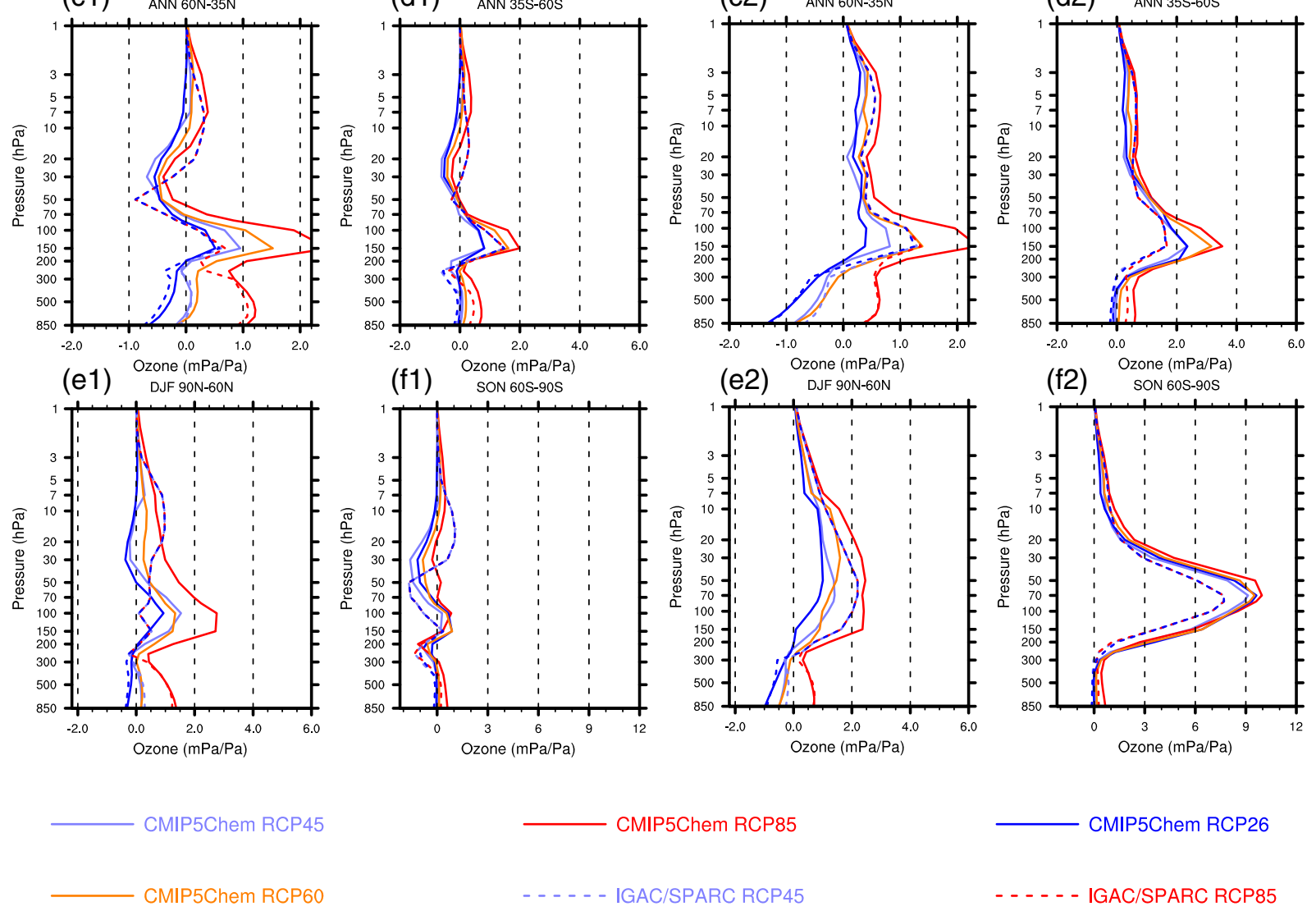

- CMIP5Chem RCP26

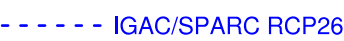

-..- - IGAC/SPARC RCP60

Figure 7. Differences in vertically resolved ozone between the 2090s and 2000s (Figures 7a1 to 7f1) and 2090s and 1960s (Figures 7a2 to 7f2) for the RCP simulations for (a1 and a2) global $\left(90^{\circ} \mathrm{S}-90^{\circ} \mathrm{N}\right)$ annual mean, (b1 and b2) tropical $\left(25^{\circ} \mathrm{S}-25^{\circ} \mathrm{N}\right)$ annual mean, (c1 and c2) NH midlatitudes $\left(35^{\circ} \mathrm{N}^{\circ}-60^{\circ} \mathrm{N}\right)$ annual mean, (d1 and d2) SH midlatitudes $\left(35^{\circ} \mathrm{S}-60^{\circ} \mathrm{S}\right)$ annual mean, (e1 and e2) Arctic $\left(60^{\circ} \mathrm{N}-90^{\circ} \mathrm{N}\right) \mathrm{March}$ mean, and (f1 and f2) Antarctic $\left(60^{\circ} \mathrm{S}-90^{\circ} \mathrm{S}\right)$ October mean.

column ozone in the 2090s looks very similar to the 1940 s, reflecting the strong decreases in precursor emissions (including methane) compared to 2000. Smaller decreases in precursor emissions, approximately level methane, and, potentially, increased stratosphere-to-troposphere transport of ozone cause RCP 4.5 and 6.0 tropospheric column ozone to remain comparable to the 2000 s by 2100 .We have briefly discussed tropospheric column ozone projections here, since differences in tropospheric column ozone (ranging from 27.8 DU in the RCP 2.6 and 43.8 DU in the RCP 8.5 by 2100 , see Figure 8 ) contribute substantially to differences in total column ozone projections among the RCPs. We therefore argue that total column ozone should not be used to project stratospheric ozone in the RCPs.

\section{Climate Impacts Associated With Stratospheric Ozone Changes}

[37] Previous studies have built a strong case for the impact of stratospheric ozone changes on climate. Here, we highlight the role of ozone on climate in the consistent 


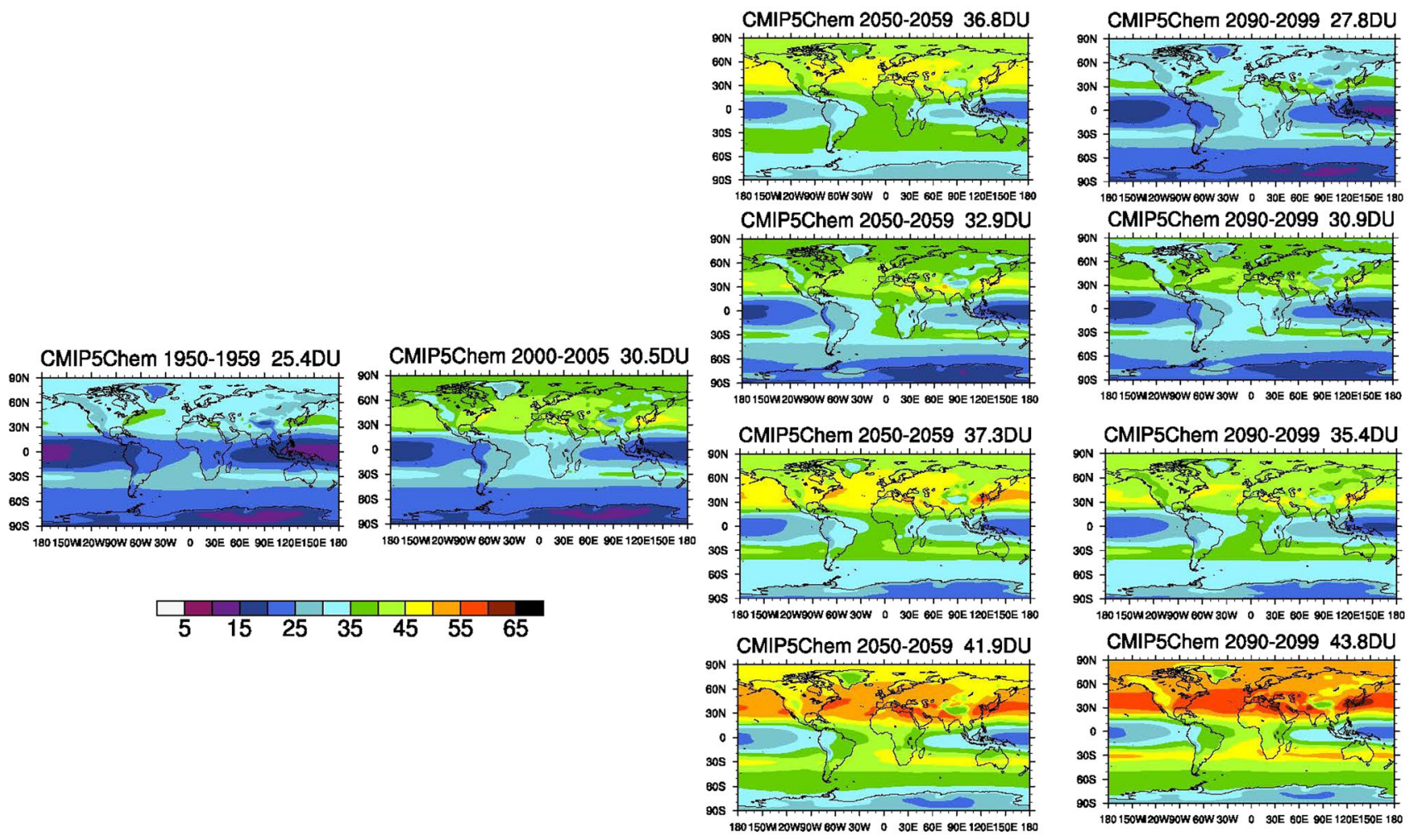

Figure 8. Decadal mean tropospheric column ozone for the 1950s and 2000s (left) and the RCPs (right); from top to bottom: RCP 2.6, RCP 4.5, RCP 6.0, and RCP8.5 shown for the 2050s and 2090s. The data are derived from the CHEM multimodel mean. For the different RCPs, the same models as in Figure 6 are included in the CMIP5 CHEM multimodel mean. A similar figure showing the IGAC/SPARC database can be found in Cionni et al. [2011].

framework of CMIP5, which includes for the first time multiple climate models that are both coupled to an ocean and have interactive chemistry and contrast these with the results of the CCMVal-2 simulations [Son et al., 2010]. We highlight that variations in ozone forcing can play a large role in some aspects of the resulting climate projections and caution that ozone differences need to be accounted for in any interpretation of associated climate shifts.

\subsection{Impact of Ozone on Lower Stratospheric Temperature Trends}

[38] Stratospheric ozone depletion is a key forcing in explaining the observed evolution of lower stratospheric global mean temperature during the satellite period, being the main contributor to the long-term cooling trend [Gillett et al., 2011; Ramaswamy et al., 2006]. Furthermore, observations indicate that the temporal variability in global mean ozone immediately following volcanic eruptions contributed to the step-like temperature decline of global mean stratospheric temperatures in the aftermath of the eruptions of El Chichon in 1982 and Mt Pinatubo in 1991 [Eyring et al., 2006; Thompson and Solomon, 2009]. Stratospheric ozone changes could also play a key role in tropical lower stratospheric temperature trends [Polvani and Solomon, 2012; Santer et al., 2012; Solomon et al., 2012; Thompson et al., 2012].

[39] To assess the impact of ozone in the CMIP5 models on the climate of the recent past, we first evaluate time series of temperatures in the lower stratosphere (TLS) for near-global annual averages (Figure 9a) and October through January averages over SH polar latitudes (Figure 9b). We compare observational estimates based on Microwave Sounding Units (MSU) of the Remote Sensing Systems (RSS) version 3.3 [Mears et al., 2011] with synthetic MSU temperatures derived from climate model output with the TLS vertical weighting function applied to

Table 4. Tropospheric Column Ozone (DU) ${ }^{\mathrm{a}}$

\begin{tabular}{ccccc}
\hline Year & RCP 2.6 & RCP 4.5 & RCP 6.0 & RCP 8.5 \\
\hline 1850 & $21.3 \pm 3.6$ & $21.3 \pm 3.6$ & $21.3 \pm 3.6$ & $21.3 \pm 3.6$ \\
1980 & $29.5 \pm 3.7$ & $29.5 \pm 3.7$ & $29.5 \pm 3.7$ & $29.5 \pm 3.7$ \\
2000 & $31.1 \pm 3.3$ & $31.1 \pm 3.3$ & $31.1 \pm 3.3$ & $31.1 \pm 3.3$ \\
2005 & $31.5 \pm 3.5$ & $31.5 \pm 3.5$ & $31.5 \pm 3.5$ & $31.5 \pm 3.5$ \\
2010 & $32.2 \pm 2.9$ & $31.7 \pm 2.5$ & $31.9 \pm 2.7$ & $31.9 \pm 2.7$ \\
2020 & $32.1 \pm 2.6$ & $32.0 \pm 2.8$ & $32.1 \pm 2.8$ & $33.2 \pm 3.1$ \\
2030 & $31.7 \pm 2.9$ & $32.6 \pm 2.8$ & $32.5 \pm 3.2$ & $34.6 \pm 3.6$ \\
2040 & $31.6 \pm 3.0$ & $32.7 \pm 2.9$ & $33.2 \pm 3.7$ & $35.6 \pm 3.7$ \\
2050 & $31.1 \pm 2.9$ & $32.8 \pm 3.2$ & $33.5 \pm 3.8$ & $36.8 \pm 3.9$ \\
2060 & $30.4 \pm 3.1$ & $32.4 \pm 3.3$ & $33.7 \pm 3.9$ & $38.2 \pm 4.5$ \\
2070 & $29.5 \pm 2.9$ & $31.6 \pm 3.1$ & $33.4 \pm 4.2$ & $39.2 \pm 4.4$ \\
2080 & $28.6 \pm 2.9$ & $31.0 \pm 3.3$ & $33.1 \pm 4.2$ & $40.0 \pm 4.8$ \\
2090 & $28.3 \pm 3.0$ & $30.7 \pm 3.4$ & $32.6 \pm 4.0$ & $40.6 \pm 4.7$ \\
2100 & $28.0 \pm 2.8$ & $30.6 \pm 3.2$ & $32.2 \pm 4.2$ & $41.3 \pm 4.9$ \\
\hline
\end{tabular}

${ }^{\mathrm{a}}$ For the various RCPs as calculated from the multimodel mean of the CMIP5 models with interactive or semi-offline tropospheric chemistry (see caption of Figure 6). The multimodel mean is given along with uncertainties $( \pm 1 \mathrm{SD})$. 
a) ANN near-global

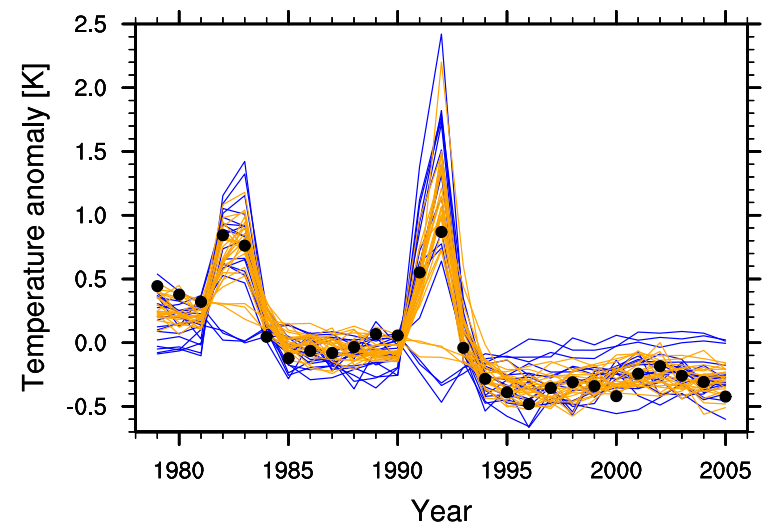

b) ONDJ (60S-82.5S)

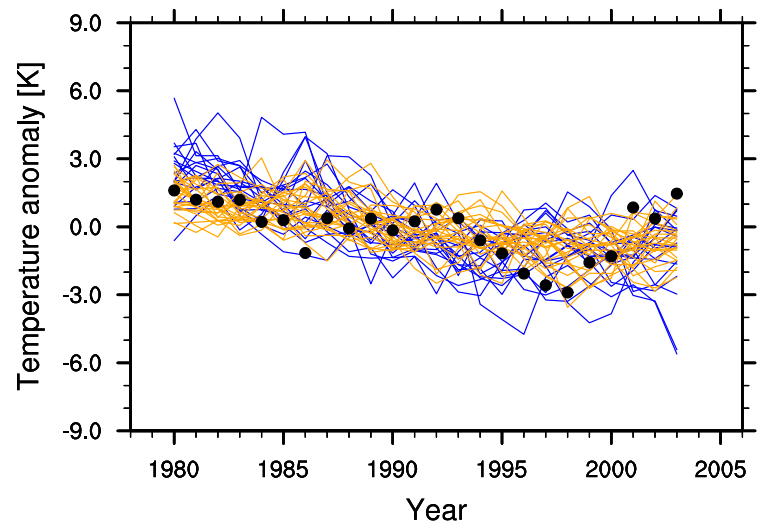

Figure 9. Time series from 1979-2005 of (a) near-global $\left(82.5^{\circ} \mathrm{S}\right.$ to $\left.82.5^{\circ} \mathrm{N}\right)$ annual mean and (b) Southern Hemisphere polar $\left(82.5^{\circ} \mathrm{S}\right.$ to $\left.60^{\circ} \mathrm{S}\right)$ October-January mean lower stratospheric temperatures (TLS) for the CMIP5 multimodel mean compared to RSS observations (black dots). The individual models of the CHEM group are shown in blue colored lines, while those from the NOCHEM group are shown in orange. The time series in Figure $9 \mathrm{~b}$ are smoothed using a 3 year running average. The multimodel mean time series are not shown due to the lack of stratospheric aerosol forcing in some of the model simulations.

the near-global $\left(82.5^{\circ} \mathrm{S}-82.5^{\circ} \mathrm{N}\right)$ domain of the MSU data.

[40] The CMIP5 models, when also including stratospheric aerosol forcing, represent well the observed step-like reduction of global mean TLS (Figure 9a). The CMIP5 multimodel mean trend over the period $(-0.28 \pm 0.08 \mathrm{~K} /$ decade $)$ underestimates the long-term cooling trend from the RSS satellite observations $(-0.35 \pm 0.07 \mathrm{~K} /$ decade $)$, consistent with Santer et al. [2012]. On average, the linear trend is slightly smaller in the CHEM group $(-0.26 \pm 0.11 \mathrm{~K} /$ decade $)$ than in the NOCHEM group $(-0.30 \pm 0.05 \mathrm{~K} /$ decade $)$. We note, however, that several models exhibit trend values similar to or larger than the observed RSS TLS estimate. The wide range of simulated global TLS historical trends is consistent with a large spread of simulated ozone trends (Table 2). This is depicted in Figures $10 \mathrm{a}$ and $10 \mathrm{~b}$, which examines the multimodel mean near-global $\left(82.5^{\circ} \mathrm{S}-82.5^{\circ} \mathrm{N}\right)$ lower stratospheric ozone $(50 \mathrm{hPa})$ and temperature $(100 \mathrm{hPa})$ trends calculated over 1979-2005 for the past and 2006-2050 for the future (consistent with Son et al. [2010]) for the CCMVal-2 and CMIP5 simulations. The ozone trends amongst the different model groups (CMIP5 all, CHEM, NOCHEM, CCMVal) are comparable for the historical period. Error bars depict the \pm 1 standard deviation across the model simulations and highlight the range of responses that result from interactively calculating ozone (CHEM and CCMVal-2) as opposed to prescribing it with a consistent database (NOCHEM). There is a clear relationship between the magnitude of the ozone depletion across the CHEM models and the near-global TLS trends (Figure 11a, represented here by the $100 \mathrm{hPa}$ level; $\mathrm{r}=0.60$ ). However, this relationship breaks down in the future simulations where $\mathrm{CO}_{2}$ forcing becomes the dominant contributor to near-global lower stratospheric cooling, while the impact of ozone changes - the dominant contributor to past stratospheric cooling-reduces.

[41] Antarctic polar stratospheric temperatures in spring (Figure 9b) are highly variable because they are affected not only by ozone changes but also by tropospheric wave forcing [Fogt et al., 2009]. RSS observations show a large decline of polar cap temperatures until 1999 followed by a 4 year period of higher temperatures in the smoothed time series. This rebound of temperature is likely episodic climate variability due to enhanced wave forcing from the troposphere [Langematz and Kunze, 2006], rather than a signal of ozone recovery, and is followed by considerably lower temperatures again after 2005 (not shown). The CMIP5 models simulate on average a slightly larger temperature decline $(-1.29 \pm 0.84 \mathrm{~K} /$ decade $)$ than that observed $(-0.79 \pm 0.55 \mathrm{~K} /$ decade $)$, but the observed trend is clearly within the spread of simulated trends. In the next section, we focus on the relationships between ozone, lower stratosphere temperatures, and the SH extratropical circulation in the model simulations.

\subsection{Ozone and the Southern Hemisphere Extratropical Circulation}

[42] Stratospheric ozone depletion in the Antarctic polar stratosphere also strongly impacts the SH extratropical circulation [Gillett and Thompson, 2003; Polvani et al., 2011b; Thompson and Solomon, 2002]. Radiative cooling associated with ozone depletion leads to an increase in the meridional temperature gradient in the UTLS and a corresponding strengthening of the stratospheric polar vortex [Thompson et al., 2011]. These stratospheric changes propagate down to the troposphere, reaching maximum amplitude in austral summer [Thompson and Solomon, 2002]. While many previous modeling studies have found an association between ozone depletion and corresponding changes in the SH extratropical tropospheric circulation [Arblaster et al., 2011; Gillett and Thompson, 2003; McLandress et al., 2011; Polvani et al., 2011b], the mechanisms by which changes in the polar stratosphere impact the troposphere remain unclear. Various hypotheses have been suggested including changes to the low-level baroclinicity and planetary wave activity due to the strengthened polar vortex [Orr et al., 2012; Simpson et al., 2012a] or via changes to synoptic wave activity which feeds back onto and results in meridional shifts in the mean flow [Chen and Held, 2007; Kushner and Polvani, 2004; Simpson et al., 2009]; see also 
EYRING ET AL.: OZONE AND ASSOCIATED CLIMATE IMPACTS

(a) $50 \mathrm{hPa}$ ANN near-global $\mathrm{O} 3$ trend

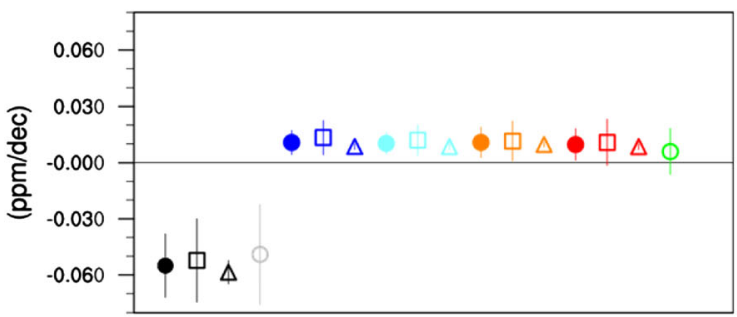

(c) $50 \mathrm{hPa}$ SOND O3 (60-90S) trend

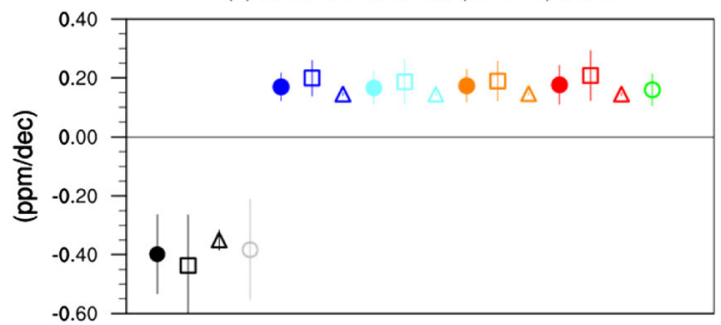

(e) $850 \mathrm{hPa}$ DJF jet position trend

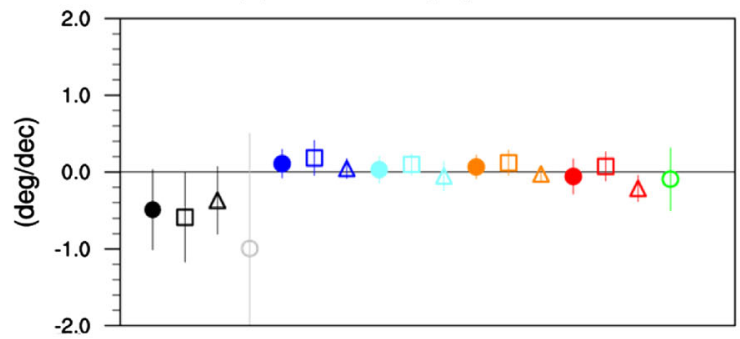

(b) $100 \mathrm{hPa}$ ANN near-global Temp trend

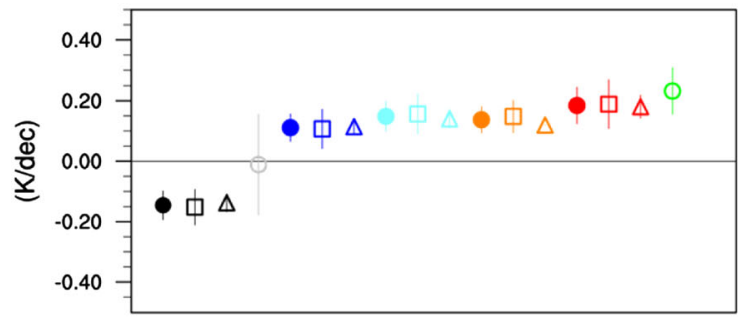

(d) $100 \mathrm{hPa}$ ONDJ Temp (60-90S) trend

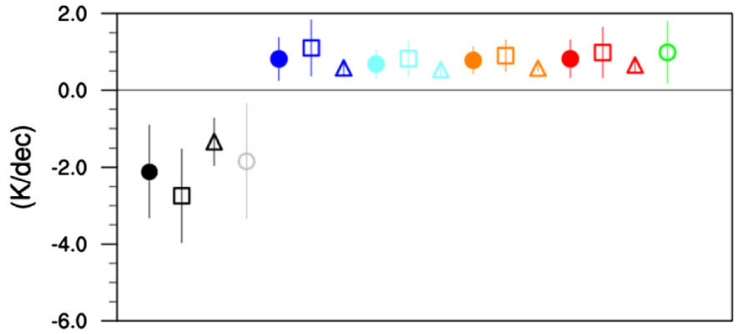

(f) $250 \mathrm{hPa}$ DJF Temp (30S-30N) trend

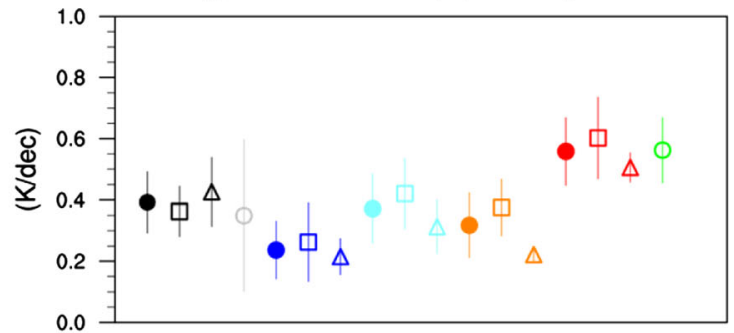

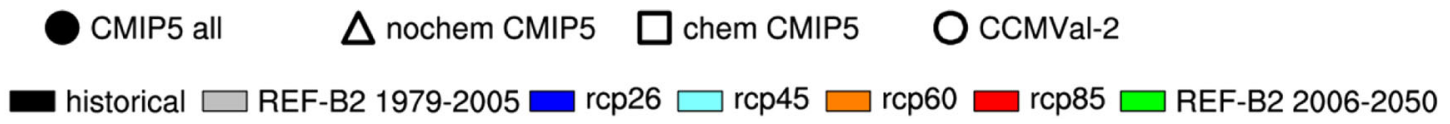

Figure 10. Trends in (a) annual-mean near-global (NG, $-82.5^{\circ} \mathrm{S}$ to $\left.82.5^{\circ} \mathrm{N}\right)$ ozone at $50 \mathrm{hPa}$, (b) annual mean near-global $\left(82.5^{\circ} \mathrm{S}\right.$ to $\left.82.5^{\circ} \mathrm{N}\right)$ temperature at $100 \mathrm{hPa}$, (c) September-October-November-December (SOND) ozone at $50 \mathrm{hPa}$ over Antarctica $\left(60^{\circ} \mathrm{S}-90^{\circ} \mathrm{S}\right)$, (d) October-November-December-January (ONDJ) temperature at $100 \mathrm{hPa}$ over Antarctica $\left(60^{\circ} \mathrm{S}-90^{\circ} \mathrm{S}\right)$, (e) DJF SH jet position at $850 \mathrm{hPa}$, and (f) DJF upper tropospheric tropical $\left(30^{\circ} \mathrm{S}-30^{\circ} \mathrm{N}\right)$ temperatures at $250 \mathrm{hPa}$.. Trends for the CMIP5 models are indicated by filled circles, CMIP5 NOCHEM models by triangles, CMIP5 CHEM models by squares, and CCMVal2 by open circles, with different colors indicating the different experiments. The trends are calculated over 1979-2005 for the past and over 2006-2050 for the future.

Thompson et al. [2011] and Gerber et al. [2012] for comprehensive reviews and references therein.

[43] During the late 20th century, ozone depletion acted in concert with increasing GHGs to impact the SH extratropical circulation and wider climate system [Son et al. 2010; Polvani et al., 2011a, 2011b; Kang et al. 2011]. However, ozone recovery will lead to increased temperatures in the Antarctic stratosphere in the future, thus having the opposite effect to ozone depletion. Previous studies have highlighted the importance of ozone recovery on either reversing or offsetting the impact of GHGs on the SH summertime atmospheric circulation projections [Arblaster et al., 2011; Perlwitz et al., 2008; Son et al., 2008; Son et al., 2010], with two recent studies [McLandress et al., 2012; Polvani et al., 2011b] suggesting that the two forcings largely cancel out any impacts on the summertime atmospheric circulation over the coming half century under the SRES A1B GHG scenario. The exact balance between the impact of ozone recovery and increasing GHGs is both model and scenario dependent, with both the modeled rate of ozone recovery [Perlwitz, 2011] and their climate sensitivity [Arblaster et al., 2011] contributing to the magnitude of the atmospheric circulation response.

[44] To provide some evaluation of the CMIP5 models, we first examine trends in December-January-February (DJF) zonal mean zonal winds over 1979-2005 for the CMIP5 multimodel mean compared to the ERA-Interim reanalysis data [Dee et al., 2011] in Figure 12. The CMIP5 multimodel mean (Figure 12b) displays a robust poleward shift in the SH zonal mean zonal wind trends, consistent in magnitude with the reanalysis (Figure 12a). Figure 12 also depicts the climatological zonal mean zonal winds in thin black contours. An equatorward bias in the latitudinal 
(a)

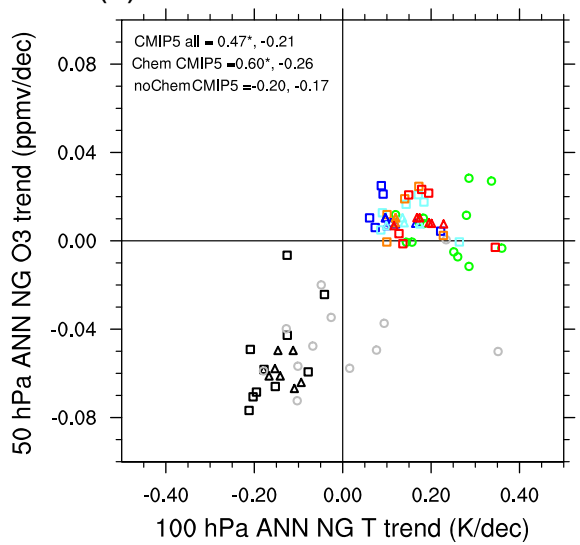

(c)

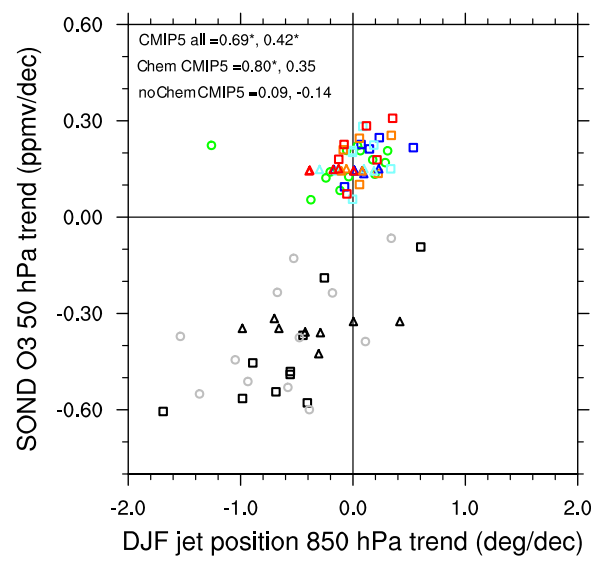

(b)

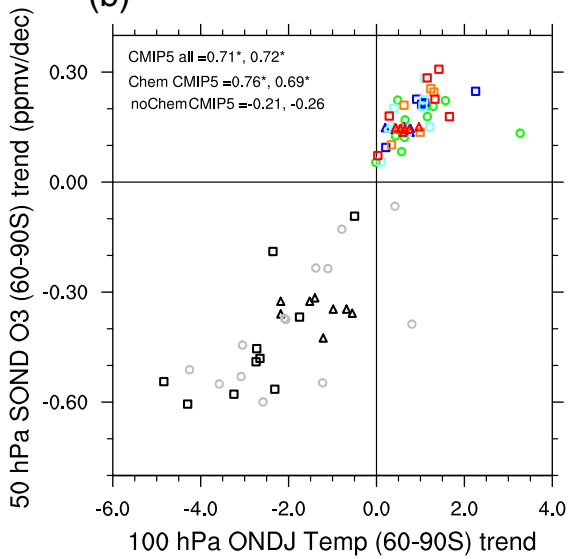

(d)

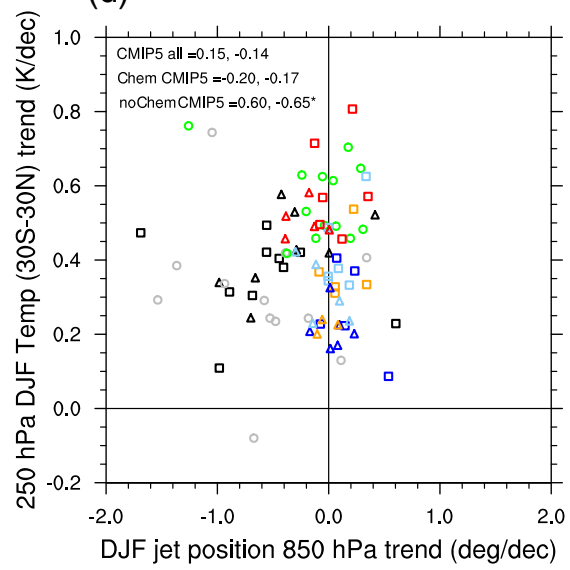

$\Delta$ nochem CMIP5 $\square$ chem CMIP5 O CCMVal-2

$\square$ historical $\square$ REF-B2 1979-2005 rcp26 $\square$ rcp45 $\square$ rcp60 $\square$ rcp85 $\square$ REF-B2 2006-2050

Figure 11. Trend relationship between (a) annual mean near-global mean ozone at $50 \mathrm{hPa}$ and temperature at $100 \mathrm{hPa}$; (b) SOND ozone at $50 \mathrm{hPa}$ and ONDJ temperature at $100 \mathrm{hPa}$ over Antarctica $\left(60^{\circ} \mathrm{S}-90^{\circ} \mathrm{S}\right)$, (c) SOND ozone at $50 \mathrm{hPa}$ and DJF jet position at $850 \mathrm{hPa}$, and (d) DJF $250 \mathrm{hPa}$ tropical $\left(30^{\circ} \mathrm{S}-30^{\circ} \mathrm{N}\right)$ temperatures and DJF jet position at $850 \mathrm{hPa}$. The correlation between the two variables is calculated for all CMIP5 models and for the NOCHEM and CHEM models for the past (first number) and all RCPs (second number). The correlation coefficients which are statistically significant at the $5 \%$ level (95\% confidence) are indicated with an asterisk. The trends are calculated over 1979-2005 for the past and 2006-2050 for the future.

position of the SH extratropical jet was found in the majority of CMIP3 models [Kidston and Gerber, 2010], Swart and Fyfe [2012], Wilcox et al. [2012], and Ceppi et al. [2012] find a similar bias is evident in the CMIP5 models although somewhat reduced compared to CMIP3 models. This bias has implications for the response of the extratropical circulation to ozone and other externally forced changes such as GHGs [Bracegirdle et al., 2013; Kidston and Gerber, 2010; Wilcox et al., 2012], although the exact mechanism by which this impacts the circulation is a focus of current research [Simpson et al., 2012b].

[45] Future trends in zonal mean zonal winds calculated over the 2006-2050 period for the four RCP scenarios are shown in Figures $12 \mathrm{c}-12 \mathrm{f}$ for the CMIP5 multimodel mean. Although the radiative forcing differences over this near-term period are not large, it is clear that as the anthropogenic GHG forcing increases from RCP 2.6 to 8,5, so does the impact on the DJF SH extratropical jet, with robust poleward shifts under RCP 8.5. Under the highmitigation scenario (RCP 2.6), which exhibits very little warming in the troposphere, ozone recovery appears to dominate the response with a weak equatorward shift of the $\mathrm{SH}$ jet, although the multimodel change is not significant. In RCP 4.5 and 6.0, the balance between increasing GHGs and ozone recovery largely offsets any changes to the SH circulation. Projected changes in the lower tropospheric winds (see Appendix Figure A3) are quite zonally symmetric in the $\mathrm{SH}$ extratropics and show weak equatorward shifts in the SH midlatitude jet under RCP 2.6 and a robust poleward shift under RCP 8.5. 

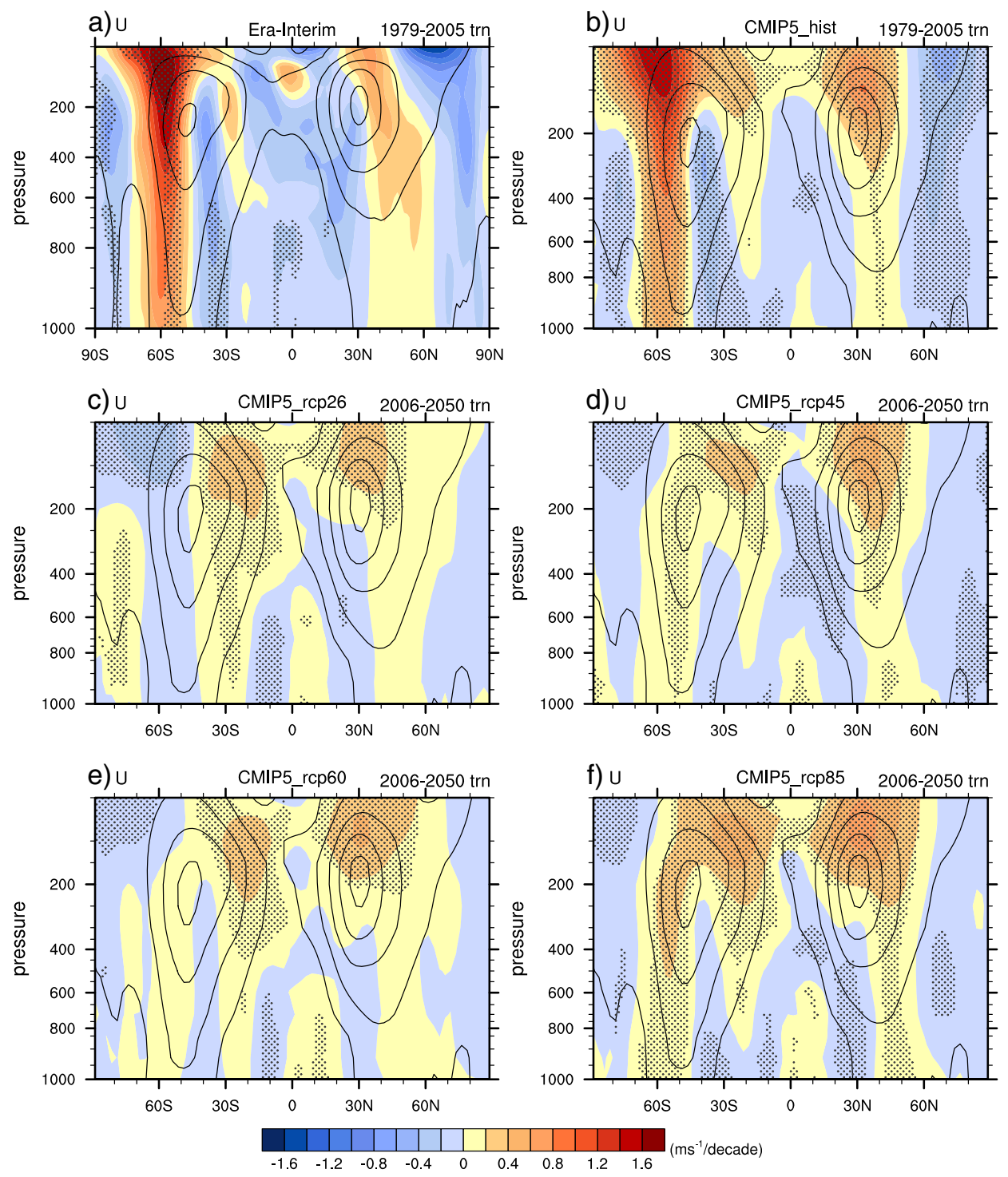

Figure 12. Long-term mean (thin black contour) and linear trend (color) of zonal mean DJF zonal winds for (a) ERA-Interim over 1979-2005; (b) CMIP5 (all models listed in Table 1 except those noted with ${ }^{\text {b}}$ ); and (c, d, e, and f) same as Figure 12b but for the four RCPs over 2006-2050. Contour intervals of climatological wind are $10 \mathrm{~ms}^{-1}$ starting from $-20 \mathrm{~ms}^{-1}$. Trends which are statistically significant at the $5 \%$ level (95\% confidence) are stippled.

[46] Figures 10 and 11 investigate the impact of stratospheric ozone on the SH climate trends of the CHEM, NOCHEM, CMIP5-all (both CHEM and NOCHEM), and CCMVal-2 models. CHEM models that were excluded earlier due to ozone biases are also excluded here, and only NOCHEM models for which ozone forcing was explicitly available at the CMIP5 data archive are analyzed. Individual model trends are shown in Figure 11, with correlation coefficients within each panel indicating the linearity of the relationships across the models for the historical and future periods.

[47] The multimodel mean trends in springtime $\mathrm{SH}$ polar lower stratospheric ozone and temperatures (Figures 10c and 10d) indicate that, while the CMIP5 historical and future changes are very similar in magnitude to the CCMVal-2 models in the multimodel mean, there is a large spread amongst the CHEM models, with somewhat weaker (and again, more consistent) trends for the NOCHEM models. Little variation in Antarctic ozone recovery or lower stratospheric temperatures is found amongst the different RCPs (see section 3.2). Significant correlations are found between the polar stratospheric ozone and temperature changes when examining the individual model trends (Figure $11 \mathrm{~b} ; \mathrm{r}=0.76$ and 0.69 across the CHEM-historical and CHEM-future, respectively). The CHEM models have both weaker and stronger temperature and ozone responses compared to the NOCHEM models in both the historical and future periods. Note that this small variation in ozone accounts for the weak NOCHEM intermodel correlations $(r=-0.21$ and -0.26 for the past and future, respectively) here. The CCMVal-2 models are interspersed amongst the CMIP5 models. 
[48] As noted above, these ozone-driven temperature changes lead to shifts in the position of the $\mathrm{SH}$ tropospheric jet (at $850 \mathrm{hPa}$ ), which are shown in Figure $10 \mathrm{e}$ for the multimodel mean and Figure 11c for individual models. The position of the westerly jet is calculated as the latitude of maximum zonal mean zonal wind at $850 \mathrm{hPa}$ as in Son et al. [2010]. The jet shifts poleward in most models for the historical period due to the combined effects of GHGs and ozone depletion. The correlation between the size of the ozone forcing and the size of the jet shift is significant at $\mathrm{r}=0.80$ for the CHEM-historical, indicating a strong sensitivity of the $\mathrm{SH}$ tropospheric circulation to ozone forcing. The NOCHEM-historical correlation is close to zero, highlighting the similarity of their ozone forcing.

[49] The CMIP5 multimodel trends of the jet position under the four RCPs (Figure 10e) for the future projections until 2050 change from a weak equatorward shift for RCP 2.6 to a weak poleward shift in RCP 8.5 (see also Figure 12) due to the increasing influence of the GHG forcing. The jet position trend is consistently more poleward in the NOCHEM than in the CHEM models, consistent with the weaker ozone changes in the NOCHEM models (Figure 10c). For the future projections, the picture is complicated by the opposing forces of ozone recovery and GHG warming on the jet position, with the relative impact of ozone recovery declining as the strength of the GHG forcing increases. Thus, the link between ozone forcing and jet position for future trends is reduced (compared to the past) with a correlation of $r=0.35$ for the CHEM models. The NOCHEM models again show little sensitivity to ozone $(\mathrm{r}=-0.14)$ in the future.

[50] The impact of GHG warming on the jet position can be further identified by examining the variations of jet position with changes in tropical upper tropospheric temperatures (Figures 10f and 11d). Since ozone trends are very similar across the NOCHEM models, the jet position trend variations are primarily associated with variations in the response to GHGs, both in terms of the range of RCP forcing and the climate sensitivity of the models. The significant correlation across the NOCHEM models for the future period $(r=-0.68)$ indicates that the model response to GHGs also plays an important role in modifying future shifts in the SH tropospheric extratropical circulation, consistent with previous studies [Arblaster et al., 2011; Wilcox et al., 2012]. Weaker correlations across the CHEM models $(\mathrm{r}=-0.17$ for the future) are likely due to the offsetting influence of ozone recovery, indicating that the rate of ozone recovery can be of similar importance to the response to GHGs, especially for the lower emission scenarios. Note that for the historical period the NOCHEM models show a positive, although insignificant, correlation. Other factors besides GHGs, such as decadal variability in ENSO, nonzonal impacts on the jet, or other forcing differences, could be driving the variations across the models for this period where GHG forcing is weaker than in the future. A weaker historical role for GHGs is also consistent with previous studies that argue for the dominance of ozone depletion on historical shifts in the jet [Polvani et al., 2011a]

[51] Weak changes in the tropospheric jets under the RCP 4.5 and 6.0 (Figure 12) are similar to that found for the CCMVal-2 simulations under the SRES A1B scenario [Son et al. [2010], Figure 4]. The response in the stratosphere in the CMIP5 multimodel mean, however, is much weaker than in the CCMVal-2 mean. Although this is somewhat surprising, given the two simulations have similar ozone forcing and the SRES A1B GHG forcing lies between RCP 4.5 and 6.0, Figure 11 shows that the size and even sign of future trends in the position of the tropospheric jet to midcentury varies widely across models.

[52] In summary, it is clear that ozone recovery plays an important role in the SH summertime extratropical circulation projections, with a reversal of the recent poleward shift in the jet possible under the high-mitigation scenario of RCP 2.6. We find a strong sensitivity of the $\mathrm{SH}$ climate to ozone forcing, which is not captured by using models with a common prescribed ozone data set. This is an important complexity that needs to be considered in studies of $\mathrm{SH}$ climate change. We emphasize that the homogeneity of the ozone forcing data set across the CMIP5 model simulations assumed by Wilcox et al. [2012] for a limited number of models is not as clear-cut for the larger sample shown here.

\section{Summary}

[53] In this study, the representation of ozone and associated climate impacts in 46 model versions participating in the Coupled Model Intercomparison Project Phase 5 (CMIP5) [Taylor et al., 2012] project has been analyzed. We first evaluated the models' ability to reproduce ozone, zonal wind, and lower stratospheric temperature changes over the recent decades and then analyzed the future evolution of ozone from 2006 to 2100 under the four Representative Concentration Pathways (RCPs), again highlighting climate impacts associated with stratospheric ozone changes.

[54] In CMIP3, around half of the models prescribed a constant ozone climatology, while the other half prescribed a time-varying ozone time series accounting for ozone depletion in the past and projected ozone recovery in the future [Son et al., 2008; Son et al., 2010]. In contrast, all CMIP5 models considered time-varying ozone, either prescribed (28), interactively coupled (9), or calculated semi-offline (9), i.e., using a similar atmospheric model but prescribed SSTs and SICs and a detailed interactive chemistry scheme. The main differences between the prescribed (NOCHEM) and interactive and semi-offline (CHEM) ozone is that the CHEM ozone projections are driven with the RCP GHG emission scenarios, whereas the ozone concentrations in the prescribed class are from a single GHG scenario different from the RCPs. For those using prescribed ozone, 23 of the 28 applied the recommended IGAC/SPARC ozone database [Cionni et al., 2011], thus following the SRES A1B GHG scenario in the future which was used to drive the CCMVal-2 simulations. The remaining five used a different data set but still based on a single GHG scenario (see details in the Appendix).

[55] Overall, ozone in the set of CMIP5 models analyzed here is reasonably well represented, but some large deviations exist for individual models, in particular, models with interactive chemistry. One goal of this paper was to document these differences for follow-up studies that require this information. For example, the recently published detection and attribution study by Santer et al. [2012] clearly illustrates that it is very difficult to understand and interpret the causes of differences between modeled and observed atmospheric temperature trends without accurate information 
regarding the forcings used in simulations of historical climate change.

[56] Another goal was to test the sensitivity of ozone projections to GHG scenarios. The results found here confirm previous conclusions [Eyring et al., 2010a], showing that future stratospheric ozone evolution is most sensitive to GHG scenarios in the Arctic ( $\sim 40$ DU difference among the four RCPs by 2100) and the northern midlatitudes ( 20 DU difference among the four RCPs by 2100), with little sensitivity in the Antarctic ozone hole. For ozone in the troposphere, the projections broadly confirms previous studies in that, due to the projected reductions in $\mathrm{NO}_{\mathrm{x}}, \mathrm{VOC}$, and $\mathrm{CO}$ emissions, the future evolution of tropospheric column ozone is largely sensitive to the $\mathrm{CH}_{4}$ level, together with an increased importance of the influx of ozone from the stratosphere [Kawase et al., 2011; Lamarque et al., 2011; Young et al., 2013b]. Other climate impacts on tropospheric ozone, such as increased loss through higher specific humidity, changes in lightning $\mathrm{NO}_{\mathrm{x}}$ emissions, and changes to reaction rates, could also be important but need to be isolated through sensitivity simulations and more detailed ozone budget diagnostic output.

[57] Finally, we examined important climate impacts that are associated with stratospheric ozone changes. Our study confirms the findings of Santer et al. [2012] that the CMIP5 multimodel mean underestimates the annual nearglobal lower stratospheric temperature (TLS) trends with the NOCHEM models on average exhibiting a slightly larger trend than the CHEM models. Observed Antarctic polar temperature trends in spring are within the spread of CMIP5 models. The analysis of temperature trends both globally and over the Antarctic illustrate the controlling factor of ozone changes on simulated past TLS temperature trends. In the NOCHEM models, in which ozone changes are prescribed with a very similar magnitude among the models, temperature trends show a smaller spread than CHEM model in which stratospheric ozone changes are simulated and affected by the interactions of stratospheric ozone chemistry and climate.

[58] Significant impacts of stratospheric ozone depletion and recovery on the $\mathrm{SH}$ extratropical circulation in the CMIP5 models are also found, confirming previous studies with earlier generations of models [Son et al., 2008; Son et al., 2010]. The influence of ozone is clearly seen in the CMIP5 multimodel mean, with a weak equatorward shift of the SH DJF midlatitude tropospheric jet under the highmitigation scenario (RCP 2.6) when warming due to GHG is limited. However, a large range of circulation responses are found for the future, indicating a strong interplay between forcing from GHGs and ozone recovery. There is a significant relationship between the strength of future ozone and jet changes, highlighting the importance of future ozone changes on $\mathrm{SH}$ climate and the requirement to incorporate realistic ozone changes.

[59] Overall, through the use of either a time-varying prescribed ozone data set or interactive chemistry, the CMIP5 models represent a notable improvement on many of their CMIP3 counterparts, especially as several studies have demonstrated the important climatic impacts of changes in the abundance of this species. However, with this added complexity likely comes increased model diversity and perhaps increased uncertainty in future projections
[Stainforth et al., 2007]. This underscores the need for well-thought out process-oriented diagnostics such as those developed by the Chemistry-Climate Model Validation (CCMVal) activity [Eyring et al., 2005; SPARC-CCMVal, 2010], as well as well-designed sensitivity experiments, both to characterize the model diversity and, together with observations, identify key areas for improvement. It is therefore recommended to collect output for process-oriented ozone evaluation from climate models with interactive chemistry in future CMIP phases.

\section{Appendix A}

[60] In this Appendix, we provide descriptions of the chemistry schemes used in the CMIP5 models with interactive and semi-offline chemistry (section A1) and for the models that prescribed ozone (section A2). In addition, we show a figure similar to Figure 1 (total column ozone climatologies, 1986 to 2005 mean) of the primary article for the individual CMIP5 models that are part of the CHEM group plus the models that use a prescribed ozone data set different from the IGAC/SPARC ozone database (Figure A1). These include the following:

[61] 1. The nine CMIP5 models with interactive chemistry: CESM1(FASTCHEM), CESM1(WACCM), CNRM-CM5, GFDL-CM3, GISS-E2-H-p2, GISS-E2-H-p3, GISS-E2-R-p2, GISS-E2-R-p3, and MIROC-ESM-CHEM (see description in section A1.1)

[62] 2. The two CMIP5 models with semi-offline chemistry: CCSM4 and IPSL-CM5A-LR (see description in section A1.2).

[63] 3. The MIROC4h model which uses a prescribed ozone database different from the IGAC/SPARC ozone database (see description in section A2.1). The other model that used a different field was GISS-E2-H p1 for which the files were not available on the Earth System Grid (ESG).

[64] Figure A2 shows maps of tropospheric columns for selected decades in the past and future, and Figure A3 shows trends in DJF zonal winds at $850 \mathrm{hPa}$ calculated for 2006-2050 for the four RCPs.

\section{A1. CMIP5 Models With Interactive or Semi-Offline Chemistry (CHEM)}

A1.1. Interactive Chemistry in the CMIP5 Simulation

[65] In nine of the 46 model versions, ozone chemistry is calculated interactively in both the stratosphere and troposphere (CESM1(FASTCHEM), CESM1(WACCM), CNRM-CM5, GFDL-CM3, GISS-E2-H-p2, GISS-E2-H-p3, GISS-E2-R-p2, GISS-E2-R-p3, and MIROC-ESM-CHEM). The main characteristics of the chemistry schemes are briefly discussed for the different models below.

\section{A1.1.1. CESM1(FASTCHEM)}

[66] The Community Earth System Model (CESM) atmospheric chemistry-climate model is based on the Community Climate System Model version 4 (CCSM4) [Gent et al., 2011], configured with a fully interactive ocean, sea ice, land, and terrestrial carbon cycle. The CMIP5 simulations with interactive chemistry were performed at $1.875^{\circ} \times 2.5^{\circ}$ horizontal resolution, with 26 vertical layers extending to $3.5 \mathrm{hPa}$. The implementation of the processes that involve interaction between chemical tracers and the physical atmosphere (such as wet deposition and convection) is described by Lamarque et al. [2012]. The chemistry mechanism uses a 


\section{Total Column Ozone}
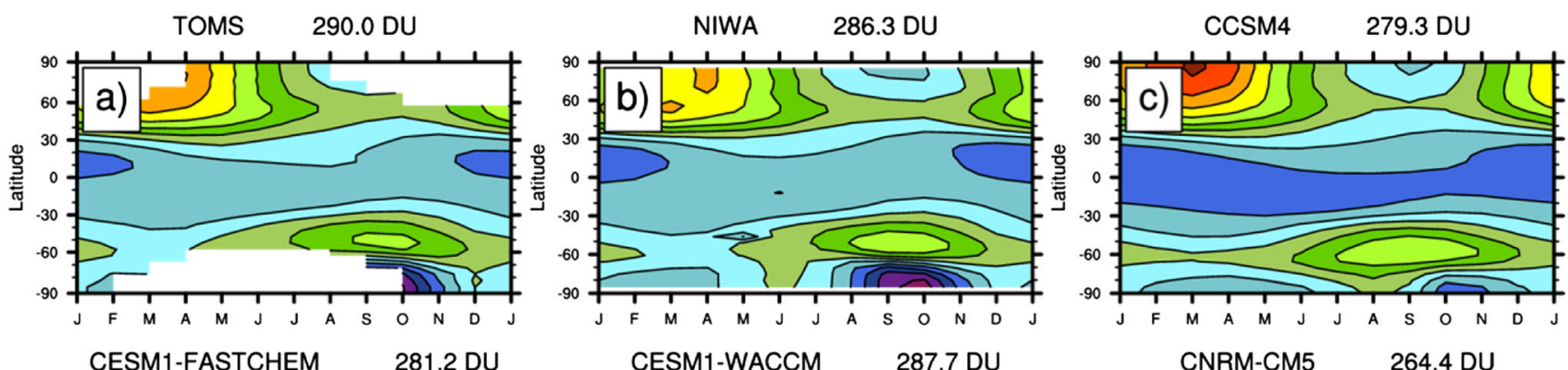

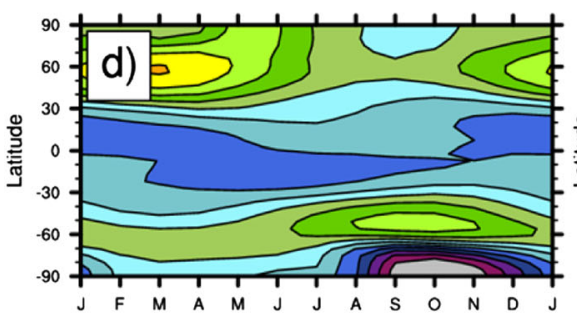

CESM1-WACCM
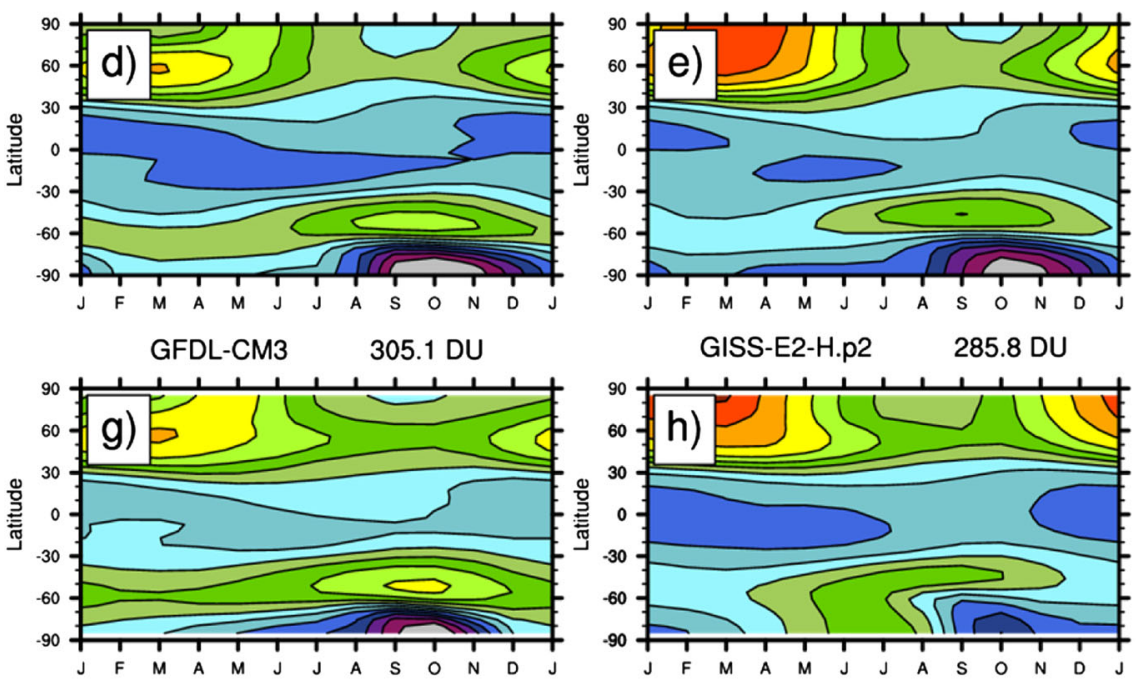

GISS-E2-R.p2

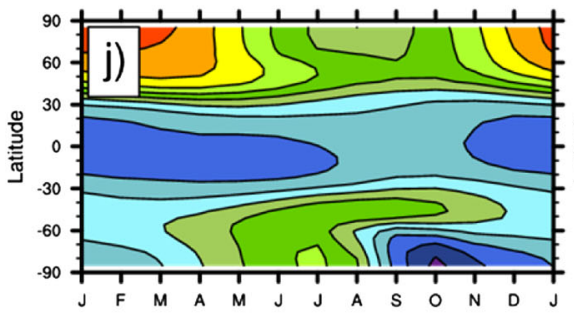

GISS-E2-H.p2 285.8 DU

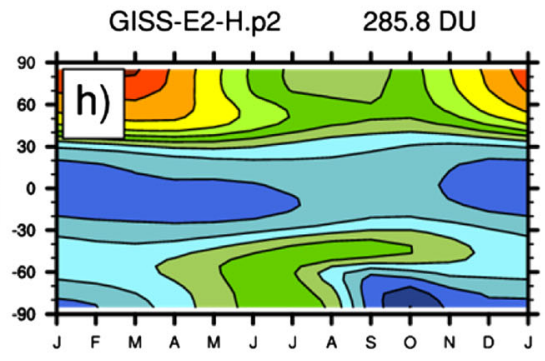

GISS-E2-R.p3

$284.5 \mathrm{DU}$

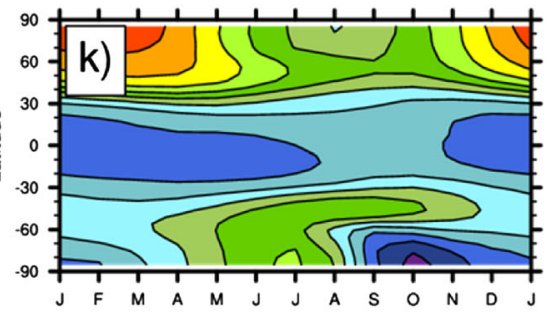

CNRM-CM5

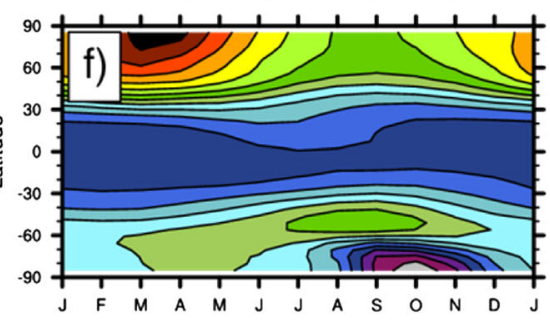

GISS-E2-H.p3

$284.0 \mathrm{DU}$

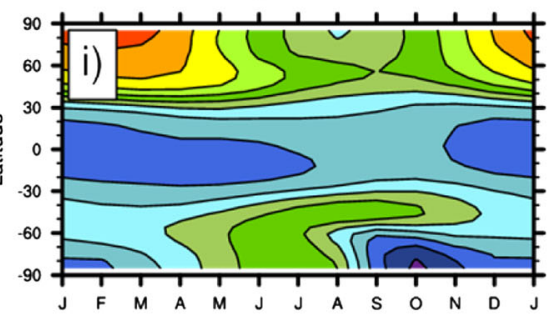

IPSL-CM5A-LR

297.5 DU

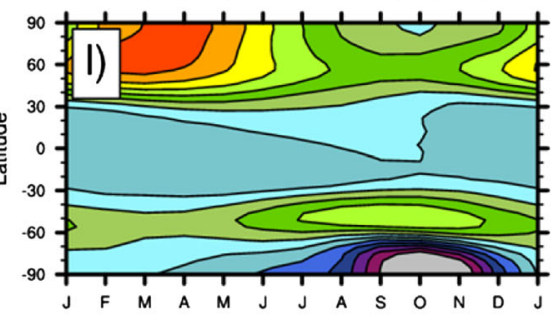

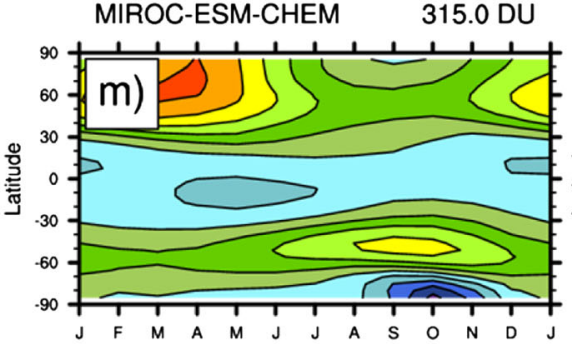
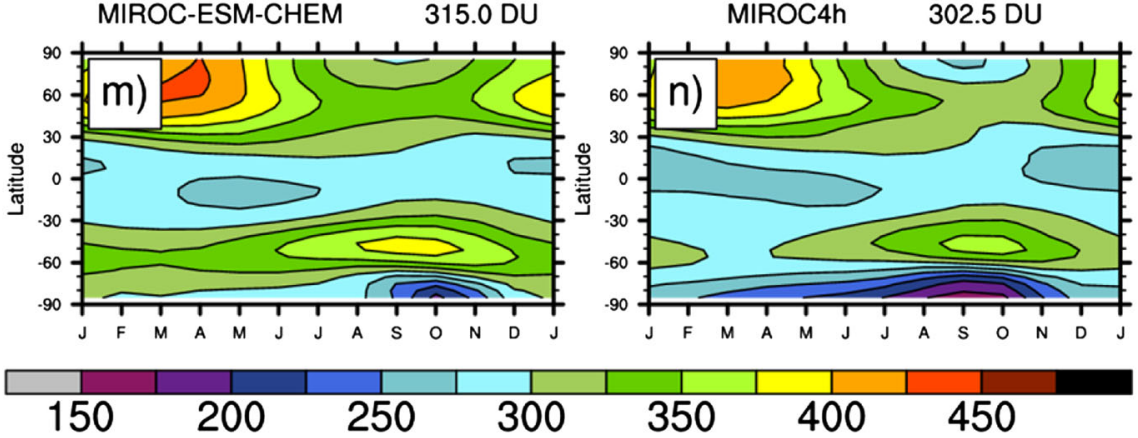

Figure A1. Same as Figure 1, but for individual CMIP5 models of the CHEM group plus MIROC4h which uses a prescribed ozone data set different from the IGAC/SPARC database.

simplified version of the LLNL-IMPACT chemistry scheme [Rotman et al., 2004] to simulate the main free troposphere processes relevant to climate change [Cameron-Smith et al., 2006] but with addition of a single isoprene tracer and omitting the species that are only relevant to the stratosphere. Stratospheric ozone is simulated instead using Linoz version 2 [Hsu and Prather, 2009], with an additional simple loss to simulate polar ozone holes using the method of Cariolle et al. [1990]. The whole chemical mechanism uses 15 tracers. The 3-D methane distribution is specified using the output of simulations of an earlier model (CAM3.5) that used a more complete chemical mechanism but fixed SSTs/ 

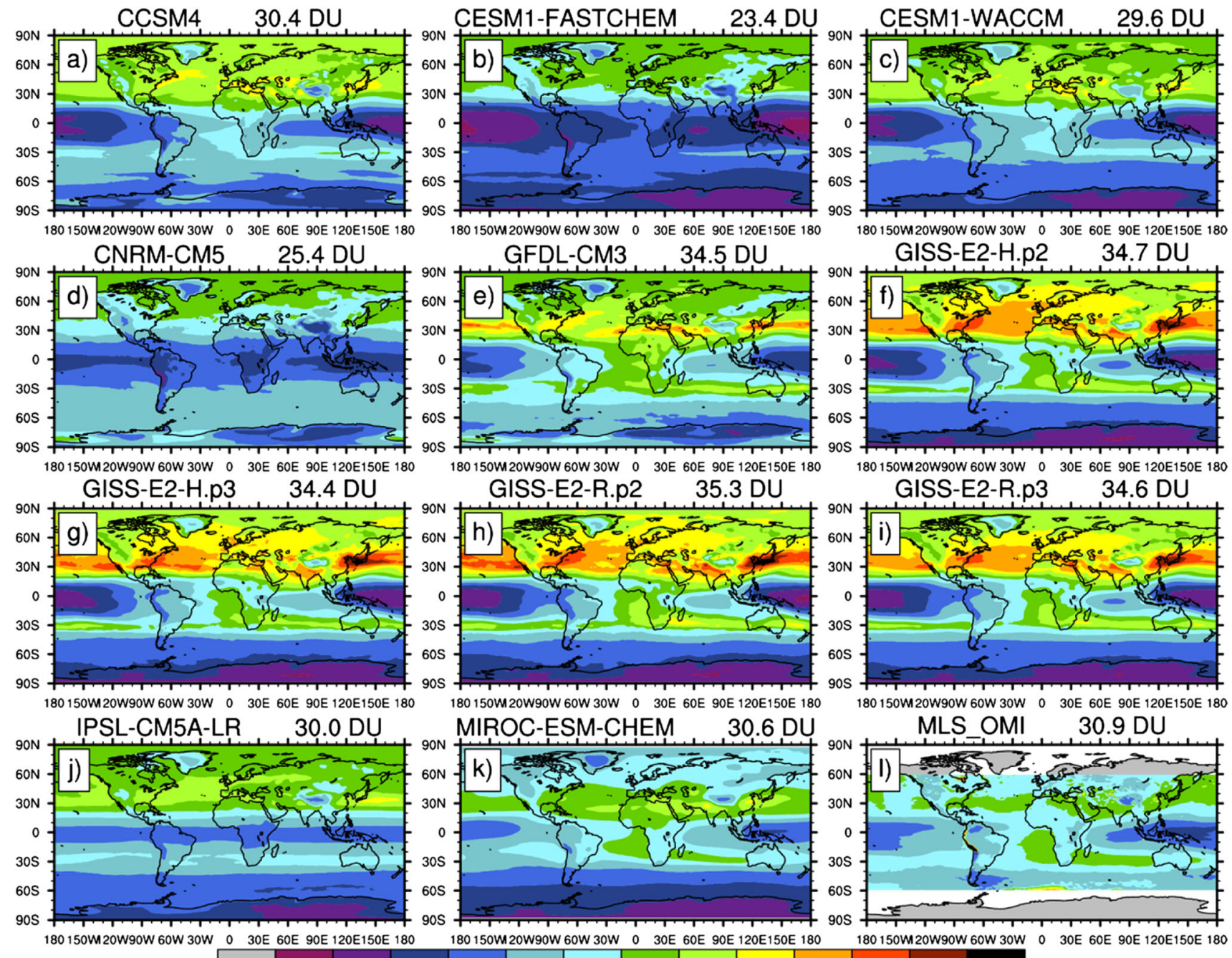

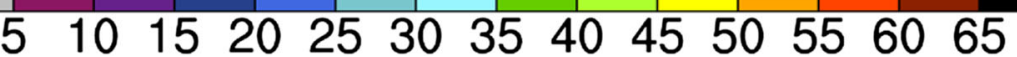

Figure A2. Same as Figure 4, but tropospheric ozone columns for the individual CMIP5 models compared to MLS/OMI. The numbers in the titles show the near-global $\left(60^{\circ} \mathrm{S}-60^{\circ} \mathrm{N}\right)$ area-weighted mean.

SICs [Lamarque et al., 2011]. The chemical emissions for the historical CMIP5 simulations followed Lamarque et al. [2010]. Due to a couple of mistakes, the CMIP5 simulations with this model were run with zero $\mathrm{NO}_{\mathrm{x}}$ from lightning and an incorrect rate constant for the $\mathrm{CO}+\mathrm{OH}$ reaction. The rate constant calculation inadvertently ignored the chemical activation channel due to a sign error in the original reference [Senosiain et al., 2003], which approximately halved the globally averaged rate constant. Fortunately, the model responded by producing excessive $\mathrm{CO}$ concentrations that almost exactly compensated for the incorrect rate constant, such that the reaction rate (given by $\mathrm{k}[\mathrm{CO}][\mathrm{OH}]$ ) was relatively unchanged, and that error had little effect on the rest of the simulation. Specifically, the rate constant error only reduced globally averaged ozone by around $1 \mathrm{pbb}$ and reduced ozone in highly polluted regions by $2-4 \mathrm{ppb}$.

\section{A1.1.2. CESM1(WACCM)}

[67] CESM1(WACCM) is a configuration of the NCAR Community Earth System Model (CESM1) with the Whole Atmosphere Community Climate Model (WACCM) version 4 as its atmospheric component [Calvo et al., 2012].
WACCM has 66 vertical levels from the surface to $4.5 \times 10^{-6} \mathrm{hPa}$ and runs at horizontal resolution of $1.9^{\circ}$ 2.5 coupled to the interactive ocean and sea-ice model components [Danabasoglu et al., 2012; Holland et al., 2012]. The capability to run WACCM as the atmospheric component in coupled simulations is one of the significant improvements over the immediate predecessor to CESM, the CCSM4 [Gent et al., 2011]. The CMIP5 simulations used WACCM version 4, which is a configuration of the Community Atmospheric Model, version 4 (CAM4), and includes all of the physical parameterizations of that model [Neale et al., 2013]. WACCM4 is a fully interactive model, where the radiatively active gases $\left(\mathrm{CO}_{2}, \mathrm{H}_{2} \mathrm{O}, \mathrm{N}_{2} \mathrm{O}, \mathrm{CH}_{4}\right.$, $\mathrm{CFCs}, \mathrm{NO}, \mathrm{O}_{3}$ ) affect heating and cooling rates and therefore dynamics. The model uses a finite volume dynamical core [Lin et al., 2004], which explicitly calculates the mass fluxes in and out of a given model grid cell, thus ensuring mass conservation. In terms of chemistry, WACCM4 incorporates a detailed neutral mechanism for the middle atmosphere [Garcia et al., 2007]. The chemistry module is based on Model for Ozone And Related chemical Tracers 

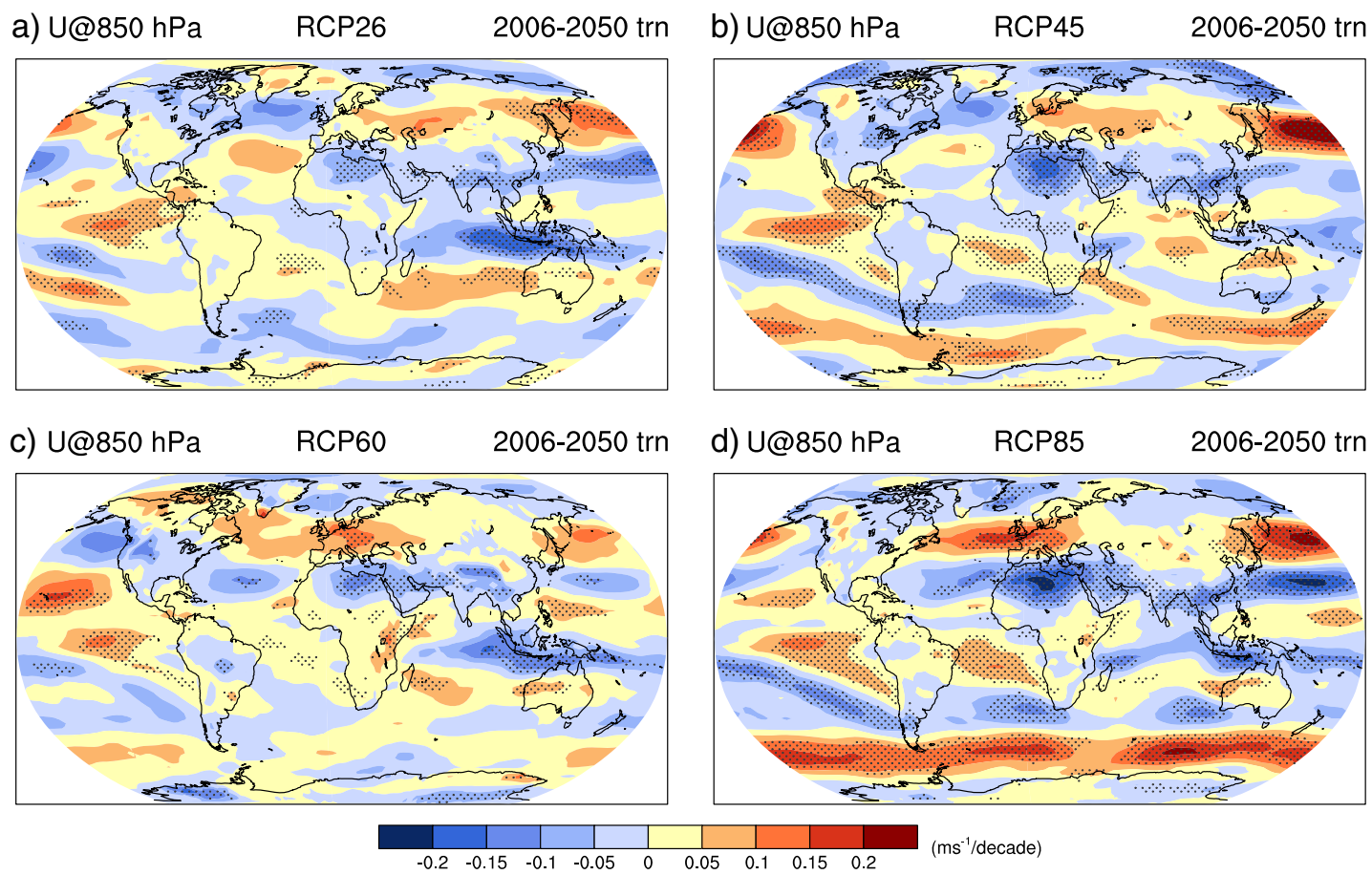

Figure A3. Zonal mean zonal wind DJF trends at $850 \mathrm{hPa}$ for the CMIP5 multimodel mean over 2006-2050 for (a) RCP 2.6, (b) RCP 4.5, (c) RCP 6.0, and (d) RCP 8.5. Model agreement is assessed through testing for significance in each model: stippling indicating most models show significant change and agree on the sign.

(MOZART) version 3 [Kinnison et al., 2007] and includes $\mathrm{O}_{\mathrm{X}}, \mathrm{NO}_{\mathrm{X}}, \mathrm{HO}_{\mathrm{X}}, \mathrm{ClO}_{\mathrm{X}}$, and $\mathrm{BrO}_{\mathrm{X}}$ chemical families, along with $\mathrm{CH}_{4}$ and its degradation products (a total of 59 species and 217 gas-phase chemical reactions). This version of WACCM does not include a detailed representation of tropospheric chemistry. Rate constants are based on Sander et al. [2006]. In addition, there are 17 heterogeneous reactions on three aerosol types: nitric acid trihydrate, supercooled ternary solution, and water ice. The reaction scheme, rates, and method of solution are identical to those evaluated for the SPARC-CCMVal [2010] report.

\section{A1.1.3. CNRM-CM5}

[68] The atmospheric component of the CNRM-CM5.1 model [Voldoire et al., 2012] is the global spectral ARPEGE-Climat atmospheric model. All CMIP5 simulations were performed at $1.4^{\circ} \times 1.4^{\circ}$ horizontal resolution, with 31 vertical layers extending to $10 \mathrm{hPa}$, including an interactive linear ozone chemistry. Within ARPEGE-Climat, the ozone mixing ratio is treated as a prognostic variable with photochemical production and loss rates computed by a two-dimensional zonal chemistry model (MOBIDIC, Cariolle and Teyssedre [2007]) and is used for the radiative transfer calculation. In this scheme, the net photochemical production in the ozone continuity equation is expanded into a firstorder Taylor series around the local value of the ozone mixing ratio, the temperature, and the overhead ozone column. An additional ozone destruction term is used to parameterize the heterogeneous chemistry as a function of the equivalent chlorine content prescribed for the actual year. The linearized scheme is based on a full chemistry scheme with 56 constituents, 175 chemical reactions, and 51 photo-reactions, implemented in a two-dimensional stratospheric model. The results of a century integration with this two-dimensional model have been used for the linearization of the photochemistry near the equilibrium. The error between the full and the linearized scheme is smaller than $10 \%$ in the two-dimensional model. The ozone mixing ratio remains a prognostic variable in the troposphere, but the parameterization is mainly developed for use in the stratosphere (i.e., some tropospheric chemical reactions are not taken into account).

\section{A1.1.4. GFDL-CM3}

[69] In the atmospheric component of the GFDL-CM3 model (called AM3) [Donner et al., 2011], the chemistry models of Horowitz et al. [2003] for the troposphere and Austin and Wilson [2006] for the stratosphere are merged. The CMIP5 simulations with interactive chemistry were performed on a cubed-sphere grid [Putman and Lin, 2007] at $\mathrm{C} 48$ horizontal resolution (with grid cell sizes varying from $163 \mathrm{~km}$ to $231 \mathrm{~km}$ ), with 48 vertical layers extending to $0.01 \mathrm{hPa}$. Vertical grid spacing is approximately $1.5 \mathrm{~km}$ near the tropopause increasing to about $3 \mathrm{~km}$ near the stratopause. AM3 simulates the atmospheric concentrations of 97 chemical species (81 gases and 16 aerosols), which undergo 172 gas-phase reactions, 41 photolytic reactions, and 11 heterogeneous reactions. Stratospheric chemistry includes $\mathrm{O}_{\mathrm{x}}, \mathrm{NO}_{\mathrm{x}}, \mathrm{HO}_{\mathrm{x}}, \mathrm{ClO}_{\mathrm{x}}$, and $\mathrm{BrO}_{\mathrm{x}}$ chemical species [Austin and Wilson, 2006]. The source of reactive chlorine and bromine are parameterized as a function of tropospheric concentrations of source gases (lagged by the stratospheric "age of air") [Austin and Wilson, 2006]. The parameterization uses observed source gas distributions to estimate the fractional rate at which source gases entering the stratosphere are photolyzed and converted into reactive halogen species along their transport path through the stratosphere. Heterogeneous reactions are included on ice and nitric acid trihydrate polar stratospheric clouds (PSCs) and in liquid 
ternary solution aerosols [Carslaw et al., 1995; Hanson and Mauersberger, 1988]. Tropospheric chemistry includes $\mathrm{O}_{\mathrm{x}}-\mathrm{NO}_{\mathrm{x}}-\mathrm{HO}_{\mathrm{x}}-\mathrm{CO}-\mathrm{CH}_{4}-\mathrm{NMHC}$ hydrocarbon chemistry (including alkanes up to a lumped $4+$ carbon species, alkenes up to propene, and isoprene and terpenes). Clear-sky photolysis frequencies are calculated using a multivariate interpolation table derived from the tropospheric ultravioletvisible radiation model [Madronich et al., 1998] suitable for calculating tropospheric and stratospheric photolysis rates, with an adjustment applied for the effects of large-scale clouds [Brasseur et al., 1998]. Kinetic reaction rates and mass accommodation coefficients and reaction probabilities are taken from Sander et al. [2006].

\section{A1.1.5. GISS-E2}

[70] The new version of the GISS climate model used for the CMIP5 simulations is called ModelE2. It is similar to ModelE [Schmidt et al., 2006] but has numerous improvements to the physics, including the ability to represent multiple downdrafts and updrafts in convective systems (Shindell et al., in prep., 2012). The CMIP5 simulations with interactive chemistry were performed at $2^{\circ} \times 2.5^{\circ}$ horizontal resolution, with 40 vertical layers extending to $0.1 \mathrm{hPa}$. The atmosphere was coupled to a full dynamic ocean, either the "Russell" ocean [Russell et al., 1995] (GISS-E2-R) or the Hybrid Coordinate Ocean Model (HYCOM) ocean [Sun and Bleck, 2006] (GISS-E2-H). The indices $p$ in Table 1 refer to non-interactive aerosols/chemistry $(p=1)$, interactive aerosols/chemistry $(p=2)$, and same as $p=2$ but with an a priori calculation of the aerosol indirect effect instead of a parameterized scheme $(p=3)$. The GISS chemical mechanism is fully embedded within ModelE2, so that chemical constituents are treated consistently with the physics of other parts of the model, such as surface fluxes of fundamental physical quantities (e.g., heat) and with transport of momentum and other constituents such as water vapor. To represent stratospheric chemistry, the model includes chlorine- and bromine-containing compounds and $\mathrm{CFC}$ and $\mathrm{N}_{2} \mathrm{O}$ source gases. PSC formation in the stratosphere is dependent upon water vapor, temperature, and $\mathrm{HNO}_{3}$ [Hanson and Mauersberger, 1988], and the heterogeneous hydrolysis of $\mathrm{N}_{2} \mathrm{O}_{5}$ on sulfate follows Kane et al. [2001] and Hallquist et al. [2003]. Chemistry and aerosols are fully integrated, so that these components interact with each other and with the physics of the climate model. The model contains 51 species for gas-phase chemistry interacting via 156 reactions. Tropospheric chemistry includes basic $\mathrm{NO}_{\mathrm{x}}-\mathrm{HO}_{\mathrm{x}}-\mathrm{O}_{\mathrm{x}}-\mathrm{CO}-\mathrm{CH}_{4}$ chemistry as well as Peroxyacetyl nitrate (PAN) and the hydrocarbons isoprene, alkyl nitrates, aldehydes, alkenes, and paraffins. Acetone chemistry [Houweling et al., 1998] and a newly identified reaction channel of $\mathrm{OH}+\mathrm{NO}_{2}$ to form $\mathrm{HNO}_{3}$ [Butkovskaya et al., 2007], the latter with a reaction rate coefficient that depends on pressure and temperature, has been added.

\section{A1.1.6. MIROC-ESM-CHEM}

[71] MIROC-ESM-CHEM is a version of the Earth system model MIROC-ESM [Watanabe et al., 2011] coupled with atmospheric chemistry. The atmospheric chemistry component is based on that used in the chemistry model CHASER [Sudo and Akimoto, 2007; Sudo et al., 2002], which considers the detailed photochemistry in the troposphere, wet and dry deposition of chemical species, and emissions of primary chemical species from a variety of sources. For Model for Interdisciplinary Research on Climate (MIROC)-ESM-CHEM, the chemistry of CHASER has been extended to include the stratosphere by incorporating halogen chemistry and related processes based on the schemes used in the Climate System Research/National Institute for Environment Studies (CCSR/NIES) stratospheric chemistry model [Akiyoshi et al., 2004]. In the configuration used for the CMIP5 simulations, the model calculates the concentrations of 92 chemical species with 262 chemical reactions at approximately $2.8^{\circ}$ by $2.8^{\circ}$ (T42) horizontal resolution with 80 vertical layers up to $0.003 \mathrm{hPa}$. The model considers the $\mathrm{O}_{\mathrm{x}}-\mathrm{NO}_{\mathrm{x}}-\mathrm{HO}_{\mathrm{x}}-\mathrm{CH}_{4}-\mathrm{CO}$ chemistry together with the oxidation of several non-methane VOCs (ethane, propane, propene, butane, acetone, methanol, isoprene, and terpenes) to represent the ozone chemistry in the troposphere. The model has detailed stratospheric chemistry, including reactions of chlorine- and brominecontaining compounds, CFCs, HFCs, OCS, and $\mathrm{N}_{2} \mathrm{O}$, as well as the formation of PSCs and associated heterogeneous reactions on their surfaces. Photolysis rates ( $J$-values) are calculated online using temperature and actinic fluxes computed in the radiation component [Sekiguchi and Nakajima, 2008] considering absorption and scattering by gases, aerosols, and clouds as well as the effect of surface albedo. The influences of short-wave radiative forcing (RF) associated with the solar cycle, volcanic eruptions, and subsequent changes in stratospheric ozone are also taken into account for the calculation of the photolysis rate.

A1.2. Semi-Offline Chemistry in the CMIP5 Simulation

[72] In nine of the 46 model versions, ozone chemistry was calculated semi-offline in both the stratosphere and troposphere (BNU-ESM, CCSM4, CESM1(BGC), CESM1 (CAM5), IPSL-CM5A-LR, IPSL-CM5A-MR, IPSL-CM5BLR, NorESM1-M, NorESM1-ME). These semi-offline ozone data sets are calculated in two different ways, which are described in the two subsections below. In the ozone figures that show individual models, only one representative of each of the two data sets is included (CCSM4, IPSL-CM5A-LR). Similarly, only CCSM4 is included in the CHEM ozone multimodel mean together with the models with interactive chemistry (section A1.2), while IPSL-CM5A is excluded because it uses a simplified scaling to estimate GHG dependence of stratospheric ozone.

\section{A1.2.1. Community Atmosphere Model \\ With Interactive Chemistry}

[73] In a subset of the model simulations (BNU-ESM, CCSM4, CESM1(BGC), CESM1(CAM5), NorESM1-M, and NorESM1-ME, entry $\mathrm{P}^{2}$ in Table 1 ), ozone is calculated semi-offline using the global 3-D Community Atmosphere Model 3.5 (CAM3.5) version [Gent et al., 2011] with interactive chemistry to calculate distributions of gases and aerosols in the troposphere and the lower to midstratosphere [Lamarque et al., 2011; Lamarque et al., 2012; Lamarque et al., 2010]. CAM3.5 also participated in CCMVal-2 and was evaluated as part of the SPARC-CCMVal [2010] report. In order to limit computational cost, this model only solves for the atmospheric and land portions of the climate system, using precomputed SSTs and SICs as boundary conditions. The model configuration consists of a horizontal resolution of $1.9^{\circ} \times 2.5^{\circ}$ and 26 hybrid levels, from the surface to $3.5 \mathrm{hPa}$ with a $30 \mathrm{~min}$ timestep. The chemical mechanism 
used is formulated to provide an accurate representation of both tropospheric and stratospheric chemistry. Specifically, a representation of stratospheric chemistry (including polar ozone loss associated with stratospheric clouds) from MOZART version 3 [Kinnison et al., 2007] is included. The tropospheric chemistry mechanism has a simplified representation of non-methane hydrocarbon chemistry in addition to standard methane chemistry, extended from Houweling et al. [1998] with the inclusion of isoprene and terpene oxidation. A monthly ozone climatology is created by averaging monthly mean ozone fields from the transient simulations for calendar months over one decade. These climatological fields are read as 3-D fields used in the radiative transfer calculation in the Community Climate System Model version 4 (CCSM4; Meehl et al. [2012]) and in the models listed above. The ozone time series was provided as decadal-average monthly mean concentrations, linearly interpolated to yearly resolution within the coupled models. These model simulations are in the class of interactive and semi-offline chemistry (CHEM) in this paper since stratospheric ozone follows the RCPs in the future unlike the IGAC/SPARC database that derives stratospheric ozone concentrations based on the SRES A1B GHG scenario.

\section{A1.2.2. IPSL}

[74] In the three IPSL coupled ocean-atmosphere climate model versions (IPSL-CM5A-LR, IPSL-CM5A-MR, and IPSL-CM5B-LR, [Dufresne et al., 2013]), ozone fields are calculated semi-offline by a tropospheric and a stratospheric version of the atmospheric general circulation model LMDz with interactive chemistry, following the four RCPs in the future. Tropospheric ozone is calculated using the tropospheric chemistry module INCA (Interaction with Chemistry and Aerosol) within a version of LMDz that has 19 vertical levels, with most of them in the troposphere [Hauglustaine et al., 2004]. Stratospheric ozone is calculated using the stratospheric chemistry module REPROBUS (Reactive Processes Ruling the Ozone Budget in the Stratosphere), using a stratospheric version of LMDz that has 50 vertical levels, with a resolution varying in the stratosphere from about $1 \mathrm{~km}$ around the tropopause region to about $3 \mathrm{~km}$ at $50 \mathrm{~km}$ [Jourdain et al., 2008].

[75] In the case of LMDz-REPROBUS, only two simulations for the future were performed: a CCMVal REFB2 simulation that follows the SRES A1B GHG scenario and a CCMVal SCN-B2c simulation, where GHGs were fixed at 1960 levels throughout the simulation [Eyring et al., 2010b]. For this reason, a rather crude approximation was used based on previous calculations carried out with CAM3.5, the only CCM that ran all the RCP calculations in Eyring et al. [2010a]. For CAM3.5, correlation plots for different vertical and latitudinal regions of the stratosphere indicate a somewhat linear dependency of stratospheric ozone change on $\mathrm{CO}_{2}$ level change over the range of RCP scenarios (see Figure 3 of Eyring et al. [2010a]). Assuming a similar linear dependency in the case of LMDz-REPROBUS, stratospheric RCP 2.6, RCP 4.5 and RCP 8.5 ozone fields were generated by interpolating or extrapolating linearly from the REF-B2 and $\mathrm{SCN}-\mathrm{B} 2 \mathrm{c}$ stratospheric ozone time series. Ozone fields are reconstructed using locally derived time-varying weighting coefficients that are assumed to be proportional to the $\mathrm{CO}_{2}$ mixing ratio.
[76] Since atmospheric measurements and model simulations constrained by emission inventories indicate that the increase in Ozone Depleting Substances (ODSs; mostly CFCs) concentrations was very marginal before 1960 [WMO, 2011], trends in stratospheric ozone are neglected before 1960. Raw monthly 3-D fields of both INCA and REPROBUS ozone time series are then zonally averaged and temporally smoothed using an 11 year running mean. Finally, the tropospheric and stratospheric zonal mean ozone time series extracted from the LMDz-INCA and LMDzREPROBUS simulations are merged at the chemical tropopause (defined as the $150 \mathrm{nmol} / \mathrm{mol}$ ozone contour). INCA ozone fields are slightly stretched or compressed in order to have the INCA tropopause altitude matching the REPROBUS tropopause altitude. The thickness of the transition region is taken to be about $3 \mathrm{~km}$, extending from $2 \mathrm{~km}$ above the tropopause to $1 \mathrm{~km}$ below the tropopause. The resulting merged zonal mean ozone fields contain INCA fields below the tropopause region and REPROBUS fields above, together with a relatively smooth transition from one field to another within the tropopause region. The entire merging procedure is described in detail by Szopa et al. [2012].

\section{A2. CMIP5 Models With Prescribed Chemistry (NOCHEM)}

\section{A2.1. IGAC/SPARC Ozone Database}

[77] In 23 model versions, the original or a modified version of the IGAC/SPARC ozone database (see section 1) was used. To represent this class of models in the figures, only the IGAC/SPARC ozone database is shown in the figures. The original IGAC/SPARC ozone database was recommended on the CMIP5 website as forcings for models without interactive chemistry. It was used in 13 of the 28 model versions with prescribed ozone (ACCESS1-0, ACCESS1-3, BCC-CSM1.1, BCC-CSM1.1-M, CSIRO-Mk3-6-0, EC-EARTH, FGOALSg2, FGOALS-s2, FIO-ESM, GFDL-ESM2G, GFDLESM2M, INM-CM4, and MRI-CGCM3). Slightly modified versions were used in 10 of the 28 model versions with prescribed ozone (CanAM4, CanCM4, CanESM2, CMCC-CM, HadCM3, HadGEM2-A, HadGEM2-CC, HadGEM2-ES, MPI-ESM-LR, and MPI-ESM-P).

[78] Since the solar cycle was not included in the future part of the IGAC/SPARC ozone data set, a modified version that included the effects of the solar cycle on future ozone concentrations was created by the Met Office [Jones et al., 2011] and used by 7 of the 31 model versions with prescribed chemistry (CMCC-CM, HadCM3, HadGEM2-A, HadGEM2CC, HadGEM2-ES, MPI-ESM-LR, and MPI-ESM-P). The solar regression index was used to build a future time series consistent with a repeating solar irradiance modeled as a sinusoid with a period of 11 years, with mean and maximumminimum values corresponding to solar cycle 23 normalized against the $180.5 \mathrm{~nm}$ time series used in the historical ozone data set. Future ozone was represented as: $\mathrm{O} 3(\mathrm{t})=\mathrm{a} * \mathrm{SOL}+$ $\mathrm{b}^{*} \mathrm{EESC}+$ seasonal cycle + residuals. For consistency, the indices of the 11 year solar cycle (SOL) and total EESC were identical to those used to prepare the original data set. In the HadGEM2-ES model [Collins et al., 2011] tropospheric chemistry was fully interactive, taking account of surface emissions of $\mathrm{CH}_{4}, \mathrm{CO}, \mathrm{NO}_{\mathrm{x}}, \mathrm{HCHO}, \mathrm{C}_{2} \mathrm{H}_{6}, \mathrm{C}_{3} \mathrm{H}_{8}, \mathrm{Me}_{2} \mathrm{CO}$, and $\mathrm{MeCHO}$. 
[79] CanAM4, CanCM4, and CanESM2 again used a slightly modified version of the IGAC/SPARC data set. Over the historical period (1850-2009), it is identical to the original database, except that it is zonally averaged. From 2010 onwards, ozone in the troposphere is also identical to the original database for all RCPs, although zonally averaged, while ozone in the stratosphere has been modified. During this future period, stratospheric ozone was derived by combining two separate terms derived from multiple linear regression (MLR). The first term represents EESC from the historical period, extended into the future using predictions of EESC from the suite of the CCMVal-2 models. The CCMVal-2 time series of future ozone was independently fitted to an EESC and a linear trend using MLR. The linear trend term from the models was the second term used to construct the future ozone, combined with the EESC term described above. Construction of the ozone time series in this manner helped ensure the response of ozone to EESC in the historical period was equal to the response of ozone to EESC in the future, as halogen concentrations decrease.

\section{A2.2. Other Ozone Data Sets}

[80] In the remaining 5 of the 28 model versions with prescribed ozone (GISS-E2-H p1, GISS-E2-R p1, MIROCESM, MIROC4h and MIROC5), data sets different from the Cionni et al. [2011] database were used. In the ozone figures that show individual models, only one representative of the two different data sets are shown with dotted lines (GISS-E2-H p1, and MIROC4h).

\section{A2.2.1. MIROC-ESM, MIROC4h and MIROC5}

[81] MIROC-ESM and MIROC5 prescribed past and future ozone concentrations using the simulations of Kawase et al. [2011], whereas MIROC4h used the Sudo et al. [2003] ozone data set for past simulations and Kawase et al. [2011] for future simulations. Kawase et al. [2011] simulated the longterm evolution of tropospheric ozone using the chemistryclimate model CHASER [Sudo et al., 2002], driven by historical and future RCP scenarios. Stratospheric ozone was based on the late 20th century climatology of the SUNYA data set [Wang et al., 1995], scaled by the observed stratospheric ozone trend from Randel and $W u$ [2007] for the past and by the projected time evolution of EESC in the future simulation (following the halogen scenario A1 of WMO [1999]). Stratospheric ozone in this data set does not reflect future changes in ozone transport that could be induced by increases in GHGs, as is projected in the IGAC/SPARC ozone database. As a consequence, this data set has a straightforward recovery of stratospheric ozone in the future toward chemically unperturbed past state (e.g., ozone is similar between the late 19 th and late 21 st century, which are two periods with negligible effects of ODSs). There is neither super-recovery nor ozone reduction in the tropical lower stratosphere in the future, which is seen in the IGAC/SPARC database. Effects of the 11 year solar cycle and volcanic aerosols are not considered in this ozone data set.

\section{A2.2.2. GISS-E2-H p1, GISS-E2-R p1}

[82] In the GISS-E2 non-interactive chemistry simulations $(p=1)$, offline ozone fields were used from the prior generation (CMIP3) GISS simulations [Hansen et al., 2007]. Tropospheric ozone changes were from an older chemistryclimate model [Shindell et al., 2003] driven by prescribed changes in precursor emissions, ocean boundary conditions (SSTs and SICs), and GHG abundances. Stratospheric ozone changes from 1979 to 1997 were from the observational analyses of Randel and Wu [1999]. Tropospheric ozone was kept constant from 1990 on, while stratospheric ozone was constant from 1997 to 2003 and then linearly returned to its 1979 value between 2004 and 2050 .

[83] Acknowledgments. We thank Ben Santer, Ulrich Schumann, Lorenzo Polvani, and two anonymous reviewers for helpful comments. Thanks to Eric Guilyardi, Tim Johns, and Florian Rauser for their help with the CMIP5 model table. We acknowledge the World Climate Research Programme's (WCRP's) Working Group on Coupled Modelling (WGCM), which is responsible for CMIP, and we thank the climate modeling groups (listed in Table 1 of this paper) for producing and making available their model output. For CMIP, the U.S. Department of Energy's Program for Climate Model Diagnosis and Intercomparison provides coordinating support and led development of software infrastructure in partnership with the Global Organization for Earth System Science Portals. We acknowledge the Chemistry-Climate Model Validation (CCMVal) Activity for WCRP's SPARC (Stratospheric Processes and their Role in Climate) project for organizing and coordinating the model data analysis activity and the British Atmospheric Data Center (BADC) for collecting and archiving the CCMVal model output. We would like to thank ETH Zurich for help in accessing data from the PCMDI archive. V.E. and K.G. were supported by the DLR Earth System Model Validation (ESMVal) project and the Earth system Model Bias Reduction and assessing Abrupt Climate change (EMBRACE) project which is funded by the European Commission under the 7th Framework Programme. J.A. was supported by the Australian Climate Change Science Program, which is administered by the Australian Department of Climate Change and Energy Efficiency and by the Office of Science, Biological and Environmental Research, U.S. Department of Energy, Cooperative Agreement No. DE-FC02-97ER62402, and the National Science Foundation. The CESM project is supported by the National Science Foundation and the Office of Science (BER) of the U.S. Department of Energy. The National Center for Atmospheric Research (NCAR) is operated by the University Corporation for Atmospheric Research under sponsorship of the National Science Foundation. K.S. and S.W. were supported by the Innovative Program of Climate Change Projection for the 21st Century, MEXT, Japan. The NIES supercomputer system (NEC SX-8R) and Earth Simulator were used for the development and integration of MIROC-ESM-CHEM model. The work of D.B. and P.C. on the CESM-FASTCHEM model was funded by the U.S. Dept. of Energy (BER), performed under the auspices of LLNL under Contract DE-AC52-07NA27344, and used the DOE Office of Science supercomputing resources of NERSC under contract DE-AC02-05CH11231 and NCCS under contract DE-AC05-00OR22725.

\section{References}

Akiyoshi, H., T. Sugita, H. Kanzawa, and N. Kawamoto (2004), Ozone perturbations in the Arctic summer lower stratosphere as a reflection of $\mathrm{NO}_{\mathrm{X}}$ chemistry and planetary scale wave activity, J. Geophys. Res. Atmos., 109(D3), D03304, doi:10.1029/2003JD003632.

Annan, J. D., and J. C. Hargreaves (2011), Understanding the CMIP3 multimodel ensemble, J. Climate, 24(16), 4529-4538, doi:10.1175/ 2011 jcli3873.1.

Arblaster, J. M., G. A. Meehl, and D. J. Karoly (2011), Future climate change in the Southern Hemisphere: Competing effects of ozone and greenhouse gases, Geophys. Res. Lett., 38, L02701, doi:10.1029/ $2010 \mathrm{gl045384}$.

Arneth, A., et al. (2010), Terrestrial biogeochemical feedbacks in the climate system, Nat. Geosci., 3(8), 525-532, doi:10.1038/Ngeo905.

Arora, V. K., J. F. Scinocca, G. J. Boer, J. R. Christian, K. L. Denman, G. M. Flato, V. V. Kharin, W. G. Lee, and W. J. Merryfield (2011), Carbon emission limits required to satisfy future representative concentration pathways of greenhouse gases, Geophys. Res. Lett., 38, L05805, doi:10.1029/2010g1046270.

Austin, J., and R. J. Wilson (2006), Ensemble simulations of the decline and recovery of stratospheric ozone, J. Geophys. Res. Atmos., 111(D16).

Austin, J., et al. (2010), Decline and recovery of total column ozone using a multimodel time series analysis, J. Geophys. Res. Atmos., 115.

Bao, Q., et al. (2013), The Flexible Global Ocean-atmosphere-Land System model Version: FGOALS-s2, Adv. Atmos. Sci., in press.

Bitz, C. M., and L. M. Polvani (2012), Antarctic climate response to stratospheric ozone depletion in a fine resolution ocean climate model, Geophys. Res. Lett., 39.

Bodeker, G. E., H. Shiona, and H. Eskes (2005), Indicators of Antarctic ozone depletion, Atmos. Chem. Phys., 5, 2603-2615.

Bracegirdle, T. J., E. Shuckburgh, J.-B. Sallee, Z. Wang, A. S. Meijers, N. Bruneau, T. Philips, and L. J. Wilcox (2013), Assessment of surface 
winds over the Atlantic, Indian, and Pacific Ocean sectors of the Southern Ocean in CMIP5 models: Historical bias, forcing response, and state dependence, J. Geophys. Res. Atmos., 118(2).

Brasseur, G. P., D. A. Hauglustaine, S. Walters, P. J. Rasch, J. F. Muller, C. Granier, and X. X. Tie (1998), MOZART, a global chemical transport model for ozone and related chemical tracers 1. Model description, J. Geophys. Res. Atmos., 103(D21), 28,265-28,289.

Butchart, N., et al. (2010), Chemistry-climate model simulations of twentyfirst century stratospheric climate and circulation changes, J. Clim., 23(20), 5349-5374.

Butchart, N., et al. (2011), Multimodel climate and variability of the stratosphere, J. Geophys. Res. Atmos., 116.

Butkovskaya, N., A. Kukui, and G. Le Bras (2007), HNO3 forming channel of the $\mathrm{HO} 2+$ NOreaction as a function of pressure and temperature in the ranges of 72-600 torr and 223-323 K, J. Phys. Chem. A, 111(37), 9047-9053.

Calvo, N., R. R. Garcia, D. R. Marsh, M. J. Mills, D. E. Kinnison, and P. J. Young (2012), Reconciling modeled and observed temperature trends over Antarctica, Geophys. Res. Lett., 39, L16803, doi:10.1029/ 2012 GL052526.

Cameron-Smith, P., J. F. Lamarque, P. Connell, C. Chuang, and F. Vitt (2006), Toward an Earth system model: Atmospheric chemistry, coupling, and petascale computing, J. Phys. Conf. Ser., 46, 343-350.

Cariolle, D., and H. Teyssedre (2007), A revised linear ozone photochemistry parameterization for use in transport and general circulation models: Multi-annual simulations, Atmos. Chem. Phys., 7(9), 2183-2196.

Cariolle, D., A. Lasserrebigorry, J. F. Royer, and J. F. Geleyn (1990), a general-circulation model simulation of the springtime Antarctic ozone decrease and its impact on midlatitudes, J. Geophys. Res. Atmos. 95(D2), 1883-1898.

Carslaw, K. S., B. P. Luo, and T. Peter (1995), An analytic-expression for the composition of aqueous $\mathrm{HNO}_{3}-\mathrm{H}_{2} \mathrm{SO}_{4}$ stratospheric aerosols including gas-phase removal of $\mathrm{HNO}_{3}$, Geophys. Res. Lett., 22(14), 1877-1880.

Ceppi, P., Y. T. Hwang, D. M. W. Frierson, and D. L. Hartmann (2012), Southern Hemisphere jet latitude biases in CMIP5 models linked to shortwave cloud forcing, Geophys. Res. Lett., 39.

Chen, G., and I. M. Held (2007), Phase speed spectra and the recen poleward shift of Southern Hemisphere surface westerlies, Geophys. Res. Lett., 34(21).

Cionni, I., V. Eyring, J. F. Lamarque, W. J. Randel, D. S. Stevenson, F. Wu, G. E. Bodeker, T. G. Shepherd, D. T. Shindell, and D. W. Waugh (2011), Ozone database in support of CMIP5 simulations: Results and corresponding radiative forcing, Atmos. Chem. Phys. Discuss., 11(4), $10,875-10,933$

Collins, W. J., R. G. Derwent, B. Garnier, C. E. Johnson, M. G. Sanderson, and D. S. Stevenson (2003), Effect of stratosphere-troposphere exchange on the future tropospheric ozone trend, J. Geophys. Res. Atmos., 108(D12)

Collins, W. J., et al. (2011), Development and evaluation of an EarthSystem model-HadGEM2, Geosci. Model Dev., 4(4), 1051-1075.

Cordero, E. C., and P. M. D. Forster (2006), Stratospheric variability and trends in models used for the IPCC AR4, Atmos. Chem. Phys., 6 , 5369-5380.

Danabasoglu, G., S. C. Bates, B. P. Briegleb, S. R. Jayne, M. Jochum W. G. Large, S. Peacock, and S. G. Yeager (2012), The CCSM4 ocean component, J. Clim., 25(5), 1361-1389.

Dee, D. P., et al. (2011), The ERA-Interim reanalysis: Configuration and performance of the data assimilation system, $Q$. J. R. Meteor Soc, 137(656), 553-597.

Dix, M., et al. (2012), The ACCESS Coupled Model: Documentation of core CMIP5 simulations and initial results, Aust. Met. Oceanog. J., in press.

Donner, L. J., et al. (2011), The dynamical core, physical parameterizations, and basic simulation characteristics of the atmospheric componen AM3 of the GFDL Global Coupled Model CM3, J. Clim., 24(13), 3484-3519.

Dufresne, J. L., et al. (2013), Climate change projections using the IPSLCM5 Earth System Model: From CMIP3 to CMIP5, Clim. Dyn., 1-43.

Dunne, J. P., et al. (2012), GFDL's ESM2 Global Coupled Climate-Carbon Earth System Models. Part I: Physical formulation and baseline simulation characteristics, J. Clim., 25(19), 6646-6665.

Eyring, V., et al. (2010a), Sensitivity of 21 st century stratospheric ozone to greenhouse gas scenarios, Geophys. Res. Lett., 37(16), L16807.

Eyring, V., et al. (2005), A strategy for process-oriented validation of coupled chemistry-climate models, B. Am. Meteorol. Soc., 86(8), 1117-1133.

Eyring, V., et al. (2010b), Multi-model assessment of stratospheric ozone return dates and ozone recovery in CCMVal-2 models, Atmos. Chem. Phys., 10(19), 9451-9472.

Eyring, V., et al. (2006), Assessment of temperature, trace species, and ozone in chemistry-climate model simulations of the recent past, J. Geophys. Res., 111(D22), D22308.
Eyring, V., et al. (2007), Multimodel projections of stratospheric ozone in the 21st century, J. Geophys. Res., 112(D16), D16303.

Fioletov, V. E., G. E. Bodeker, A. J. Miller, R. D. McPeters, and R. Stolarski (2002), Global and zonal total ozone variations estimated from ground-based and satellite measurements: 1964-2000, J. Geophys. Res. Atmos., 107(D22)

Fogt, R. L., J. Perlwitz, S. Pawson, and M. A. Olsen (2009), Intra-annual relationships between polar ozone and the SAM, Geophys. Res. Lett., 36.

Forster, P. M. D., and K. P. Shine (1997), Radiative forcing and temperature trends from stratospheric ozone changes, J. Geophys. Res. Atmos., 102(D9), 10,841-10,855.

Forster, P. M. D., G. Bodeker, R. Schofield, S. Solomon, and D. Thompson (2007), Effects of ozone cooling in the tropical lower stratosphere and upper troposphere, Geophys. Res. Lett., 34(23).

Freckleton, R. S., E. J. Highwood, K. P. Shine, O. Wild, K. S. Law, and M. G. Sanderson (1998), Greenhouse gas radiative forcing: Effects of averaging and inhomogeneities in trace gas distribution, Q. J. R. Meteor Soc, 124(550), 2099-2127.

Garcia, R. R., D. R. Marsh, D. E. Kinnison, B. A. Boville, and F. Sassi (2007) Simulation of secular trends in the middle atmosphere, 1950-2003, J. Geophys. Res. Atmos., 112(D9).

Gent, P. R., et al. (2011), The Community Climate System Model Version 4, J. Clim., 24(19), 4973-4991.

Gerber, E. P., et al. (2012), Assessing and understanding the impact of stratospheric dynamics and variability on the Earth system, B. Am Meteorol. Soc., 93(6), 845-859.

Gillett, N. P., and D. W. Thompson (2003), Simulation of recent Southern Hemisphere climate change, Science, 302(5643), 273-275.

Gillett, N. P., et al. (2011), Attribution of observed changes in stratospheric ozone and temperature, Atmos. Chem. Phys., 11(2), 599-609.

Gordon, C., C. Cooper, C. A. Senior, H. Banks, J. M. Gregory, T. C. Johns, J. F. B. Mitchell, and R. A. Wood (2000), The simulation of SST, sea ice extents and ocean heat transports in a version of the Hadley Centre coupled model without flux adjustments, Clim. Dyn., 16(2-3), 147-168. Guenther, A. (2007), Estimates of global terrestrial isoprene emissions using MEGAN (Model of Emissions of Gases and Aerosols from Nature) (vol 6, pg 3181, 2006), Atmos. Chem. Phys., 7(16), 4327-4327.

Guenther, A., T. Karl, P. Harley, C. Wiedinmyer, P. I. Palmer, and C. Geron (2006), Estimates of global terrestrial isoprene emissions using MEGAN (Model of Emissions of Gases and Aerosols from Nature), Atmos. Chem Phys., 6(11), 3181-3210.

Hallquist, M., D. J. Stewart, S. K. Stephenson, and R. A. Cox (2003), Hydrolysis of N2O5 on sub-micron sulfate aerosols, Phys. Chem. Chem. Phys., 5(16), 3453-3463.

Hansen, J., et al. (2007), Climate simulations for 1880-2003 with GISS modelE, Clim. Dyn., 29(7-8), 661-696.

Hanson, D., and K. Mauersberger (1988), Laboratory studies of the nitricacid trihydrate-Implications for the south polar stratosphere, Geophys Res. Lett., 15(8), 855-858.

Hassler, B., G. E. Bodeker, S. Solomon, and P. J. Young (2011), Changes in the polar vortex: Effects on Antarctic total ozone observations at various stations, Geophys. Res. Lett., 38.

Hauglustaine, D. A., J. Lathiere, S. Szopa, and G. A. Folberth (2005), Future tropospheric ozone simulated with a climate-chemistry-biosphere model, Geophys. Res. Lett., 32(24).

Hauglustaine, D. A., F. Hourdin, L. Jourdain, M. A. Filiberti, S. Walters J. F. Lamarque, and E. A. Holland (2004), Interactive chemistry in the Laboratoire de Meteorologie Dynamique general circulation model: Description and background tropospheric chemistry evaluation, J. Geophys. Res. Atmos., 109(D4).

Hazeleger, W., et al. (2012), EC-Earth V2.2: Description and validation of a new seamless earth system prediction model, Clim. Dyn., 39(11), 2611-2629.

Hegglin, M. I., and T. G. Shepherd (2009), Large climate-induced changes in ultraviolet index and stratosphere-to-troposphere ozone flux, Nat Geosci., 2(10), 687-691.

Holland, M. M., D. A. Bailey, B. P. Briegleb, B. Light, and E. Hunke (2012), Improved sea ice shortwave radiation physics in CCSM4: The impact of melt ponds and aerosols on Arctic sea ice, J. Climate, 25(5), $1413-1430$

Horowitz, L. W., et al. (2003), A global simulation of tropospheric ozone and related tracers: Description and evaluation of MOZART, version 2, J. Geophys. Res. Atmos., 108(D24).

Houweling, S., F. Dentener, and J. Lelieveld (1998), The impact of nonmethane hydrocarbon compounds on tropospheric photochemistry, J. Geophys. Res. Atmos., 103(D9), 10,673-10,696.

Hsu, J., and M. J. Prather (2009), Stratospheric variability and tropospheric ozone, J. Geophys. Res. Atmos., 114

IPCC (2000), Intergovernmental Panel on Climate Change (IPCC), Special report on emissions scenarios: a special report of Working Group III of the Intergovernmental Panel on Climate Change, Rep., 599 pp, Cambridge, U.K 
IPCC (2007), Intergovernmental Panel on Climate Change (IPCC), Climate Change 2007: The Physical Science Basis. Contribution of Working Group I to the Fourth Assessment Report of the Intergovernmental Pane on Climate ChangeRep., Cambridge, United Kingdom and New York, NY, USA.

Isaksen, I. S. A., et al. (2009), Atmospheric composition change: Climatechemistry interactions, Atmos. Environ., 43(33), 5138-5192.

Iversen, T., et al. (2012), The Norwegian Earth System Model, NorESM1M. Part 2: Climate response and scenario projections, Geosci. Model Dev. Discuss., 5, 2933-2998.

Jacob, D. J., and D. A. Winner (2009), Effect of climate change on air quality, Atmos. Environ., 43(1), 51-63.

Jacobson, M. Z., and D. G. Streets (2009), Influence of future anthropogenic emissions on climate, natural emissions, and air quality, J. Geophys. Res. Atmos., 114.

Johnson, C. E., W. J. Collins, D. S. Stevenson, and R. G. Derwent (1999), Relative roles of climate and emissions changes on future tropospheric oxidant concentrations, J. Geophys. Res. Atmos., 104 (D15), 18,631-18,645.

Jones, C. D., et al. (2011), The HadGEM2-ES implementation of CMIP5 centennial simulations, Geosci. Model Dev., 4(3), 543-570.

Jourdain, L., S. Bekki, F. Lott, and F. Lefevre (2008), The coupled chemistryclimate model LMDz-REPROBUS: Description and evaluation of a transient simulation of the period 1980-1999, Ann. Geophys.-Germany, 26(6), 1391-1413.

Jun, M., R. Knutti, and D. W. Nychka (2008), Spatial analysis to quantify numerical model bias and dependence: How many climate models are there?, J. Am. Stat. Assoc., 103(483), 934-947.

Kane, S. M., F. Caloz, and M. T. Leu (2001), Heterogeneous uptake of gaseous $\mathrm{N} 2 \mathrm{O} 5$ by (NH4)(2)SO4, NH4HSO4, and $\mathrm{H} 2 \mathrm{SO} 4$ aerosols, J. Phys. Chem. A, 105(26), 6465-6470.

Kang, S., L. Polvani, J. Fyfe, and M. Sigmond (2011), Impact of polar ozone depletion on subtropical precipitation, Science (New York, N.Y.), 332(2cc667b2-3b2e-2079-e7bf-d14d5b7771d1), 951-955.

Kawase, H., T. Nagashima, K. Sudo, and T. Nozawa (2011), Future changes in tropospheric ozone under representative concentration pathways (RCPs), Geophys. Res. Lett., 38.

Kidston, J., and E. P. Gerber (2010), Intermodel variability of the poleward shift of the austral jet stream in the CMIP3 integrations linked to biases in 20th century climatology, Geophys. Res. Lett., 37.

Kinnison, D. E., et al. (2007), Sensitivity of chemical tracers to meteorological parameters in the MOZART-3 chemical transport model, J. Geophys. Res. Atmos., 112(D20).

Knutti, R., D. Masson, and A. Gettelman (2013), Climate model genealogy: Generation CMIP5 and how we got there, Geophys. Res. Lett., 40, doi:10.1002/grl.50256.

Kushner, P. J., and L. M. Polvani (2004), Stratosphere-troposphere coupling in a relatively simple AGCM: The role of eddies, J. Clim., $17(3), 629-639$

Lamarque, J. F., G. P. Kyle, M. Meinshausen, K. Riahi, S. J. Smith, D. P. van Vuuren, A. J. Conley, and F. Vitt (2011), Global and regional evolution of short-lived radiatively-active gases and aerosols in the Representative Concentration Pathways, Clim. Chang., 109(1-2), 191-212.

Lamarque, J. F., et al. (2012), CAM-chem: Description and evaluation of interactive atmospheric chemistry in the Community Earth System Model, Geosci. Model Dev., 5(2), 369-411.

Lamarque, J. F., et al. (2010), Historical (1850-2000) gridded anthropogenic and biomass burning emissions of reactive gases and aerosols: Methodology and application, Atmos. Chem. Phys., 10(15), 7017-7039.

Langematz, U., and M. Kunze (2006), An update on dynamical changes in the Arctic and Antarctic stratospheric polar vortices, Clim. Dyn., 27(6), $647-660$

Lanzante, J. R. (2007), Diagnosis of radiosonde vertical temperature trend profiles: Comparing the influence of data homogenization versus mode forcings, J. Clim., 20(21), 5356-5364.

Lary, D. J. (1997), Catalytic destruction of stratospheric ozone, J. Geophys. Res. Atmos., 102(D17), 21,515-21,526.

Lathiere, J., D. A. Hauglustaine, N. De Noblet-Ducoudre, G. Krinner, and G. A. Folberth (2005), Past and future changes in biogenic volatile organic compound emissions simulated with a global dynamic vegetation model, Geophys. Res. Lett., 32(20).

Le Quere, C., et al. (2007), Saturation of the Southern Ocean $\mathrm{CO}_{2}$ sink due to recent climate change, Science, 316(5832), 1735-1738.

Lenton, A., F. Codron, L. Bopp, N. Metzl, P. Cadule, A. Tagliabue, and J. Le Sommer (2009), Stratospheric ozone depletion reduces ocean carbon uptake and enhances ocean acidification, Geophys. Res. Lett., $36(12)$, L12606.

Li, L. J., et al. (2013), The Flexible Global Ocean-atmosphere-Land System Model version g2, Adv. Atmos. Sci., doi:10.1007/s00376-012-2140-6.
Lin, B., T. M. Wong, B. A. Wielicki, and Y. X. Hu (2004), Examination of the decadal tropical mean ERBS nonscanner radiation data for the iris hypothesis, J. Climate, 17(6), 1239-1246.

Logan, J. A. (1999), An analysis of ozonesonde data for the troposphere: Recommendations for testing 3-D models and development of a gridded climatology for tropospheric ozone, J. Geophys. Res. Atmos., 104(D13), 16115-16149.

Loyola, D. G., and M. Coldewey-Egbers (2012), Multi-sensor data merging with stacked neural networks for the creation of satellite long-term climate data records, Eurasip J. Adv. Sig. Pr.

Loyola, D. G., R. M. Coldewey-Egbers, M. Dameris, H. Garny, A. Stenke, M. Van Roozendael, C. Lerot, D. Balis, and M. Koukouli (2009), Globa long-term monitoring of the ozone layer-a prerequisite for predictions, Int. J. Remote Sens., 30(15-16), 4295-4318.

Madronich, S., R. L. McKenzie, L. O. Bjorn, and M. M. Caldwell (1998), Changes in biologically active ultraviolet radiation reaching the Earth's surface, J. Photoch. Photobio. B., 46(1-3), 5-19.

Martin, G. M., et al. (2011), The HadGEM2 family of Met Office Unified Model climate configurations, Geosci. Model Dev., 4(3), 723-757.

Masson, D., and R. Knutti (2011), Spatial-scale dependence of climate model performance in the CMIP3 ensemble, J. Clim., 24(11), 2680-2692.

McLandress, C., T. G. Shepherd, S. Polavarapu, and S. R. Beagley (2012), Is missing orographic gravity wave drag near 60 degrees $\mathrm{S}$ the cause of the stratospheric zonal wind biases in chemistry climate models?, J. Atmos. Sci, 69(3), 802-818.

McLandress, C., T. G. Shepherd, J. F. Scinocca, D. A. Plummer, M. Sigmond, A. I. Jonsson, and M. C. Reader (2011), Separating the dynamical effects of climate change and ozone depletion. Part II Southern Hemisphere troposphere, J. Clim., 24(6), 1850-1868.

Mears, C. A., F. J. Wentz, P. Thorne, and D. Bernie (2011), Assessing uncertainty in estimates of atmospheric temperature changes from MSU and AMSU using a Monte-Carlo estimation technique, J. Geophys. Res. Atmos., 116.

Meehl, G. A., et al. (2012), Climate system response to external forcings and climate change projections in CCSM4, J. Clim., 25(11), 3661-3683.

Meinshausen, M., et al. (2011), The RCP greenhouse gas concentrations and their extensions from 1765 to 2300, Clim. Chang., 109(1-2), 213-241.

Miller, A. J., et al. (2002), A cohesive total ozone data set from the SBUV(/2) satellite system, J. Geophys. Res. Atmos., 107(D23).

Moss, R. H., et al. (2010), The next generation of scenarios for climate change research and assessment, Nature, 463(7282), 747-756.

Neale, R. B., J. Richter, S. Park, P. H. Lauritzen, S. J. Vavrus, P. J. Rasch, and M. Zhang (2013), The mean climate of the Community Atmosphere Model (CAM4) in forced SST and fully coupled experiments, J. Clim., doi:10.1175/jcli-d-12-00236.1.

O'Connor, F. M., et al. (2013), Evaluation of the new UKCA climatecomposition model. Part II. The troposphere, Geosci. Model Dev. Discuss., 6, 1743-1857.

Olsen, M. A., M. R. Schoeberl, and A. R. Douglass (2004), Stratospheretroposphere exchange of mass and ozone, J. Geophys. Res. Atmos., 109(D24).

Orr, A., T. J. Bracegirdle, J. S. Hosking, T. Jung, J. D. Haigh, T. Phillips, and W. H. Feng (2012), Possible dynamical mechanisms for Southern Hemisphere climate change due to the ozone hole, J. Atmos. Sci., 69(10), 2917-2932.

Pennell, C., and T. Reichler (2011), On the effective number of climate models, J. Clim., 24(9), 2358-2367.

Perlwitz, J. (2011), Atmospheric science: Tug of war on the jet stream, Nat Clim. Change, 1(1), 29-31.

Perlwitz, J., S. Pawson, R. L. Fogt, J. E. Nielsen, and W. D. Neff (2008), Impact of stratospheric ozone hole recovery on Antarctic climate, Geophys. Res. Lett., 35(8).

Polvani, L. M., and S. Solomon (2012), The signature of ozone depletion on tropical temperature trends, as revealed by their seasonal cycle in model integrations with single forcings, J. Geophys. Res. Atmos., 117.

Polvani, L. M., M. Previdi, and C. Deser (2011a), Large cancellation, due to ozone recovery, of future Southern Hemisphere atmospheric circulation trends, Geophys. Res. Lett., 38 .

Polvani, L. M., D. W. Waugh, G. J. P. Correa, and S. W. Son (2011b), Stratospheric ozone depletion: The main driver of twentieth-century atmospheric circulation changes in the Southern Hemisphere, J. Clim., 24(3), 795-812

Price, C., and D. Rind (1994), Modeling global lightning distributions in a general-circulation model, Mon. Weather Rev., 122(8), 1930-1939.

Putman, W. M., and S. H. Lin (2007), Finite-volume transport on various cubed-sphere grids, J. Comput. Phys., 227(1), 55-78.

Ramaswamy, V., M. D. Schwarzkopf, W. J. Randel, B. D. Santer, B. J. Soden, and G. L. Stenchikov (2006), Anthropogenic and natural influences in the evolution of lower stratospheric cooling, Science, 311(5764), 1138-1141. 
Randel, W. J., and F. Wu (1999), A stratospheric ozone trends data set for global modeling studies, Geophys. Res. Lett., 26(20), 3089-3092.

Randel, W. J., and F. Wu (2007), A stratospheric ozone profile data set for 1979-2005: Variability, trends, and comparisons with column ozone data J. Geophys. Res. Atmos., 112(D6)

Rotman, D. A., et al. (2004), IMPACT, the LLNL 3-D global atmospheric chemical transport model for the combined troposphere and stratosphere: Model description and analysis of ozone and other trace gases, J. Geophys. Res. Atmos., 109(D4).

Rotstayn, L. D., S. J. Jeffrey, M. A. Collier, S. M. Dravitzki, A. C. Hirst, J. I. Syktus, and K. K. Wong (2012), Aerosol- and greenhouse gasinduced changes in summer rainfall and circulation in the Australasian region: A study using single-forcing climate simulations, Atmos. Chem. Phys., 12(14), 6377-6404.

Russell, G. L., J. R. Miller, and D. Rind (1995), A coupled atmosphereocean model for transient climate change studies, Atmos Ocean, 33(4), $683-730$.

Sakamoto, T. T., et al. (2012), MIROC4h-A new high-resolution atmosphere-ocean coupled general circulation model, J. Meteorol. Soc. Jpn., 90(3), 325-359.

Sander, S. P., et al. (2006), Chemical Kinetics and Photochemical Data for Use in Atmospheric Studies, Evaluation Number 15, Rep.

Sanderson, M. G., C. D. Jones, W. J. Collins, C. E. Johnson, and R. G. Derwent (2003), Effect of climate change on isoprene emissions and surface ozone levels, Geophys. Res. Lett., 30(18).

Santer, B. D., et al. (2012), Identifying human influences on atmospheric temperature, PNAS, Early Edition.

Schmidt, G. A., et al. (2006), Present-day atmospheric simulations using GISS ModelE: Comparison to in situ, satellite, and reanalysis data, J. Climate, 19(2), 153-192.

Schumann, U., and H. Huntrieser (2007), The global lightning-induced nitrogen oxides source, Atmos. Chem. Phys., 7(14), 3823-3907.

Scinocca, J. F., D. B. Stephenson, T. C. Bailey, and J. Austin (2010), Estimates of past and future ozone trends from multimodel simulations using a flexible smoothing spline methodology, J. Geophys. Res. Atmos., 115.

Sekiguchi, M., and T. Nakajima (2008), A k-distribution-based radiation code and its computational optimization for an atmospheric general circulation model, J. Quant Spectrosc Ra, 109(17-18), 2779-2793.

Senosiain, J. P., C. B. Musgrave, and D. M. Golden (2003), Temperature and pressure dependence of the reaction of $\mathrm{OH}$ and $\mathrm{CO}$ : Master equation modeling on a high-level potential energy surface, Int. J. Chem. Kinet., 35(9), 464-474

Shepherd, T. G. (2008), Dynamics, stratospheric ozone, and climate change, Atmos. Ocean, 46(1), 117-138.

Shindell, D. T., and G. Faluvegi (2009), Climate response to regional radiative forcing during the twentieth century, Nat. Geosci., 2(4), 294-300.

Shindell, D. T., G. Faluvegi, and N. Bell (2003), Preindustrial-to-present-day radiative forcing by tropospheric ozone from improved simulations with the GISS chemistry-climate GCM, Atmos. Chem. Phys., 3, 1675-1702.

Shindell, D. T., G. Faluvegi, N. Unger, E. Aguilar, G. A. Schmidt, D. M. Koch, S. E. Bauer, and R. L. Miller (2006), Simulations of preindustrial, present-day, and 2100 conditions in the NASA GISS composition and climate model G-PUCCINI, Atmos. Chem. Phys., 6, 4427-4459.

Shindell, D. T., et al. (2013), Interactive ozone and methane chemistry in GISS-E2 historical and future climate simulations, Atmos. Chem. Phys. 13(5), 2653-2689.

Sigmond, M., and J. C. Fyfe (2010), Has the ozone hole contributed to increased Antarctic sea ice extent?, Geophys. Res. Lett., 37.

Simpson, I. R., M. Blackburn, and J. D. Haigh (2009), The role of eddies in driving the tropospheric response to stratospheric heating perturbations, J. Atmos. Sci., 66(5), 1347-1365.

Simpson, I. R., M. Blackburn, and J. D. Haigh (2012a), A mechanism for the effect of tropospheric jet structure on the annular mode-like response to stratospheric forcing, J. Atmos. Sci., 69(7), 2152-2170.

Simpson, I. R., P. Hitchcock, T. G. Shepherd, and J. F. Scinocca (2012b), Southern annular mode dynamics in a comprehensive global climate model. Part 1: The influence of climatological zonal wind biases, J. Clim., doi: http://dx.doi.org/10.1175/JCLI-D-12-00348.1.

Singh, H. B., et al. (1996), Low ozone in the marine boundary payer of the tropical Pacific Ocean: Photochemical loss, chlorine atoms, and entrainment, J. Geophys. Res. Atmos., 101(D1), 1907-1917.

Smith, K. L., L. M. Polvani, and D. R. Marsh (2012), Mitigation of 21 st century Antarctic sea ice loss by stratospheric ozone recovery, Geophys. Res. Lett., 39.

Solomon, S., P. J. Young, and B. Hassler (2012), Uncertainties in the evolution of stratospheric ozone and implications for recent temperature changes in the tropical lower stratosphere, Geophys. Res. Lett., 39.

Solomon, S., R. W. Portmann, T. Sasaki, D. J. Hofmann, and D. W. J. Thompson (2005), Four decades of ozonesonde measurements over Antarctica, J. Geophys. Res. Atmos., 110(D21), D21311.
Son, S. W., N. F. Tandon, L. M. Polvani, and D. W. Waugh (2009), Ozone hole and Southern Hemisphere climate change, Geophys. Res. Lett., 36(15), L15705.

Son, S. W., L. M. Polvani, D. W. Waugh, H. Akiyoshi, R. Garcia, D. Kinnison, S. Pawson, E. Rozanov, T. G. Shepherd, and K. Shibata (2008), The impact of stratospheric ozone recovery on the Southern Hemisphere westerly jet, Science, 320(5882), 1486-1489.

Son, S. W., et al. (2010), Impact of stratospheric ozone on Southern Hemisphere circulation change: A multimodel assessment, J. Geophys. Res., 115, D00M07.

SPARC-CCMVal (2010), SPARC Report on the Evaluation of ChemistryClimate Models, in SPARC Report, WCRP-132, WMO/TD-No. 1526, edited by V. Eyring, T. G. Shepherd and D. W. Waugh.

Stainforth, D. A., M. R. Allen, E. R. Tredger, and L. A. Smith (2007), Confidence, uncertainty and decision-support relevance in climate predictions, Philos. T. R. Soc. A., 365(1857), 2145-2161.

Stevenson, D. S., et al. (2006), Multimodel ensemble simulations of present-day and near-future tropospheric ozone, J. Geophys. Res., $111(\mathrm{D} 8), \mathrm{D} 08301$.

Stolarski, R. S., and S. M. Frith (2006), Search for evidence of trend slowdown in the long-term TOMS/SBUV total ozone data record: The importance of instrument drift uncertainty, Atmos. Chem. Phys., 6, 4057-4065.

Sudo, K., and H. Akimoto (2007), Global source attribution of tropospheric ozone: Long-range transport from various source regions, J. Geophys. Res. Atmos., 112(D12)

Sudo, K., M. Takahashi, and H. Akimoto (2003), Future changes in stratosphere-troposphere exchange and their impacts on future tropospheric ozone simulations, Geophys. Res. Lett., 30(24).

Sudo, K., M. Takahashi, J. Kurokawa, and H. Akimoto (2002), CHASER: A global chemical model of the troposphere-1. Model description, J. Geophys. Res. Atmos., 107(D17)

Sun, S., and R. Bleck (2006), Multi-century simulations with the coupled GISS-HYCOM climate model: Control experiments, Clim. Dyn., 26(4), 407-428.

Swart, N. C., and J. C. Fyfe (2012), Observed and simulated changes in the Southern Hemisphere surface westerly wind-stress, Geophys. Res. Lett., 39.

Szopa, S., et al. (2012), Aerosol and ozone changes as forcing for climate evolution between 1850 and 2100, Clim. Dyn., 1-28

Taylor, K. E., R. J. Stouffer, and G. A. Meehl (2012), An overview of Cmip5 and the experiment design, B. Am. Meteorol. Soc., 93(4), 485-498.

Thompson, D. W. J., and S. Solomon (2002), Interpretation of recent Southern Hemisphere climate change, Science, 296(5569), 895-899.

Thompson, D. W. J., and S. Solomon (2009), Understanding recent stratospheric climate change, J. Clim., 22(8), 1934-1943.

Thompson, D. W. J., S. Solomon, P. J. Kushner, M. H. England, K. M. Grise, and D. J. Karoly (2011), Signatures of the Antarctic ozone hole in Southern Hemisphere surface climate change, Nat. Geosci. 4(11), 741-749.

Thompson, D. W. J., D. J. Seidel, W. J. Randel, C. Z. Zou, A. H. Butler, C. Mears, A. Osso, C. Long, and R. Lin (2012), The mystery of recent stratospheric temperature trends, Nature, 491(7426), 692-697.

Turner, J., R. Bindschadler, P. Convey, G. di Prisco, E. Fahrbach, J. Gutt, D. A. Hodgson, P. A. Mayewski, and C. P. Summerhayes (2009a), Antarctic climate change and the environment, Rep, $554 \mathrm{pp}$.

Turner, J., J. C. Comiso, G. J. Marshall, T. A. Lachlan-Cope, T. Bracegirdle, T. Maksym, M. P. Meredith, Z. M. Wang, and A. Or (2009b), Non-annular atmospheric circulation change induced by stratospheric ozone depletion and its role in the recent increase of Antarctic sea ice extent, Geophys. Res. Lett., 36.

Vichi, M., E. Manzini, P. G. Fogli, A. Alessandri, L. Patara, E. Scoccimarro, S. Masina, and A. Navarra (2011), Global and regional ocean carbon uptake and climate change: Sensitivity to a substantial mitigation scenario (vol 37, pg 1929, 2011), Clim. Dyn., 37(11-12), 2551-2551.

Voldoire, A., et al. (2012), The CNRM-CM5.1 global climate model: Description and basic evaluation, Clim. Dyn.

Volodin, E. M., N. A. Dianskii, and A. V. Gusev (2010), Simulating present-day climate with the INMCM4.0 coupled model of the atmospheric and oceanic general circulations, Izv. Atmos. Ocean. Phy., 46(4), 414-431.

von Salzen, K., et al. (2013), The Canadian Fourth Generation Atmospheric Global Climate Model (CanAM4). Part I: Representation of physical processes, Atmos. Ocean, 51(1), 104-125.

Wang, W. C., X. Z. Liang, M. P. Dudek, D. Pollard, and S. L. Thompson (1995), Atmospheric ozone as a climate gas, Atmos. Res., 37(1-3), 247-256.

Watanabe, M., et al. (2010), Improved climate simulation by MIROC5. Mean states, variability, and climate sensitivity, J. Clim., 23(23), 6312-6335. 
EYRING ET AL.: OZONE AND ASSOCIATED CLIMATE IMPACTS

Watanabe, S., et al. (2011), MIROC-ESM 2010: Model description and basic results of CMIP5-20c3m experiments, Geosci. Model Dev., 4(4), 845-872.

Wilcox, L. J., A. J. Charlton-Perez, and L. J. Gray (2012), Trends in Austral jet position in ensembles of high- and low-top CMIP5 models, J. Geophys. Res., 117(D13), D13115.

WMO (1999), (World Meteorological Organization), Scientific assessment of ozone depletion: 1998, Rep, Geneva, Switzerland.

WMO (2003), (World Meteorological Organization), Scientific Assessment of Ozone Depletion: 2002, Rep, Geneva, Switzerland.

WMO (2007), (World Meteorological Organization), Scientific Assessment of Ozone Depletion: 2010, Rep, Geneva, Switzerland.

WMO (2011), (World Meteorological Organization), Scientific Assessment of Ozone Depletion: 2010Rep, 516pp. Geneva, Switzerland.

$\mathrm{Wu}, \mathrm{T}$. W. (2012), A mass-flux cumulus parameterization scheme for large-scale models: Description and test with observations, Clim. Dyn., 38(3-4), 725-744.

Young, P. J., A. Arneth, G. Schurgers, G. Zeng, and J. A. Pyle (2009), The $\mathrm{CO} 2$ inhibition of terrestrial isoprene emission significantly affects future ozone projections, Atmos. Chem. Phys., 9(8), 2793-2803.
Young, P. J., A. H. Butler, N. Calvo, L. Haimberger, P. J. Kushner, D. R. Marsh, W. J. Randel, and K. H. Rosenlof (2013a), Agreement in late twentieth century Southern Hemisphere stratospheric temperature trends in observations and CCMVal-2, CMIP3 and CMIP5 models, J. Geophys. Res., 118(2), 605-613.

Young, P. J., et al. (2013b), Pre-industrial to end 21st century projections of tropospheric ozone from the Atmospheric Chemistry and Climate Model Intercomparison Project (ACCMIP), Atmos Chem Phys, 13(4), 2063-2090.

Yukimoto, S., et al. (2012), A new global climate model of the Meteorological Research Institute: MRI-CGCM3-model description and basic performance, J. Meteorol. Soc. Jpn., 90A, 23-64.

Zeng, G., J. A. Pyle, and P. J. Young (2008), Impact of climate change on tropospheric ozone and its global budgets, Atmos. Chem. Phys., 8(2), 369-387.

Ziemke, J. R., S. Chandra, G. J. Labow, P. K. Bhartia, L. Froidevaux, and J. C. Witte (2011), A global climatology of tropospheric and stratospheric ozone derived from Aura OMI and MLS measurements, Atmos. Chem. Phys., 11(17), 9237-9251. 